Aus der Abteilung Humangenetik

(Prof. Dr. med. Dr. h. c. W. Engel)

im Zentrum Hygiene und Humangenetik

der Medizinischen Fakultät der Universität Göttingen

\title{
Das CHARGE-Syndrom - Quantifizierung eines Gonadenmosaiks und Interaktionspartnersuche des CHD7-Gens
}

\section{INAUGURAL-DISSERTATION}

\author{
zur Erlangung des Doktorgrades \\ der Medizinischen Fakultät \\ der Georg-August-Universität zu Göttingen
}

vorgelegt von

Lasse Pieper

aus Flensburg

Göttingen 2012 
Dekan: Prof. Dr. med. M. Schön

I. Berichterstatter: Prof. Dr. med. Dr. h. c. Engel

II. Berichterstatter: Prof. Dr. med. Brockmann

Tag der mündlichen Prüfung: 11. Februar 2013 


\section{Inhaltsverzeichnis}

Abkürzungsverzeichnis ...................................................................................

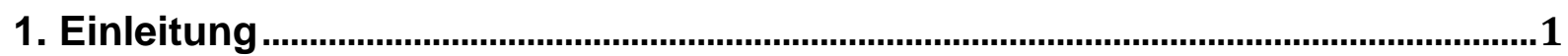

1.1 Das CHARGE-Syndrom ......................................................................................1

1.2 Molekulargenetik des CHARGE-Syndroms ...................................................................2

1.3 Familiärer CHARGE-Fall ................................................................................................2

1.4 Pathomechanismus des CHARGE-Syndroms ..........................................................4

2. Material und Methoden ...........................................................................................

2.1 Chemikalien und Reagenzien .........................................................................................7

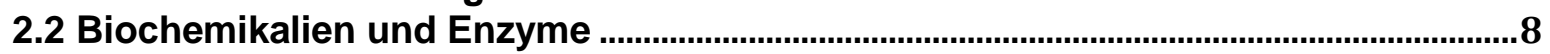

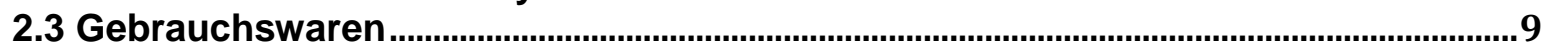

2.4 Geräte............................................................................................................

2.5 Sterilisationsverfahren ..............................................................................................10

2.6 Gebrauchsfertige Reaktionssysteme ..........................................................................10

2.7 Lösungen und Puffer ..............................................................................................11

2.8 Medien, Antibiotika, Agarplatten .............................................................................12

2.8.1 Medium für Bakterien..........................................................................................................................12

2.8.2. Medien für Hefen ...........................................................................................................................13

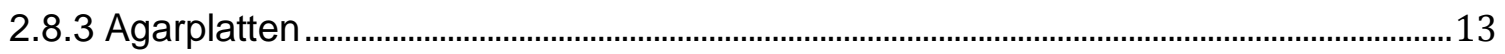

2.8.4 Medien für eukaryontische Zellkulturen ..............................................................................14

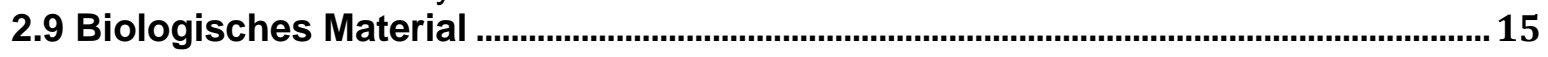

2.9.1 Bakterienstämme .................................................................................................................................15

2.9.2 Eukaryontische Zelllinien ......................................................................................................................15

2.9.3 Humane Spermien................................................................................................................................15

2.9.4 Synthetische DNA-Oligonukleotide............................................................................................15

2.9.5 Antikörper..................................................................................................................................17



2.9.7 Verwendete Konstrukte und Plasmide ................................................................................18

2.9.8 Datenbanken ...............................................................................................................................19

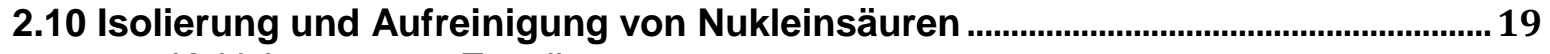

2.10.1 Kultivierung von E. coli .........................................................................................................19

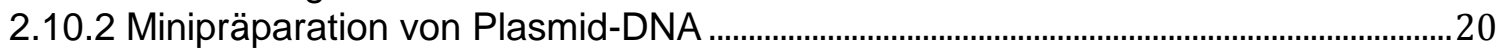

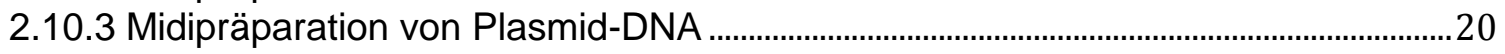

2.10.4 Herstellung von Bakterien-Glycerin-Stocks ....................................................................20

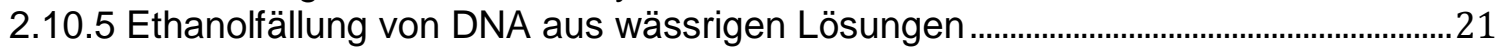

2.10.6 Säulenaufreinigung von DNA..........................................................................................21

2.10.7 Isolierung von DNA aus Agarosegelen ................................................................................21

2.10.8 Konzentrationsbestimmung von Nukleinsäuren ..............................................................21

2.11 Klonierungstechniken ...............................................................................................22

2.11.1 Spaltung von DNA mit Restriktionsendonukleasen ........................................................22

2.11.2 Ligation von DNA-Fragmenten ...................................................................................................23

2.11.3 Subklonierung von DNA-Produkten ......................................................................................2

2.11.4 Transformation kompetenter Zellen mit Plasmid-DNA .....................................................24

2.12 Gelelektrophorese..........................................................................................................24

2.12.1 Gelelektrophorese von DNA ..................................................................................................24

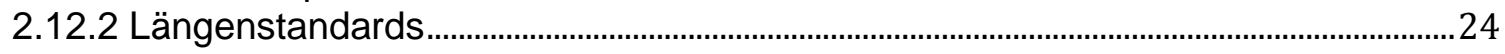

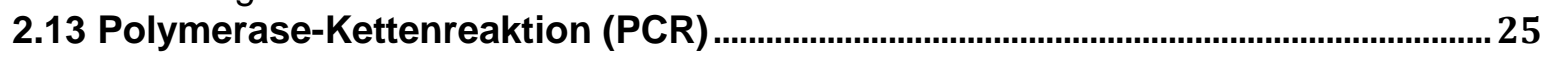

2.13.1 PCR an genomischer und Plasmid-DNA....................................................................2

2.13.2 „Nested" PCR .....................................................................................................................................26






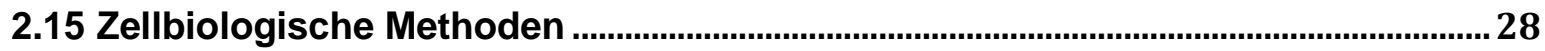

2.15.1 Zellkultur eukaryontischer Zellen.....................................................................................28

2.15.2 Kryokonservierung und Revitalisierung von eukaryontischen Zellen ........................28

2.15.3 Transfektion eukaryontischer Zellen....................................................................................29

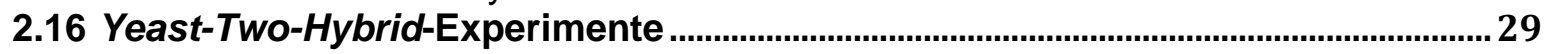

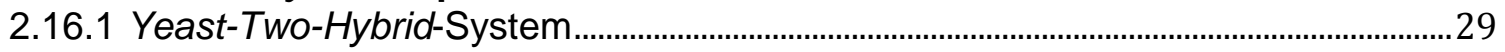

2.16.2 Transformation kompetenter Hefezellen ..................................................................... 31

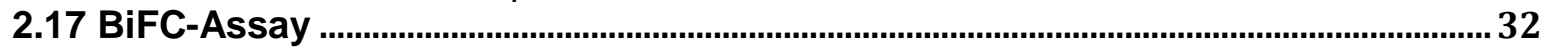

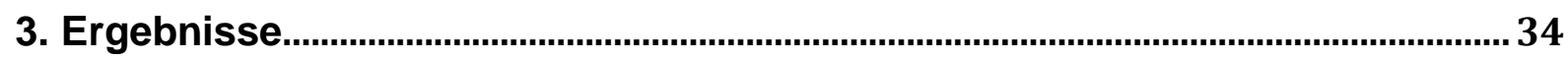

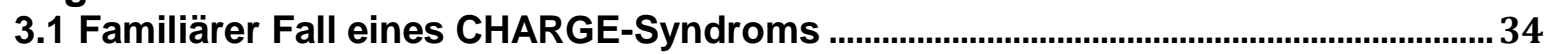

3.1.1 Untersuchung verschiedener Zelltypen des Vaters zweier betroffener CHARGE-

Kinder auf die Mutation c.7302dupA im CHD7-Gen..........................................................34

3.1.2 Etablierung einer molekulargenetischen Analyse an Einzelspermien ..........................35

3.1.3 Untersuchung von Einzelspermien zur Mosaikbestimmung ...........................................51

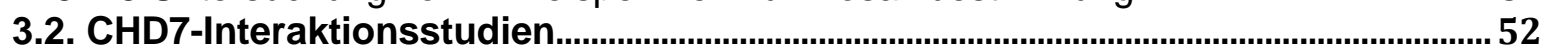

3.2.1 Verwendete Konstrukte.................................................................................................. 52

3.2.2 Direkter Yeast-Two-Hybrid-Assay von CHD7 und seinen Teilstücken mit einem

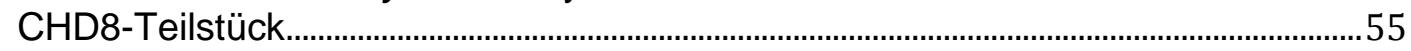

3.2.3 Eingrenzung der Interaktionsstelle................................................................................56

3.2.4 Eingrenzung der Interaktion im CR3-Teil des CHD7-Gens............................................58

3.2.5 Interaktion von CHD7 mit der Missense-Mutation Trp2091Arg mit CHD8................59

3.2.6 Direkter Yeast-Two-Hybrid-Assay von CHD7 und CHD7 sowie CHD8 und CHD8

3.2.7 Ko-Lokalisation der Proteine CHD7 und CHD8.............................................................62

3.2.8 Nachweis der Interaktion von CHD7 und CHD8 mit Hilfe des BiFC-Assays ............64

4. Diskussion ...............................................................................................................67

4.1 Familiärer Fall eines CHARGE-Syndroms ……………............................................67

4.1.1 Nachweis eines Gonadenmosaiks bei familiärem CHARGE-Syndrom.........................67

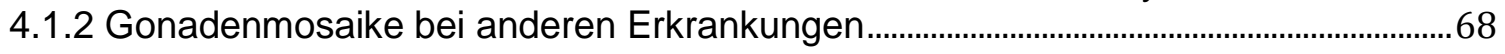

4.1.3 Quantitative Bestimmung von Gonadenmosaiken im Vergleich ......................................70

4.1.4 Konsequenzen für die Genetische Beratung und Ausblick ...............................................71

4.2 CHD7-Interaktionsstudien ..................................................................................73

4.2.1 CHD7 und CHD8 enthaltende Proteinkomplexe ................................................................74

4.2.2 Mögliche Bedeutung von Mutationen im CHD8-Gen für die Pathogenese des

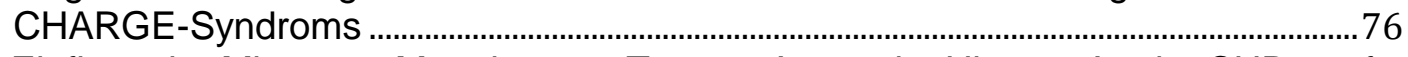

4.2.3 Einfluss der Missense-Mutationen p.Trp2091Arg und p.His2096Arg im CHD7 auf

die Interaktion mit CHD8 ..............................................................................................77

4.2.4 Ausblick auf weitere Untersuchungen zur Interaktion zwischen CHD7 und CHD8

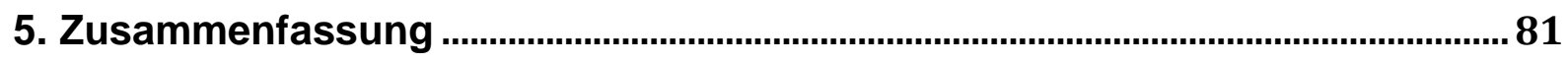

6. Literaturverzeichnis............................................................................................ 


\section{Abkürzungsverzeichnis}

\begin{tabular}{|c|c|}
\hline Abb. & Abbildung \\
\hline ad. & addiere \\
\hline Amp & Ampicillin \\
\hline AS & Aminosäure \\
\hline ATP & Adenosintriphosphat \\
\hline bp & Basenpaar \\
\hline bzw. & beziehungsweise \\
\hline${ }^{\circ} \mathrm{C}$ & Grad Celsius \\
\hline ca. & circa (ungefähr) \\
\hline cDNA & komplementäre DNA \\
\hline DAPI & 4',6'-Diamidino-2-Phenylindol \\
\hline dATP & Desoxyadenosintriphosphat \\
\hline dCTP & Desoxycytosintriphosphat \\
\hline dGTP & Desoxyguanosintriphosphat \\
\hline DMSO & Dimethylsulfoxid \\
\hline DNA & Desoxyribonukleinsäure \\
\hline dNTPs & Desoxyribonukleosidtriphosphate \\
\hline DTT & 1,4-Dithiothreitol \\
\hline dTTP & Desoxythymidintriphosphat \\
\hline EDTA & Ethylendiamintetraessigsäure \\
\hline et al. & et alii \\
\hline$g$ & Erdbeschleunigung $\left(\approx 9,81 \mathrm{~m} / \mathrm{s}^{2}\right)$ \\
\hline GFP & green fluorescent protein \\
\hline ggf. & gegebenenfalls \\
\hline $\mathrm{h}$ & Stunde \\
\hline His & Histidin \\
\hline ICSI & Intrazytoplasmatische Spermieninjektion \\
\hline IPTG & Isopropyl-ß-thiogalactopyranosid \\
\hline Kan & Kanamycin \\
\hline $\mathrm{kb}$ & Kilobasenpaare \\
\hline $\mathrm{kD}$ & Kilodalton \\
\hline
\end{tabular}




\begin{tabular}{|c|c|}
\hline$\mu$ & mikro $=10^{-6}$ \\
\hline$\mu \mathrm{g}$ & Mikrogramm \\
\hline$\mu l$ & Mikroliter \\
\hline$\mu \mathrm{m}$ & Mikrometer \\
\hline$\mu \mathrm{M}$ & Mikromolar \\
\hline $\mathrm{m}$ & milli $=10^{-3}$ \\
\hline M & Molar \\
\hline MCS & multiple cloning site \\
\hline $\mathrm{mg}$ & Milligramm \\
\hline $\min$ & Minute \\
\hline $\mathrm{ml}$ & Milliliter \\
\hline $\mathrm{mM}$ & Millimolar \\
\hline MRT & Magnetresonanztomographie \\
\hline $\mathrm{n}$ & nano $=10^{-9}$ \\
\hline OD & Optische Dichte \\
\hline PBS & Phosphat-gepufferte Kochsalzlösung \\
\hline PCR & Polymerase-Kettenreaktion \\
\hline $\mathrm{pH}$ & negativer dekadischer Logarithmus der Protonenkonzentration \\
\hline RT & Raumtemperatur \\
\hline s. & siehe \\
\hline $\mathrm{sec}$ & Sekunde \\
\hline s.o. & siehe oben \\
\hline Tab. & Tabelle \\
\hline Taq & Thermus aquaticus \\
\hline$U$ & Unit $=$ definierte Enzymeinheit \\
\hline u.a. & unter anderem \\
\hline UV-Licht & ultraviolettes Licht \\
\hline V & Volt \\
\hline Vol & Volumen \\
\hline$x-G a l$ & 5-Brom-4-Chlor-3-Indol-B-D-Galactopyranosid \\
\hline z.B. & zum Beispiel \\
\hline z.T. & zum Teil \\
\hline
\end{tabular}




\section{Einleitung}

\subsection{Das CHARGE-Syndrom}

Beim CHARGE-Syndrom handelt es sich um ein autosomal dominantes Dysmorphiesyndrom. Die Inzidenz wird auf bis zu 1:8.500 Lebendgeburten geschätzt (Issekutz et al. 2005). Das Syndrom wurde erstmals als Assoziation im Jahre 1979 unabhängig voneinander von Hall und Hittner beschrieben (Hall BD 1979, Hittner et al. 1979). Die Namensgebung CHARGE erfolgte im Jahr 1981 durch Pagon und Kollegen und beschreibt als häufige Manifestationen Kolobome (Colobome), Herzfehler, eine Atresie der Choanen, die Retardierung des Wachstums und der psychomotorischen Entwicklung, eine Genitalhypoplasie, Anomalien des Ohres (Ear) und Gehörlosigkeit (Pagon et al. 1981). Weitere Organfehlbildungen, z.B. eine Fazialisparese, Lippen-Kiefer-Gaumenspalte oder Ösophagusatresie, können vorliegen. Insgesamt besteht beim CHARGE-Syndrom eine große klinische Variabilität. Es wurden klinisch diagnostische Kriterien aufgestellt, die mehrfach revidiert wurden. Blake et al. teilten die Symptome 1998 in Haupt- und Nebenkriterien ein. Bei Patienten mit vier Haupt- oder drei Haupt- und drei Nebenkriterien sollte klinisch die Diagnose CHARGE-Syndrom gestellt werden können. Zu den Hauptkriterien zählten die Atresie der Choanen, Kolobome, charakteristische Ohranomalien sowie Anomalien der Hirnnerven, da vermutet wurde, dass es sich hierbei um CHARGE-Syndrom-typische Symptome handelt (Blake et al. 1998). Eine Erneuerung der Diagnosekriterien erfolgte durch Verloes im Jahr 2005. Verloes schlug als Hauptkriterien die Atresie der Choanen, Kolobome sowie eine Hypoplasie der Bogengänge vor. Als Nebenkriterien wurden Dysfunktionen des Rhombenzephalons, Dysfunktionen in der hypothalamohypophysären Achse, Abnormitäten des äußeren Ohres, Fehlbildungen der Mediastinalorgane und eine mentale Retardierung beschrieben. Bei Vorliegen von drei Hauptkriterien oder zwei Hauptkriterien und drei Nebenkriterien kann danach die Diagnose CHARGE-Syndrom klinisch gestell werden. Ein partielles CHARGESyndrom besteht, wenn zwei Hauptkriterien und ein Nebenkriterium vorliegen. Von einem atypischen CHARGE-Syndrom spricht man, wenn zwei Hauptkriterien und kein Nebenkriterium oder ein Hauptkriterium und mindestens drei Nebenkriterien 
festzustellen sind (Verloes 2005).

2004 beschrieben Vissers und Kollegen, dass Mutationen im CHD7-Gen (Chhromodomänen- Helicase-ㅁNA-bindendes Protein-7-Gen) zum Phänotyp des CHARGE-Syndroms führen (Vissers et al. 2004). Bei Patienten mit der klinischen Diagnose eines CHARGE-Syndroms finden sich in $58 \%$ (Lalani et al. 2006) bzw.

$64 \%$ (Jongmans et al. 2006) der Fälle Mutationen im CHD7-Gen. In einer kleinen Kohorte ließ sich eine Mutation bei $71 \%$ der Patienten nachweisen (Aramaki et al. 2006).

\subsection{Molekulargenetik des CHARGE-Syndroms}

Das CHD7-Gen besteht aus 38 Exons und erstreckt sich über $188 \mathrm{~kb}$ auf dem Chromosom 8q12.1 mit einem 8994 bp umfassenden offenen Leserahmen. Das Startcodon befindet sich in Exon 2, das Stopcodon liegt im Exon 38. CHD7 wird in unterschiedlichen fetalen und adulten Geweben exprimiert, dazu gehören auch die beim CHARGE-Syndrom typischerweise betroffenen Gewebe (Vissers et al. 2004). Im Mausmodell führt die heterozygote Chd7-Mutation zur Ausprägung von Symptomen, die dem Phänotyp des CHARGE-Syndroms beim Menschen entsprechen. Ein homozygoter Status dieser Mutationen ist im Mausmodell embryonal letal (Bosman et al. 2005, Hurd et al. 2007).

In einer Studie mit 110 CHARGE-Patienten konnte gezeigt werden, dass die Mutationen über das gesamte Gen $C H D 7$ verteilt vorkommen, einen sog. Mutationshotspot findet man nicht. Es handelt sich in den meisten Fällen um Nonsense-Mutationen, gefolgt von Frameshift-Mutationen. Missense-Mutationen, bei denen ein verändertes Protein gebildet wird, machen nur etwa $11 \%$ der Mutationen aus (Lalani et al. 2006). Durch den Vergleich der Phänotypen bei eineiigen Zwillingen mit derselben Mutation im CHD7-Gen konnte gezeigt werden, dass keine PhänotypGenotyp-Korrelation besteht (Jongmans et al. 2006).

\subsection{Familiärer CHARGE-Fall}

Bei den meisten Patienten mit CHARGE-Syndrom handelt es sich um sporadische Fälle. Es wurden nur wenige Familien mit mehreren von einem CHARGE-Syndrom 
Betroffenen und einer Mutation im CHD7-Gen beschrieben. In diesen Familien wurde sowohl über ein somatisches Mosaik bei einem der Eltern (Jongmans et al. 2006) als auch eine Eltern-Kind-Vererbung (Mitchell et al. 1985, Metlay et al. 1987) berichtet. Fälle mit betroffenen eineiigen Zwillingen wurden in der Literatur beschrieben (Levin et al. 1973, Oley et al. 1988). In einigen wenigen familiären Fällen konnte die beim Kind detektierte Mutation nicht in den elterlichen Lymphozyten nachgewiesen werden. Ein Gonadenmosaik wurde in diesen Fällen vermutet, aber nicht durch weiterführende Untersuchungen bestätigt (Lalani et al. 2006, Jongmans et al. 2008). Im Rahmen der Diagnostik wurde uns eine Familie überwiesen, die zwei vom CHARGE-Syndrom betroffene Kinder hat. Die Eltern sind klinisch gesund.

Die betroffene 6-jährige Tochter wurde in der 36. Schwangerschaftswoche per Sektion wegen einer vorzeitigen Plazentalösung entbunden. Die Schwangerschaft war unauffällig und ohne Einnahme von Medikamenten. Das Geburtsgewicht betrug $2700 \mathrm{~g}$ und die Größe $48 \mathrm{~cm}$. Postpartal kam es zu Atemstillständen und Atembeschwerden. Im MRT wurde eine Unterentwicklung des Kleinhirnwurmes festgestellt. Es gibt keinen Hinweis auf kardiale oder abdominale Fehlbildungen. Es bestehen eine Fazialisparese, Schallleitungsschwerhörigkeit, bilaterale Kolobome, Atem- und Schluckbeschwerden, Entwicklungsverzögerung sowie eine Wachstumsretardierung.

Der betroffene 3-jährige Bruder ist das zweitgeborene Kind von dizygoten Zwillingen, seine Zwillingsschwester ist gesund. Die Geburt erfolgte nach $32+6$ unauffälligen Schwangerschaftswochen per Sektion aufgrund von respiratorischen Beschwerden bei der Mutter. Das Geburtsgewicht betrug $2390 \mathrm{~g}$ bei einer Größe von $47 \mathrm{~cm}$ und $33 \mathrm{~cm}$ Kopfumfang. Der APGAR-Score betrug 7/8/9. Nachgeburtlich fielen eine Ösophagusatresie (Typ Vogt IIlb) und eine Lippen-Gaumen-Spalte auf, welche chirurgisch korrigiert wurden. Außerdem liegen eine Tracheomalazie, Schwierigkeiten bei der Nahrungsaufnahme und respiratorische Probleme, ein fehlender Kleinhirnwurm sowie ein persistierender Ductus arteriosus vor. Die augenärztliche Untersuchung zeigte ein einseitiges Kolobom der Pupille. Es besteht eine beidseitige Schalleitungsschwerhörigkeit und eine Störung des Gleichgewichtsorgans. Die Entwicklung des Jungen ist verzögert, und er zeigt, wie seine ältere vom CHARGE-Syndrom betroffene Schwester auch, keine aktive Sprachentwicklung. Es waren chirurgische Interventionen zur Korrektur eines gastroösophagealen Refluxes und eines Kryptorchismus nötig. Weiterhin bestehen 
ein Mikropenis und eine Wachstumsverzögerung. Eine DHPLC-Analyse vom Exon 34 des CHD7-Gens ergab ein abnormes Profil bei beiden betroffenen Kindern, die Sequenzierung der PCR-Produkte zeigte eine Frameshift-Mutation in diesem Exon. Durch Klonierung und Sequenzierung der PCR-Produkte konnte die verursachende Mutation c.7302dupA im Exon 34 des CHD7-Gens identifiziert werden. Die Mutation führt zu einer Verschiebung des Leserahmens und damit zu einem vorzeitigen Stopcodon. Beide Eltern sind gesund, die Mutation ließ sich in aus Lymphozyten gewonnener DNA nicht nachweisen. Durch eine Linkage-Analyse konnte gezeigt werden, dass die Mutation c.7302dupA bei den betroffenen Kindern dem väterlichen Allel zuzuordnen ist. Der Vater ist gesund und zeigt keinerlei Symptome des CHARGE-Syndroms. Aufgrund dieser Konstellation ist das Vorliegen eines Gonadenmosaiks beim Vater wahrscheinlich (Pauli et al. 2009).

Die erste Fragestellung dieser Arbeit bestand darin, ein Gonadenmosaik beim Vater zu bestätigen und dieses zu quantifizieren, um eine Aussage über das Wiederholungsrisiko treffen zu können. Zur Quantifizierung des Mosaiks sollte eine Methode zur molekulargenetischen Einzelspermienanalyse etabliert werden.

\subsection{Pathomechanismus des CHARGE-Syndroms}

Die CHD-Genfamilie umfasst beim Menschen neun Mitglieder, welche die Kombination von zwei N-terminalen Chromodomänen, eine SNF2-artige ATPase/Helikase-Domäne und eine DNA-bindende Domäne aufweisen (Woodage et al. 1997, Flaus et al. 2006, Flanagan et al. 2007). Aufgrund zusätzlicher Domänen findet eine weitere Einteilung in Subgruppen statt. CHD7 wird zusammen mit CHD6, CHD8 und CHD9 zur Subgruppe III gezählt. Diese Subgruppenmitglieder zeichnen sich durch drei konservierte Bereiche (CR1-CR3), eine SANT-Domäne und zwei BRK-Domänen aus (Hall JA und Georgel 2007, Marfella und Imbalzano 2007). Den CHD-Proteinen wird eine zentrale Rolle in der frühen Embryonalentwicklung durch ihren Einfluss auf die Chromatinstruktur und die Genexpression zugesprochen (Cavalli und Paro 1998).

Mitglieder der CHD-Genfamilie, insbesondere das CHD1, sind in Prozesse des Chromatin-remodeling involviert (Delmas et al. 1993, Hall JA und Georgel 2007). 
Veränderungen in der Chromatinstruktur sind notwendig für die Regulation der Transkription (Li et al. 1997), DNA-Reparatur, Replikation und Rekombination (Shen et al. 2000). Enzyme des Chromatin-remodeling können in zwei Kategorien aufgeteilt werden, in solche, die die Chromatinstruktur durch Modifikation der Histone verändern (Zhang und Reinberg 2001) und in solche, die unter Hydrolyse von ATP energieabhängig die Histon-DNA-Kontakte im Nukleosom verändern (Becker und Hörz 2002). Die Mitglieder der CHD-Genfamilie gehören zur SNF2-Superfamilie der ATP-abhängigen Chromatin-remodeler (Flaus et al. 2006, Marfella und Imbalzano 2007). Das Säugetiergenom kodiert für etwa 30 solcher Gene, die wahrscheinlich nicht redundant und für die normale Embryonalentwicklung unentbehrlich sind ( $\mathrm{Ho}$ und Crabtree 2010). Für die meisten SNF2-artigen ATPasen wurde nachgewiesen, dass sie Komponenten eines großen Komplexes mit vielen Untereinheiten sind. Für einige Mitglieder der CHD-Genfamilie wurden diverse Protein-Protein-Interaktionen beschrieben. Das CHD1-Protein von S. cervisiae ist eine Komponente der zwei sehr homologen Acetyltransferase-Komplexe SAGA und SLIK (Pray-Grant et al. 2005), CHD3 interagiert mit CHD4 und stellt eine Kernkomponente des Nukleosomremodeling-und-Histon-deacetylase (NuRD) -Komplexes dar (Hall JA und Georgel 2007). CHD8 interagiert direkt mit WDR5 (Thompson et al. 2008), einer Komponente des Histon-H3-Lysin-4-Methyltransferase-MLL-Komplexes (Song und Kingston 2008).

Die Chromodomänen des CHD7-Proteins interagieren in vitro mit der methylierten Form des Histons-3-Lysin-4 (H3K4) (Schnetz et al. 2009). Schnetz et al. schlugen 2010 ein Modell vor, in dem die Funktion von CHD7 bezogen auf die Transkriptionsregulation beschrieben wird. CHD7 bindet an Enhancer-Bereiche, welche mit mono- und dimethyliertem H3K4 markiert sind. In embryonalen Stammzellen bildet CHD7 einen Komplex mit P300, OCT4, SOX2 und NANOG. Es wird postuliert, dass diese Proteine zusammen die Genexpression durch EnhancerPromoter-Interaktionen modifizieren können. CHD7 wird daher eine Funktion in der Feinmodulierung der Expression von spezifischen Zielgenen zugesprochen (Schnetz et al. 2010).

In humanen Neuralleistenzellen agiert CHD7 mit dem Komplex BAF und PBAF (polybromo- and BRG1- associated factor-containing complex) und spielt dort eine Rolle in der Genexpression in der Embryogenese (Bajpai et al. 2010). Möglicherweise besteht der Komplex aus weiteren Untereinheiten, daher könnten 
Bindungspartner des CHD7 ursächliche Kandidatengene für das CHARGE-Syndrom sein. Bei anderen autosomal dominant vererbten Erkrankungen, wie z.B. beim Cornelia-de-Lange-Syndrom, wurde gezeigt, dass Mutationen in verschiedenen Genen ursächlich für den Phänotyp des Syndroms sind. Es wurden Mutationen in den Genen NIPBL (Tonkin et al. 2004), SMC1L1 (Musio et al. 2006) und bei Mitgliedern SMC3 und SMC1A des Cohesin-Komplexes (Deardorff et al. 2007) als Ursache für das Cornelia-de-Lange-Syndrom identifiziert. Während es sich bei diesen Genen nicht um Interaktionspartner handelt, konnte z.B. bei der spastischen hereditären Paraplegie (HSP) gezeigt werden, dass Interaktionspartner eine ursächliche Rolle für die Erkrankung spielen können. Mutationen im Spastin (SPG4) und in seinem Bindungspartner ZFYVE27 (SPG33) führen zur HSP (Mannan et al. 2006). Aufgrund dieser Daten erfolgte eine Interaktionspartnersuche des CHD7Proteins. In einem in Vorarbeiten durchgeführten Yeast-Two-Hybrid-Library-Screen mit einem Teil des CHD7-Proteins als Bait wurde CHD8, ein anderes Mitglied der CHD-Subgruppe III, als potentieller Interaktionspartner von $\mathrm{CHD} 7$ identifiziert.

Die zweite Aufgabe dieser Arbeit bestand darin, den in den Vorarbeiten identifizierten Interaktionsparter von CHD7 - CHD8 - mit spezifischeren Methoden zu bestätigen und die mögliche Interaktionsstelle näher einzugrenzen. Dazu sollten sowohl direkte Yeast-Two-Hybrid-Experimente als auch ein bimolekularer Fluoreszenzkomplementations-Assay (BiFC) durchgeführt werden. Des Weiteren sollte der Einfluss von MissenseMutationen im CHD7-Gen auf die Interaktion der beiden Proteine untersucht werden. 


\section{Material und Methoden}

\subsection{Chemikalien und Reagenzien}

Alle nicht aufgeführten Chemikalien und Reagenzien wurden von den Firmen Roth (Karlsruhe) und Sigma-Aldrich (Deisenhofen) bezogen.

\section{Chemikalie}

Adeninsulfat

Agar

Agarose

Aminosäuren

Ammoniumsulfat

Ampicillin

Ampuwa

Adenosintriphosphat

Bacto-Trypton

Bromphenol

Buffer AE Elution Buffer

Buffer EL Erythrocyte Lysis Buffer

Dimethyldicarbonat (DMPC)

Dimethylsulfoxid

Dithiothreitol

DMEM

dNTPs (100 mM)

DPBS

Ethanol

Ethidiumbromid

Ethylendiamintetraacetat

Glukose

Glycerol

Glycin

\section{Hersteller}

AppliChem GmbH, Darmstadt

Carl Roth $\mathrm{GmbH}$, Karlsruhe

Bio-Budget Technologies, GmbH

Biomol GmbH, Hamburg

Carl Roth GmbH, Karlsruhe

Carl Roth GmbH, Karlsruhe

Fresenius AG, Bad Homburg

Biomol GmbH, Hamburg

Carl Roth GmbH, Karlsruhe

Carl Roth $\mathrm{GmbH}$, Karlsruhe

QIAGEN GmbH, Hilden

QIAGEN GmbH, Hilden

Sigma-Aldrich, Taufkirchen

Merck, Darmstadt

AppliChem GmbH, Darmstadt

PAN, Aidenbach

Invitrogen, Karlsruhe

PAN, Aidenbach

Carl Roth GmbH \& Co., Karlsruhe

Inno-Train Diagnostik GmbH,

Kronberg/Taunus

ICN, Aurora, OH, USA

Carl Roth $\mathrm{GmbH}$, Karlsruhe

Carl Roth GmbH, Karlsruhe

Carl Roth GmbH, Karlsruhe 
Hefeextrakt

Isopropyl-ß-D-thiogalactopyranosid

Kanamycin

Lipofectin $₫$

Natriumdodecylsulfat (SDS)

Opti-MEM® I

Penicillin/Streptomycin

Polyvinylpyrrolidon (PVP)

S.O.C. Medium

Tris

VectaShield mit DAPI

X- $\alpha$-Gal

X-Gal

Zellkulturmedien

Xylencyanol
Carl Roth $\mathrm{GmbH}$, Karlsruhe

Biomol GmbH, Hamburg

Sigma-Aldrich, Deisenhofen

Invitrogen, Karlsruhe

Serva, Heidelberg

Invitrogen, Karlsruhe

Carl Roth $\mathrm{GmbH}$, Karlsruhe

MediCult, Kopenhagen

Invitrogen, Karlsruhe

Carl Roth $\mathrm{GmbH}$, Karlsruhe

VectorLab, Burlingame, CA, USA

Clontech, Mountain View, CA, USA

Biomol GmbH, Hamburg

PAN, Aidenbach

Carl Roth $\mathrm{GmbH}$, Karlsruhe

\subsection{Biochemikalien und Enzyme}

\section{Biochemikalien}

DNAse I

Fetales Kälberserum (FKS)

Immolase-DNA-Polymerase

Lachsspermien-DNA

Mango Taq-DNA-Polymerase

PfuUltra-HF-DNA-Polymerase

Restriktionsenzyme

T4-DNA-Ligase

Trypsin-like-Enzyme ${ }^{\mathrm{TM}}$

\section{Hersteller}

Sigma-Aldrich, Taufkirchen

PAN, Aidenbach

Bioline, Luckenwalde

Sigmal-Aldrich, Taufkirchen

Bioline, Luckenwalde

Stratagene, La Jolla, CA, USA

Invitrogen, Karlsruhe

Promega, Mannheim

Invitrogen, Karlsruhe 


\subsection{Gebrauchswaren}

Die nicht gesondert aufgeführten Gebrauchswaren wurden von den Firmen OMNILAB-Krannich GmbH \& Co. KG (Göttingen) und Th. Geyer GmbH \& Co. KG (Hamburg) bezogen.

\section{Gebrauchswaren}

FALCON culture slides

Petrischalen

Pipettenspitzen

Plastikwaren

Quarz-Küvette

Reaktionsgefäße

Sterilfilter

Zellkulturflaschen

Zellkulturröhrchen

\section{Hersteller}

Becton Dickinson $\mathrm{GmbH}$, Heidelberg

Greiner Nunc., Nürtingen

Sarstedt, Nümbrecht

Greiner, Solingen und Falkon, Heidelberg

Hellma, Mühlheim

Eppendorf, Hamburg und Sarstedt,

Nümbrecht

Sartorius AG, Göttingen

Greiner, Nürtingen

Greiner, Nürtingen

\subsection{Geräte}

\section{Geräte}

$\mathrm{CO}_{2}$-Brutschrank

Dampfdruckautoklav

Kühlzentrifuge

Magnetrührer

Megafuge1.0 R

Mikromanipulator

Mikroskop BX60

Pipette Research $\circledast$

Sequenzierer MegaBACE1000

Sterilbank SG 400

Thermocycler Primus

\section{Hersteller}

Heraeus, Osterode

Webco, Bad Schwartau

Eppendorf, Hamburg

Schütt Labortechnik, Göttingen

Heraeus, Hanau

Luigs \& Neumann, Ratingen

Olympus, München

Eppendorf, Hamburg

Amersham Bioscience, Freiburg

Baker Company, Sanford, ME, USA

MWG-Biotech, Ebersberg 
Tischzentrifuge 5415C

Transilluminator, UVT-28M

Umluft-Sterilbank Zellkultur

UV-Tisch

Waagen

Wärmeschrank Heraeus 6000

Zentrifuge
Eppendorf, Hamburg

Herolab, Wiesloch

Heraeus, Osterode

PEQLAB Biotechnologie $\mathrm{GmbH}$, Erlangen

Sartorius, Göttingen

Heraeus, Hamburg

Sigma Laborzentrifugen $\mathrm{GmbH}$, Osterode am Harz

\subsection{Sterilisationsverfahren}

Die Sterilisation von Gebrauchswaren, Lösungen und Kulturmedien erfolgte für 20 min bei $121{ }^{\circ} \mathrm{C}$ und 1,5 Bar im Dampfdruckautoklaven oder bei hitzeempfindlichen Lösungen durch Sterilfiltration (Sterilfilter mit Porengröße 0,2-0,45 $\mu \mathrm{m}$ ).

\subsection{Gebrauchsfertige Reaktionssysteme}

\section{Reaktionssystem}

DYEnamic ET-Terminator-Mix

KAPA2G Robust PCR Kit

Lipofectamin2000 ${ }^{\mathrm{TM}}$ Transfection

Reagenz

Montage $^{\mathrm{TM}}$ PCR Centrifugal

Filter Devices

Plasmid Midi Kit

QIA Ex II Gel Extraction Kit

QIAprep ${ }^{\circledR}$ Spin miniprep Kit

\section{Hersteller}

GE Healthcare, München

PEQLAB Biotechnologie, Erlangen

Invitrogen, Karlsruhe

Millipore, Schwalbach

Invitrogen Karlsruhe

QIAGEN, Hilden

QIAGEN, Hilden 


\subsection{Lösungen und Puffer}

Die für den Routinegebrauch benötigten Lösungen wurden wie durch Sambrook et al. (1989) beschrieben angesetzt. Sie wurden nach Bedarf mit deionisiertem Wasser $\left(\mathrm{dH}_{2} \mathrm{O}\right)$ oder Ampuwa (pyrogenfreies Wasser für molekularbiologisches Arbeiten) hergestellt und anschließend gegebenenfalls steril filtiert oder dampfdrucksterilisiert. Die Aufbewahrung erfolgte bei $-20^{\circ} \mathrm{C}$ bzw. $4^{\circ} \mathrm{C}$.

\section{Lösung/ Puffer}

AP-Puffer

Glycinpuffer (1x)

P1 Pufer (Plasmid-Minipräparation)

P2 Puffer (Plasmid-Minipräparation)

P3 Puffer (Plasmid-Minipräparation)

PBS (10x)

$\operatorname{SSC}(20 \mathrm{x})$

\section{Zusammensetzung}

$100 \mathrm{mM} \mathrm{NaCl}$

$50 \mathrm{MM} \mathrm{MgCl}_{2}$

$100 \mathrm{mM}$ Tris/HCl pH 9.5

$1,44 \%$ (w/v) Glycin

$0,3 \%(w / v)$ Tris

$0,1 \%(w / v)$ SDS

$50 \mathrm{mM}$ Tris- $\mathrm{HCl}, \mathrm{pH} 8,0$

10 mM EDTA

$100 \mu \mathrm{g} / \mathrm{ml}$ RNase A

$200 \mathrm{mM} \mathrm{NaOH}$

$1 \%$ SDS

3 M Kaliumacetat $(\mathrm{pH} \mathrm{5,5)}$

$1,37 \mathrm{M} \mathrm{NaCl}$

$81 \mathrm{mM} \mathrm{Na}_{2} \mathrm{HPO}_{4}$

$27 \mathrm{mM} \mathrm{KCl}$

$14,7 \mathrm{mM} \mathrm{KH}_{2} \mathrm{PO}_{4}$

$3 \mathrm{M} \mathrm{NaCl}$

$0,3 \mathrm{M}$ Natriumcitrat, $\mathrm{pH} 7,0$ mit $\mathrm{NaOH}$ 
Stop-Mix I

Stop-Mix II

TAE-Puffer (50x)

TBE-Puffer (5x)

TE-Puffer

X-Gal-Stammlösung
$95 \%$ Formamid

20 mM EDTA

0,05 \% Bromphenolblau

$0,05 \%$ Xylencyanol

$15 \%$ Ficoll 400

$200 \mathrm{mM}$ EDTA

$0,1 \%$ Orange $G$

2 M Tris-Acetat, $\mathrm{pH} 8,3$

0,05 M EDTA

$445 \mathrm{mM}$ Tris/ $\mathrm{HCl}, \mathrm{pH} 8,0$

445 mM Borsäure

10 mM EDTA

$10 \mathrm{mM}$ Tris/ $\mathrm{HCl}, \mathrm{pH} 8,0$

1 mM EDTA

$20 \mathrm{mg} \mathrm{X-Gal/ml} \mathrm{N.N.-Dimethyl-formamid}$

\subsection{Medien, Antibiotika, Agarplatten}

\subsubsection{Medium für Bakterien}

Das Medium wurde mit bidestilliertem Wasser angesetzt, autoklaviert und bei $4{ }^{\circ} \mathrm{C}$ aufbewahrt. Zur Selektion wurden der Resistenz entsprechend Ampicillin (Endkonzentration 50-200 $\mathrm{gg} / \mathrm{ml}$ ) bzw. Kanamycin (Endkonzentration $25 \mu \mathrm{g} / \mathrm{ml}$ ) hinzugefügt.

LB(Luria-Bertani)-Medium: $\quad 1 \%$ Trypton

$$
0,5 \% \text { Hefeextrakt }
$$


$\mathrm{pH} 7,0$.

\subsubsection{Medien für Hefen}

Die Medien wurden mit bidestilliertem $\mathrm{H}_{2} \mathrm{O}$ angesetzt, autoklaviert und bei $4^{\circ} \mathrm{C}$ aufbewahrt.

SD-Medium:

1,7 g/l Hefe-Stickstoff-Basis ohne Aminosäuren

$5 \mathrm{~g} / \mathrm{l}$ Ammoniumsulfat

$10 \%$ sterile Mangel-Nährlösung

$2 \%$ Glukose.

YPDA-Medium:

$20 \mathrm{~g} / \mathrm{l}$ Pepton

$10 \mathrm{~g} / \mathrm{l} \mathrm{Hefeextrakt}$

$2 \%$ Glukose

$20 \mathrm{mg} / \mathrm{l}$ Adeninhemisulfat

pH 5,8 durch $\mathrm{HCl}$-Zugabe.

Mangel-Nährlösung (10x): Durch Weglassen einzelner oder mehrerer Aminosäuren wurde das entsprechende Selektionsmedium hergestellt.

Tryptophan $(200 \mathrm{mg} / \mathrm{l})$

Leucin $(1000 \mathrm{mg} / \mathrm{l})$

Adenin $(200 \mathrm{mg} / \mathrm{l})$

Histidin $(200 \mathrm{mg} / \mathrm{l})$

\subsubsection{Agarplatten}

Die Herstellung von Agarplatten erfolgte durch Zugabe von 1,5 \% (w/v) Agar zu den LB-, SD- und YPDA-Medien vor dem Autoklavieren. Für eine ggf. gewünschte Selektion wurden dem Medium nach dem Autoklavieren und Abkühlen auf $55^{\circ} \mathrm{C}$ Ampicillin (Endkonzentration $50 \mu \mathrm{g} / \mathrm{ml}$ ) bzw. Kanamycin (Endkonzentration $25 \mu \mathrm{g} / \mathrm{ml}$ ) 
zugegeben. Das Medium wurde in Petrischalen gegossen, nach dem Aushärten wurden die Agarplatten bei $4{ }^{\circ} \mathrm{C}$ aufbewahrt.

X-Gal-Oja-Platten wurden für die Blau/Weiß-Selektion erfolgreich transfizierter pGEM-T Easy Vektoren benötigt, die Herstellung erfolgte durch Zugabe von Ampicillin (Endkonzentratrion $50 \mu \mathrm{g} / \mathrm{ml}$ ), $2 \% \mathrm{x}$-Gal sowie 0,1\% 1M IPTG zu LBMedium nach dem Autoklavieren und Abkühlen auf $55{ }^{\circ} \mathrm{C}$. Das Medium wurde wie oben beschrieben weiterbehandelt.

\subsubsection{Medien für eukaryontische Zellkulturen}

Das Medium zur Kultur eukaryontischer Zellen wurde erworben (PAN, Aidenbach). Vor dem Gebrauch wurde es mit fetalem Kälberserum und Antibiotika (Penicillin und Streptomycin) versetzt und steril filtriert. Für die Zellkultur wurden folgende Medien verwendet:

NIH3T3-Zellen:

DMEM (PAN, Aidenbach)

$2 \mathrm{mM}$ L-Glutamin

$10 \%$ FKS

$100 \mu \mathrm{g} / \mathrm{ml}$ Streptomycin

100 U/ml Penicillin.

HeLa-Zellen:

DMEM (Pan, Aidenbach)

$10 \%$ FKS

$2 \%$ Penicillin (50 U/ml)

$2 \%$ Streptomycin $(50 \mu \mathrm{g} / \mathrm{ml})$. 


\subsection{Biologisches Material}

\subsubsection{Bakterienstämme}

Für die Transformation von Plasmiden in kompetente Bakterienstämme wurde der folgende Bakterienstamm verwendet:

Escherichia coli DH5a Invitrogen $\mathrm{GmbH}$, Karlsruhe.

(Hanahan 1983)

\subsubsection{Eukaryontische Zelllinien}

Für die Transfektion von eukaryontischen Zellen im Rahmen der Ko-Lokalsation und Live-Cell-Interaktion (BiFC-Assay) wurden folgende Zelllinien verwendet:

\footnotetext{
NIH3T3-Zellen Mausfibroblasten, ATCC, Rockville, MD, USA. (Jainchill et al. 1969)
}

HeLa-Zellen Humane Zervixkarzinomzellen, ATCC, Rockville, MD, USA.

(Scherer et al. 1953)

\subsubsection{Humane Spermien}

Die Spermien stammten aus einer Ejakulatprobe vom Vater der betroffenen Kinder des familiären CHARGE-Syndrom-Falles und wurden uns mit seinem Einverständnis zur Verfügung gestellt.

\subsubsection{Synthetische DNA-Oligonukleotide}

Für die Sequenzierung von DNA-Abschnitten und die Generierung von Konstrukten für die Yeast-Two-Hybrid-Experimente, die Ko-Lokalisation sowie den BiFC-Assay 
wurden synthetische, sequenzspezifische Oligonukleotide der Firma Operon (Köln) verwendet. Die zum Teil eingefügten Schnittstellen für Restriktionsenzyme sind in der Aufstellung hervorgehoben.

Primer für die Sequenzierung von Exon 34 des CHD7-Gens:
CHD7Ex34externF
5'-CAGTACTGTTTTGGCTCACTGCAA-3'
CHD7Ex34externR
5'-ACTAGGGAGCCATTAAGGAGATGC-3'
CHD7Ex34internF
5'-GAAATCTCATGGAGATGGTTGC-3'
CHD7Ex34internR
5'-GGAGCAGTTCCATTTGAGTCTTA-3'

CHD7-spezifische Primer für die Erstellung der Konstrukte:

$\begin{array}{ll}\text { chd7NdeIF } & \text { 5'-AGCATATGCGTCCCCAGGATAAGT-3' } \\ \text { chd7EcoRIR } & \text { 5'-TAGCGAATTCGGCTTGTTCCAGTA-3' } \\ \text { chd7CR1NcolF } & \text { 5'-ATTTACCATGGGTCCCCAGGATAA-3' } \\ \text { chd7CR1EcoRIR } & \text { 5'-TTTCCGAATTCACTTGAGTCAGCAC-3' } \\ \text { chd7CR2EcoRIF } & \text { 5'-TTAATGAATTCCAGAGCACACAGC-3' } \\ \text { chd7CR2SallR } & \text { 5'-TATTGGTCGACTCACTTCCTCTCG-3' } \\ \text { chd7CR3NcolF } & \text { 5'-TAAACCATGGAAGCTCTGGAAGC-3' } \\ \text { chd7CR3UeNEcoRIR } & \text { 5'-GTCGGAATTCTTATGGAGGAGAGG-3' } \\ \text { chd7CR3UeCNcolF } & \text { 5'-AATTCCATGGACCTCTCCTCCATAA-3' } \\ \text { chd7SANTNcoIF } & \text { 5'-ATAACCATGGAAAAGCGGCAAAA-3' } \\ \text { chd7SANTEcoRIR } & \text { 5'-ATATGAATTCCATGGCCACAAAACA-3' } \\ \text { chd7SANTCR3- } & \\ \text { His2096ArgEcoRIR } & \text { 5'-ATATGAATTCGTCTCGGTCACGC-3' } \\ \text { chd7SANTCR3EcoRIR } & \text { 5'-ATATGAATTCGTCTCGGTCATGC-3' } \\ \text { chd7pCMV-HAEcoRIF } & \text { 5'-GGAATTCGTCCCCAGGATAAGT-3' } \\ \text { chd7pCMV-HASallR } & \text { 5'-GTCGACTAAGGCTCCTCCACTTT-3' } \\ \text { chd7FPCA-V1EcoRIF } & \text { 5'-GGAATTCGGATGGATAAGTCACAGG-3' } \\ \text { chd7FPCA-V1SallR } & \text { 5'-GTCGACAAAGGCTCCTCCACTTT-3' }\end{array}$


CHD7-spezifische Sequenzierprimer:

$\begin{array}{ll}\text { chd7CR1-3F } & \text { 5'-CGGCGTCCCCAGGATAAGT-3' } \\ \text { chd7CR1-3R } & \text { 5'-TGGGTTTTCAGGCTCCTCCA-3' } \\ \text { chd7CR1R } & \text { 5'-GGGATCCACACATCGGCTTC-3' } \\ \text { chd7CR2F } & \text { 5'-CTGCAACCCAGATGCCCTGT-3' } \\ \text { chd7CR2R } & \text { 5'-AGCTTCCCTTTCCGCTTCCA-3' } \\ \text { chd7CR3F } & \text { 5'-CGGCCTCGAGAGGAAGTGAG-3' }\end{array}$

CHD8-spezifische Primer für die Erstellung der Konstrukte:

chd8FPCA-V2KpnIF 5'-ACTTAGGTACCCGGACTCTGAGCT-3'

chd8FPCA-V2BgIIIR 5'-TTGAGATCTATCAGTCATCAGCATCT-3'

CHD8-spezifische Sequenzierprimer:

chd81R

5'-CCTTCCTCATCTTTGATTTGAACTG-3'

chd82F

5'-AAGCATCTGCAGTCAGCACAG-3'

chd82R

5'-TAGAAAGGTCTGGTCGCATCCTA-3'

chd83F

5'-GAAAAAGGGTCATCACACTGAAAC-3'

FPCA-V2seqF

5'-GCTCAGAAAGGGACTTCTCACTCA-3'

FPCA-V2seqR

5'-ACTCTCATCAGTGCTGGAGCTG-3'

\subsubsection{Antikörper}

Für die Ko-Lokalisation von CHD7 und CHD8 wurden folgende Antikörper verwendet:

Primäre Antikörper:

anti-HA, Kaninchen (Roche, Mannheim),

anti-c-Myc, Maus (Millipore, Eschborn). 
Sekundäre Antikörper:

anti-Kaninchen IgG, Cy3 konjugiert (C2306), Schaf (Sigma-Aldrich, Taufkirchen), anti-Maus IgG, FITC konjugiert (F0257), Ziege (Sigma-Aldrich, Taufkirchen).

\subsubsection{Vektoren}

Vektor

pCMV-HA

pCMV-Myc

FPCA-V1

FPCA-V2

\section{Methode}

Ko-Lokalisation

BiFC-Assay

Yeast-Two-Hybrid

pGADT7

pGADT7-Rec

pGBKT7

pGEM-T Easy

Klonierung

\section{Hersteller}

Clontech, Mountain View, CA, USA

Clontech, Mountain View, CA, USA

Herstellung durch Frau Prof. Dr. S. Hoyer-

Fender (Abteilung Entwicklungsbiologie,

Universität Göttingen) auf Basis von

p-EGFP-N1 bzw. pQM-Ntag/B

Clontech, Mountain View, CA, USA

Clontech, Mountain View, CA, USA

Clontech, Mountain View, CA, USA

Promega, WI, USA

\subsubsection{Verwendete Konstrukte und Plasmide}

Die zu klonierenden Fragmente wurden mittels PCR amplifiziert. Die Fragmente wurden zunächst in den Vektor pGEM-T Easy kloniert. Anschließend erfolgten eine Plasmidisolierung und eine Sequenzierung des kompletten Inserts. Dann erfolgte die Klonierung in die Zielvektoren unter Verwendung von Restriktionsenzymen. Eine Übersicht über die erstellten und verwendeten Konstrukte befindet sich im Ergebnisteil (Tab. 3.10). 


\subsubsection{Datenbanken}

\section{Verwendung}

Analyse von DNA- und

Proteinsequenzen

\section{Programm}

BLAST-Programm (http://www.ncbi.nlm.nih.gov)

(Altschul et al. 1990)

Gene-Programm

(http://www.ncbi.nlm.nih.gov/gene)

HomoloGene-Programm

(http://www.ncbi.nlm.nih.gov/homologene)

Protein Database-Programm

(http://www.ncbi.nlm.nih.gov/protein)

Analyse von humanen Proteinen Human Protein Reference Database

(http://www.hrpd.org)

Auswahl von Oligonukleotiden Primer3 (http://frofo.wi.mit.edu/chi-

bin/primer3/primer3_www.cgi)

Restriktionsschnittstellen

NEB Cutter 2.0

(http://tools.neb.com/NEBcutter2/index.php)

Literaturrecherche

Analyse von Genmutationen
Pubmed

(http://www.ncbi.nlm.nih.gov/pubmed)

OMIM-Programm

(http://www.ncbi.nlm.nih.gov/omim)

(Hamosh et al. 2005)

\subsection{Isolierung und Aufreinigung von Nukleinsäuren}

\subsubsection{Kultivierung von E. coli}

Zur Gewinnung von Einzelkolonien wurde etwas Kulturlösung auf eine Petrischale mit LB-Medium ausplattiert. Zur Selektion von E. coli mit einem gewünschten Plasmid wurde ein Antibiotikum hinzugegeben, für welches das Plasmid ein Resistenzgen enthält. Die Petrischale wurde über Nacht in einem Brutschrank bei $37^{\circ} \mathrm{C}$ inkubiert. Flüssigkulturen wurden hergestellt, indem mit einem entsprechenden Antibiotikum versetztes LB-Medium mit einer Einzelkolonie $E$. coli beimpft und dieser 
Ansatz über Nacht in einem Schüttler inkubiert wurde (Ausubel et al. 1994).

\subsubsection{Minipräparation von Plasmid-DNA}

Für die schnelle Isolation von Plasmiden aus einer Bakterienkultur wurden $5 \mathrm{ml}$ einer angeimpften Übernachtkultur zunächst bei 5.000 x g für 15 min zentrifugiert und der Überstand verworfen. Das Bakterienpellet wurde in $200 \mu \mathrm{l} \mathrm{P1-Lösung} \mathrm{resuspendiert,}$ in einen neuen 1,5-ml-Eppendorf-Cup übertragen und mit $200 \mu \mathrm{l}$ P2-Lösung versetzt. Nach Invertieren und 1 min Inkubation bei Raumtemperatur wurden $200 \mu \mathrm{l} \mathrm{P3-}$ Lösung hinzugefügt und erneut invertiert. Der Ansatz wurde für 15 min mit $16.000 \times \mathrm{g}$ bei Raumtemperatur zentrifugiert und der Überstand in einen neuen 1,5-mlEppendorf-Cup übertragen. Die Plasmid-DNA wurde mit $900 \mu 100 \%$-Isopropanol versetzt und $30 \mathrm{~min}$ mit $16.000 \times \mathrm{g}$ bei $4{ }^{\circ} \mathrm{C}$ zentrifugiert und gefällt. Der Überstand wurde verworfen und das Pellet mit $200 \mu \mathrm{l} 70 \%$-Ethanol für $10 \mathrm{~min}$ mit 16.000 x g bei $4{ }^{\circ} \mathrm{C}$ zentrifugiert und gewaschen. Danach wurde der Überstand erneut verworfen, das Pellet bei Raumtemperatur getrocknet und in $20 \mu \mathrm{l} \mathrm{H}_{2} \mathrm{O}$ gelöst.

\subsubsection{Midipräparation von Plasmid-DNA}

Für die hochreine Präparation größerer Mengen Plasmid-DNA wurde das PureLink ${ }^{\mathrm{TM}}$ HiPure Plasmid Midiprep Kit von Invitrogen (Karslruhe) verwendet. Die DNA wird dabei über lonenaustauschchromatographie aufgereinigt, die Präparation erfolgte nach dem Protokoll des Herstellers. Die mit diesem Kit extrahierte DNA wurde u.a. für die Transfektion von Fibroblasten und Hefezellen, Sequenzierung, Subklonierung sowie für Restriktionen verwendet.

\subsubsection{Herstellung von Bakterien-Glycerin-Stocks}

Die Stocks wurden erzeugt, indem $1 \mathrm{ml}$ einer Bakteriensuspension mit $100 \mu \mathrm{l}$ sterilem Glycerin vermischt und bei $-80^{\circ} \mathrm{C}$ aufbewahrt wurde. 


\subsubsection{Ethanolfällung von DNA aus wässrigen Lösungen}

Die Ethanolfällung wurde eingesetzt, um DNA von Salzverunreinigungen zu befreien und sie zu konzentrieren. Dazu wurde die DNA-Lösung auf $100 \mu \mathrm{l}$ mit Wasser aufgefüllt und $400 \mu$ kaltes $100 \%$-Ethanol sowie $10 \mu \mathrm{l}$ 3 NaAc (pH 5,2) zugefügt. Der Ansatz wurde gut vermischt und für 30 min mit $16.000 \times$ g bei $4^{\circ} \mathrm{C}$ zentrifugiert. Der Überstand wurde verworfen und das Pellet mit $100 \mu \mathrm{l} 70$ \%-Ethanol 10 min mit $16.000 \times \mathrm{g}$ bei $4{ }^{\circ} \mathrm{C}$ zentrifugiert und gewaschen. Nach erneutem Verwerfen des Überstandes wurde das Pellet bei Raumtemperatur getrocknet und im gewünschten Wasservolumen gelöst (Sambrook et al. 1989).

\subsubsection{Säulenaufreinigung von DNA}

Für die Säulenaufreinigung von DNA wurde das Montage® PCR Filter Units Kit von Millipore Corp. (Bedford, MA, USA) verwendet. Die Aufreinigung der DNA erfolgte nach dem Protokoll des Herstellers. Derart aufgereinigte DNA wurde für die Sequenzierung sowie zur Klonierung verwendet.

\subsubsection{Isolierung von DNA aus Agarosegelen}

Die Extraktion und Aufreinigung von DNA aus Agarosegelen erfolgte mit dem QIAEX II Gel Extraction Kit von Qiagen (Hilden) mittels Adsorption der DNA an Silica-GelPartikeln. Die gewünschten DNA-Banden wurden mit einem sterilen Skalpell aus dem Gel geschnitten, die weitere Durchführung der Isolierung erfolgte nach dem Protokoll des Herstellers. Das Produkt wurde für die Sequenzierung und zur Ligation verwendet.

\subsubsection{Konzentrationsbestimmung von Nukleinsäuren}

Im Rahmen einiger molekularbiologischer Ansätze war es notwendig, die Konzentration der eingesetzten Nukleinsäuren photometrisch zu quantifizieren. Das Prinzip der photometrischen Konzentrationsbestimmung basiert auf der spezifischen Absorption aromatischer Basen doppelsträngiger DNA bei $260 \mathrm{~nm}$. Die Probe wurde 
dazu nach Abgleich der Nullwerte in einer Quartzküvette mit dem BioPhotometer von Eppendorf (Hamburg) UV-spektrometrisch vermessen. Eine Absorption von 1 entspricht einer Konzentration von $50 \mu \mathrm{g} / \mathrm{ml}$ doppelsträngiger DNA. Über die ermittelte Absorption ließ sich die Konzentration der Nukleinsäuren mittels folgender Formel bestimmen (Sambrook et al. 1989):

$$
C=A_{260} \times F \times K
$$

c: Konzentration DNA-Probe $[\mu \mathrm{g} / \mathrm{ml}]$

A $260_{0}$ : Absorption bei $260 \mathrm{~nm}$

F: Verdünnungsfaktor der DNA-Probe

K: Konzentration der DNA-Probe bei einer Absorption von $1(50 \mu \mathrm{g} / \mathrm{ml}$ bei doppelsträngiger DNA).

\subsection{Klonierungstechniken}

\subsubsection{Spaltung von DNA mit Restriktionsendonukleasen}

Für die enzymatische Spaltung von DNA wurde ein Reaktionsansatz mit einem Volumen von mindestens $10 \mu \mathrm{l}$ verwendet. Pro $\mu \mathrm{l}$ DNA wurden 2-3 U Restriktionsenzym sowie der entsprechende Puffer hinzugegeben und der Ansatz für $2 \mathrm{~h}$ bei der für das Enzym optimalen Temperatur inkubiert. Bei gleichzeitiger Spaltung mit zwei Restriktionsenzymen wurde ein Puffer verwendet, welcher für beide Enzyme gute Reaktionsbedingungen bietet. Sofern dies nicht möglich war, wurde die Restriktion in zwei aufeinanderfolgenden Schritten mit zwischenzeitlicher Aufreinigung durchgeführt. Für die Kontrolle der erfolgreichen Spaltung wurden $2 \mu \mathrm{l}$ des Restriktionsansatzes auf ein Agarosegel aufgetragen und nach dem Lauf mit einem DNA-Längenstandard verglichen. 


\subsubsection{Ligation von DNA-Fragmenten}

Die Verknüpfung von DNA-Fragmenten mit linearisierter Plasmid-DNA erfolgte katalytisch mit dem Enzym T4-DNA-Ligase. Dabei werden Phospodiesterbindungen zwischen dem 3'-Hydroxyl- und dem 5'-Phosphatende der zu verknüpfenden DNAFragmente gebildet, wobei rekombinante DNA-Moleküle entstehen. Für die Ligation wurde folgender Ansatz verwendet:

$\begin{array}{ll}25-50 \mathrm{ng} & \text { linearisierte Vektor-DNA } \\ 30-120 \mathrm{ng} & \text { Insert-DNA } \\ 1 \mu \mathrm{l} & \text { T4-DNA-Ligase } \\ 1 \mu \mathrm{l} & 10 \times \text { Ligationspuffer } \\ \text { ad. } 10 \mu \mathrm{l} & \mathrm{H}_{2} \mathrm{O} .\end{array}$

Der Ligationsansatz wurde über Nacht bei $4{ }^{\circ} \mathrm{C}$ inkubiert.

\subsubsection{Subklonierung von DNA-Produkten}

Die Subklonierung von PCR-Produkten wurde mit dem pGEM-T Easy Vektorsystem mit 5'-T-Überhängen durchgeführt. Für die Klonierung wurden PCR-Produkte mit 3'A-Überhängen benötigt. Taq- und andere Polymerasen besitzen eine terminale Transferase-Aktivität, die zur Addition eines Nukleotids an das 3'-Ende des PCRProduktes führt. Diese terminale Transferaseaktivität bildet somit die Grundlage für die TA-Subklonierung. Es wurde folgender Ansatz verwendet:

$\begin{array}{ll}50 \mathrm{ng} & \text { pGEM-T Easy Vektor } \\ & \text { PCR-Produkt (im Verhältnis 3:1 zum Vektor) } \\ 1 \mu \mathrm{l} & \text { T4-DNA-Ligase } \\ 1 \mu \mathrm{l} & 10 \times \text { Ligationspuffer } \\ \text { ad. } 10 \mu \mathrm{l} & \mathrm{H}_{2} \mathrm{O} .\end{array}$

Der Ansatz wurde durch Invertieren vermischt und über Nacht bei $4{ }^{\circ} \mathrm{C}$ inkubiert. 


\subsubsection{Transformation kompetenter Zellen mit Plasmid-DNA}

Für die Transformation wurden zunächst 50-100 $\mu$ l kompetente E. coli DH5a-Zellen (Invitrogen $\mathrm{GmbH}$, Karslruhe) auf Eis aufgetaut. Der gesamte Ligationsansatz wurde den aufgetauten Zellen hinzugefügt und das Gemisch für 30 min auf Eis inkubiert. Dann wurden die Zellen für $50 \mathrm{~s}$ einem Hitzeschock von $42^{\circ} \mathrm{C}$ ausgesetzt und sofort wieder für 2 min auf Eis inkubiert. Der Ansatz wurde mit $1 \mathrm{ml} \mathrm{SOC-Medium} \mathrm{aufgefüllt}$ und für $1,5 \mathrm{~h}$ bei $37^{\circ} \mathrm{C}$ unter Schütteln inkubiert. Danach wurden 50-300 $\mu \mathrm{l}$ auf für die Selektion geeignete Agarplatten ausplattiert und über Nacht bei $37^{\circ} \mathrm{C}$ inkubiert (Hanahan 1983).

\subsection{Gelelektrophorese}

\subsubsection{Gelelektrophorese von DNA}

Die Auftrennung von DNA-Fragmenten erfolgte mittels Agarose-Gelelektrophorese. Abhängig von der Größe der Fragmente wurden Gele mit 0,5 - $3 \%$ (w/v) Agaroseanteil verwendet. Dazu wurde die entsprechende Menge Agarose in 0,5 x TBE-Puffer gekocht und mit Ethidiumbromid versetzt (Endkonzentration 0,5 $\mu \mathrm{l} / \mathrm{ml}$ ). Das flüssige Gel wurde in den Gelträger überführt, nach der vollständigen Verfestigung wurde es mit 0,5 x TBE-Puffer überschichtet. Die Gelelektrophorese wurde bei 60-115 V durchgeführt.

\subsubsection{Längenstandards}

Zur Bestimmung der Längen von DNA-Fragmenten auf den Gelen wurden Längenstandards parallel mitgeführt.

$1 \mathrm{~kb}$ DNA Ladder

$\lambda$-DNA
Invitrogen, Karlsruhe

MBI Fermentas, St. Leon-Rot

Die DNA-Fragmente wurden durch das interkalierende Ethidiumbromid unter UVLicht (354 nm) sichtbar gemacht. 


\subsection{Polymerase-Kettenreaktion (PCR)}

Saiki et al. beschrieben 1985 die Polymerase-Kettenreaktion. Die folgenden Methoden sind an diese Arbeit angelehnt. Die Polymerase-Kettenreaktion als eine der wichtigsten Techniken der Molekularbiolgie ermöglicht die exponentielle Amplifikation von spezifischen DNA-Sequenzen in vitro durch die Verwendung sequenzspezifischer synthetischer Oligonukleotide (Primer). Eine PCR startet mit einem Paar von Oligonukletiden (Primer), von denen der vorwärts gerichtete Primer in Richtung des rückwärts gerichteten Primers DNA synthetisiert und umgekehrt. Die Synthese des neuen DNA-Stranges wird durch eine hitzestabile Taq DNAPolymerase (Chien et al. 1976) katalysiert. Dieser ist komplementär zur TemplateDNA in der 5'- zur 3'-Richtung, indem die Primer durch komplementäre Basen verlängert werden. Dadurch wird ein neuer DNA-Abschnitt, flankiert durch die beiden Primer, generiert. Über mehrere aufeinanderfolgende Amplifikationszyklen kann eine beliebige Menge an spezifischer DNA-Sequenz aus einer kleinen DNAAusgangsmenge erzeugt werden.

\subsubsection{PCR an genomischer und Plasmid-DNA}

Zur Amplifikation von Produkten aus genomischer bzw. Plasmid-DNA wurde, soweit nicht im Ergebnisteil anders beschrieben, folgender Ansatz verwendet:

$\begin{array}{ll}10-50 \mathrm{ng} & \text { template-DNA (genomisch bzw. Plasmid) } \\ 5 \mu \mathrm{l} & 10 \times \text { ImmoBuffer } \\ 1 \mu \mathrm{l} & \text { dNTPs }(10 \mathrm{mM}) \\ 1,5 \mu \mathrm{l} & 50 \mathrm{mM} \mathrm{MgCl} 2 \\ 0,4 \mu \mathrm{l} & \text { Immolase DNA-Polymerase }(5 \mathrm{U} / \mu \mathrm{l}) \\ 1 \mu \mathrm{l} & \text { Primer } \mathrm{F} \text { (sequenzspezifischer Forward-Primer) } \\ 1 \mu \mathrm{l} & \text { Primer R (sequenzspezifischer Reverse-Primer) } \\ \text { ad. } 50 \mu \mathrm{l} & \mathrm{H}_{2} \mathrm{O} .\end{array}$

Die DNA-Amplifikation fand durch eine Touch-Down-PCR (Don et al. 1991) in einem Primus 96 Thermocycler der Firma MWG Biotech (High Point, NC, USA) statt. Eine Touch-Down-PCR ist eine Methode zur Verringerung der Amplifiktion von 
unspezifischen DNA-Sequenzen. Bei der PCR wird die Spezifität der zu amplifizierenden Sequenz durch die Annealing-Temperatur bestimmt. Der Schmelzpunkt der Primer stellt die höchstmögliche Annealing-Temperatur dar, mit der die größte Spezifität erreicht wird. Die Touch-Down-PCR beginnt mit einer dem Schmelzpunkt der Primer nahen bzw. höheren Temperatur, um eine große Spezifität zu erreichen und fährt in den folgenden Zyklen mit einer geringeren Temperatur fort, um die Ausbeute an DNA zu vergrößern. Die Anzahl der Zyklen, die Temperaturschritte sowie die einzelnen Zeiten wurden individuell je nach DNAFragment sowie der zugehörigen Primer angepasst. Die PCR wurde nach folgendem Schema durchgeführt:

\begin{tabular}{|c|c|c|c|}
\hline $94^{\circ} \mathrm{C}$ & $5 \mathrm{~min}$ & & Initiale Denaturierung \\
\hline $94^{\circ} \mathrm{C}$ & $30-60 \mathrm{sec}$ & & Denaturierung \\
\hline $65^{\circ} \mathrm{C}-60^{\circ} \mathrm{C}$ & $30-90 \mathrm{sec}$ & 5 Touch-Down-Zyklen & Annealing \\
\hline $72{ }^{\circ} \mathrm{C}$ & $30-90 \mathrm{sec}$ & & Elongation \\
\hline $94^{\circ} \mathrm{C}$ & $30-60 \mathrm{sec}$ & & Denaturierung \\
\hline $60^{\circ} \mathrm{C}$ & $30-90 \mathrm{sec}$ & 30-35 Zyklen & Annealing \\
\hline $72{ }^{\circ} \mathrm{C}$ & $30-90 \mathrm{sec}$ & & Elongation \\
\hline $72{ }^{\circ} \mathrm{C}$ & $7 \mathrm{~min}$ & & Finale Elongation. \\
\hline
\end{tabular}

Nach erfolgter Amplifikation wurde 1/10 des Ansatzes mit $4 \mu$ Stop-Mix II gemischt, auf ein 1-2 \%iges Agarosegel mit Ethidiumbromid aufgetragen und elektrophoretisch aufgetrennt.

\subsection{2 „Nested“ PCR}

Bei einer sehr geringen Ausgangsmenge an DNA kann die Anzahl der Zyklen in der PCR gesteigert werden, um eine ausreichende Menge des Amplifikats zu erhalten. Dadurch entsteht jedoch ein höheres Risiko für Fehlhybridisierungen. Zur Erhaltung der Spezifität der PCR wird daher eine zweite PCR am Produkt der ersten PCR 
vorgenommen. Die Primer für die zweite, sogenannte "nested" PCR, wurden dabei so gewählt, dass sie innerhalb des ersten Fragments liegen. Der Ansatz und die Bedingungen für die durchgeführte „nested" PCR sind im Ergebnisteil beschrieben.

\subsection{Sequenzanalyse}

Die nichtradioaktive Sequenzierung basiert auf dem Prinzip des Kettenabbruchverfahrens (Sanger et al. 1977). Analog zur PCR bindet ein sequenzspezifischer Primer an die denaturierte DNA, so dass eine DNA-Polymerase einen komplementären Nukleinsäurestrang erzeugen kann. Es kommen neben dNTPs (Desoxyribonukleosidtriphosphate) vier Didesoxynukleotide zum Einsatz, welche jeweils mit verschiedenen Fluoreszenzfarbstoffen markiert sind und bei Einbau in den Strang zu einem Abbruch führen. Sie können bei der gelelektrophoretischen Analyse über Laserabtastung automatisch detektiert werden. Die Sequenzreaktion bestand jeweils aus $100 \mathrm{ng} / 1000$ bp DNA bzw. Plasmid-DNA, 10 pmol sequenzspezifischem Primer und $4 \mu \mathrm{l}$ ET-Mix (DYEnamic ET terminator Cycle sequencing Kit der Firma Amersham, Freiburg) und wurde in einem Gesamtansatz von $10 \mu \mathrm{l}\left(\mathrm{ad} . \mathrm{H}_{2} \mathrm{O}\right)$ in einem Thermocycler vom Typ Primus (MWGBiotech AG) nach folgendem Programm durchgeführt:

\begin{tabular}{|c|c|c|c|}
\hline $95^{\circ} \mathrm{C}$ & $1 \min$ & & Initiale Denaturierung der DNA \\
\hline $95^{\circ} \mathrm{C}$ & $30 \mathrm{sec}$ & & Denaturierung \\
\hline $60^{\circ} \mathrm{C}$ & $30 \mathrm{sec}$ & 25 Zyklen & Annealing \\
\hline $60^{\circ} \mathrm{C}$ & $2 \min$ & & Elongation \\
\hline $60^{\circ} \mathrm{C}$ & $5 \mathrm{~min}$ & & Finale Elongation. \\
\hline
\end{tabular}

Nach der Sequenzreaktion wurde $10 \mu \mathrm{H}_{2} \mathrm{O}$ hinzugefügt und der Ansatz über SephadexG50-Säulen aufgereinigt. Die Sequenzanalyse erfolgte über die automatische Sequenzanlage MegaBACE ${ }^{\mathrm{TM}} 1000$ der Firma Molecular Dynamics (Amersham). 


\subsection{Zellbiologische Methoden}

\subsubsection{Zellkultur eukaryontischer Zellen}

Die Kultivierung der adhärent wachsenden HeLa-Zellen und NIH3T3-Zellen erfolgte in entsprechendem Kulturmedium, wie unter 2.8 .4 beschrieben, jeweils in oberflächenbehandelten Gewebekulturflaschen. Die Inkubation erfolgte im Brutschrank bei $37{ }^{\circ} \mathrm{C}$ und unter Begasung mit $5 \% \mathrm{CO}_{2}$. Die Zellen wurden in Abhängigkeit von der erreichten Konfluenz 1-2 mal pro Woche gewaschen und geteilt. Dabei wurden die Zellen mit DPBS gewaschen, in Trypsin-like-Enzyme ${ }^{\mathrm{TM}}$ inkubiert bis sie sich vom Boden der Gewebekulturflasche lösten, mit DMEM-Medium mit Zusatz von 1,2 \% Penicillin/Streptomycin sowie $10 \%$ FKS aufgefüllt und für 5 min bei $200 \times \mathrm{g}$ zentrifugiert. Der Überstand wurde verworfen und das Pellet mit $5 \mathrm{ml}$ DPBS resuspendiert und erneut für 5 min bei $200 \times$ g zentrifugiert. Nach erneutem Verwerfen des Überstandes wurde das Pellet in DMEM-Medium mit Zusatz von 1,2 \% Penicillin/Streptomycin sowie $10 \%$ FKS resuspendiert und im Verhätnis 1:5 auf neue Gewebekulturflaschen aufgeteilt und mit frischem Medium aufgefüllt.

\subsubsection{Kryokonservierung und Revitalisierung von eukaryontischen Zellen}

Zur Aufbewahrung wurden die Zellen mit einer Konfluenz von mindestens $80 \%$ mit DPBS gewaschen, in Trypsin-like-Enzyme ${ }^{\mathrm{TM}}$ inkubiert, gelöst und anschließend in einer entsprechenden Menge Kulturmedium mit Zusatz von $8 \%$ DMSO resuspendiert und für eine Woche bei $-70^{\circ} \mathrm{C}$ aufbewahrt. Danach wurden sie in flüssigem Stickstoff kryokonserviert.

Die Revitalisierung erfolgte durch zügiges Auftauen, Überführen in vorgewärmtes Kulturmedium und Inkubation über Nacht. Zur vollständigen Entfernung des DMSO wurde das Medium am nächsten Tag gewechselt. Die Zellen wurden weiterbehandelt wie oben beschrieben (s. 2.15.1). 


\subsubsection{Transfektion eukaryontischer Zellen}

Die Transfektion eukaryontischer Zellen erfolgte zur Durchführung der KoLokalisation und des BiFC-Assays. Zur Transfektion wurde das Transfektionsreagenz Lipofectin ${ }^{\circledR}$ Transfection Reagent (Invitrogen) nach Herstellerangaben verwendet. Einen Tag vor der geplanten Transfektion wurden Zellen in entsprechende Kulturflaschen überführt, so dass zum Zeitpunkt der Transfektion eine Konfluenz in der Kulturflasche von ungefähr $80 \%$ bestand. $1 \mu \mathrm{g}$ DNA bei Einzeltransfektion bzw. jeweils $0,5 \mu \mathrm{g}$ DNA bei Doppeltransfektion wurden auf $100 \mu \mathrm{l}$ mit Opti-MEM I aufgefüllt und für 10 min bei RT inkubiert. Gleichzeitig wurde $3 \mu$ Lipofectin $₫$ auf 100 $\mu \mathrm{l}$ Opti-MEM I aufgefüllt. Diese Ansätze wurden dann vorsichtig miteinander vermischt und für weitere $30 \mathrm{~min}$ inkubiert. Zwischendurch wurden die Zellen zweimalig mit DPBS gewaschen und mit Opti-MEM I eingedeckt. Schließlich wurden die Falcon Culture Slides mit Zellen beimpft und der Transfektionsansatz vorsichtig Tropfen für Tropfen hinzugegeben. Nach $3 \mathrm{~h}$ Inkubation bei $37{ }^{\circ} \mathrm{C}$ und $5 \% \mathrm{CO}_{2}$ wurde 20 \% FKS Opti-MEM I Medium hinzugegeben und für weitere $2 \mathrm{~h}$ inkubiert. Danach wurde das Medium verworfen, die Zellen zweimalig mit DPBS gewaschen und mit normalem Zellkulturmedium versetzt. Nach 24 h bzw. 48 h Inkubation zur Proteinexpression wurden die Zellen entsprechend des Versuchsansatzes weiterverwendet.

\subsection{Yeast-Two-Hybrid-Experimente}

\subsubsection{Yeast-Two-Hybrid-System}

Das Yeast-Two-Hybrid-System eignet sich zur in-vivo-Identifikation von putativen Interaktionspartnern auf Proteinebene (Fields und Song 1989) in der Hefe Saccharomyces cerevisiae. Es wurde zum Interaktionsnachweis von einem CHD8Teilstück mit Teilstücken von CHD7 mit und ohne Mutationen, von CHD8-Teilstücken untereinander und CHD7-Teilstücken untereinander zum Interaktionsnachweis eingesetzt. Die Tatsache, dass viele eukaryontische Transkriptionsfaktoren aus zwei funktionell unabhängigen Domänen bestehen, erlaubt die Kopplung jeder dieser 
unterschiedlichen Domänen an die Proteine, deren Interaktion nachgewiesen werden soll. Im Falle einer Interaktion bilden die Domänen wieder eine funktionelle Einheit. Der GAL4-Transkriptionsaktivator der Hefe enthält eine DNA-Bindungsdomäne (DNA-BD) und eine transkriptionsaktivierende Domäne (AD). Die DNA-BD erkennt und bindet an eine als UAS (upstream activating sequence) bezeichnete Sequenz stromaufwärts von GAL4-responsiven Domänen. Die AD interagiert mit anderen Komponenten des Transkriptionsapparates, welche an der Einleitung der Transkription beteiligt sind. Im Normalfall sind beide Domänen Teile eines einzigen Proteins, welches zur Aktivierung der Transkription eines Gens benötigt wird. Die Tatsache, dass die Aktivierung auch bei Lokalisation der Domänen auf zwei unterschiedlichen Proteinen möglich ist, wird im Yeast-Two-Hybrid-System durch die Klonierung von zwei verschiedenen Vektoren ausgenutzt. Der Vektor pGBKT7 kodiert für die DNA-BD, der Vektor pGADT7 für die AD. Die Gensequenzen der Proteine, zwischen denen jeweils die Interaktion untersucht werden soll, werden durch Integration in die Vektoren mit den entsprechenden Interaktionsdomänen fusioniert. Nach Transformation der Plasmide in den Hefestamm AH109 können die Fusionsproteine exprimiert und in den Zellkern transportiert werden. Bei Vorliegen einer Interaktion beider Proteine kommt es zu einer räumlichen Verbindung zwischen GAL4-DNA-BD und GAL4-AD und somit zu einer funktionellen Rekonstitution des kompletten GAL4-Transkriptionsaktivators. Die Transkription der stromabwärtsliegenden Reportergene ADE2, MEL1, lacZ und HIS3 des Hefestammes AH109 wird dadurch eingeleitet. Die Proteininteraktion wird phänotypisch detektierbar (Abb. 2.1). Der Vektor pGBKT7 kodiert für die Aminosäure Tryptophan (T), der Vektor pGADT7 für die Aminosäure Leucin (L). Zur Transfektionskontrolle werden dem Nährboden die essentiellen Aminosäuren Leucin und Tryptophan entzogen, dadurch werden die Hefezellen selektioniert, welche erfolgreich mit dem pGBKT7- bzw. mit dem pGADT7-Vektor transformiert wurden. Für die Selektion und den Nachweis der Proteininteraktion werden dem Nährboden zusätzlich noch die für AH109 essentiellen Aminosäuren Histidin ( $\mathrm{H}$; Reporter: HIS3) und Adenin ( $\mathrm{A}$; Reporter: $A D E 2)$, welche durch den GAL4-Transkriptionsaktivator kontrolliert werden, entzogen. Durch Zugabe von X- $\alpha$-Gal (Reporter: MEL1) oder X-Gal (Reporter: lacZ) als Substrat kann eine farbliche Selektion vorgenommen werden. Im Yeast-TwoHybrid dieser Arbeit wurde dem Nährboden X- $\alpha$-Gal hinzugefügt. Die Interaktion der untersuchten Proteine zeigte sich nach einigen Stunden durch eine eintretende 
Blaufärbung, nachdem die $\alpha$-Galaktosidase (MEL1) das künstlich zugesetzte Substrat umgesetzt hat.
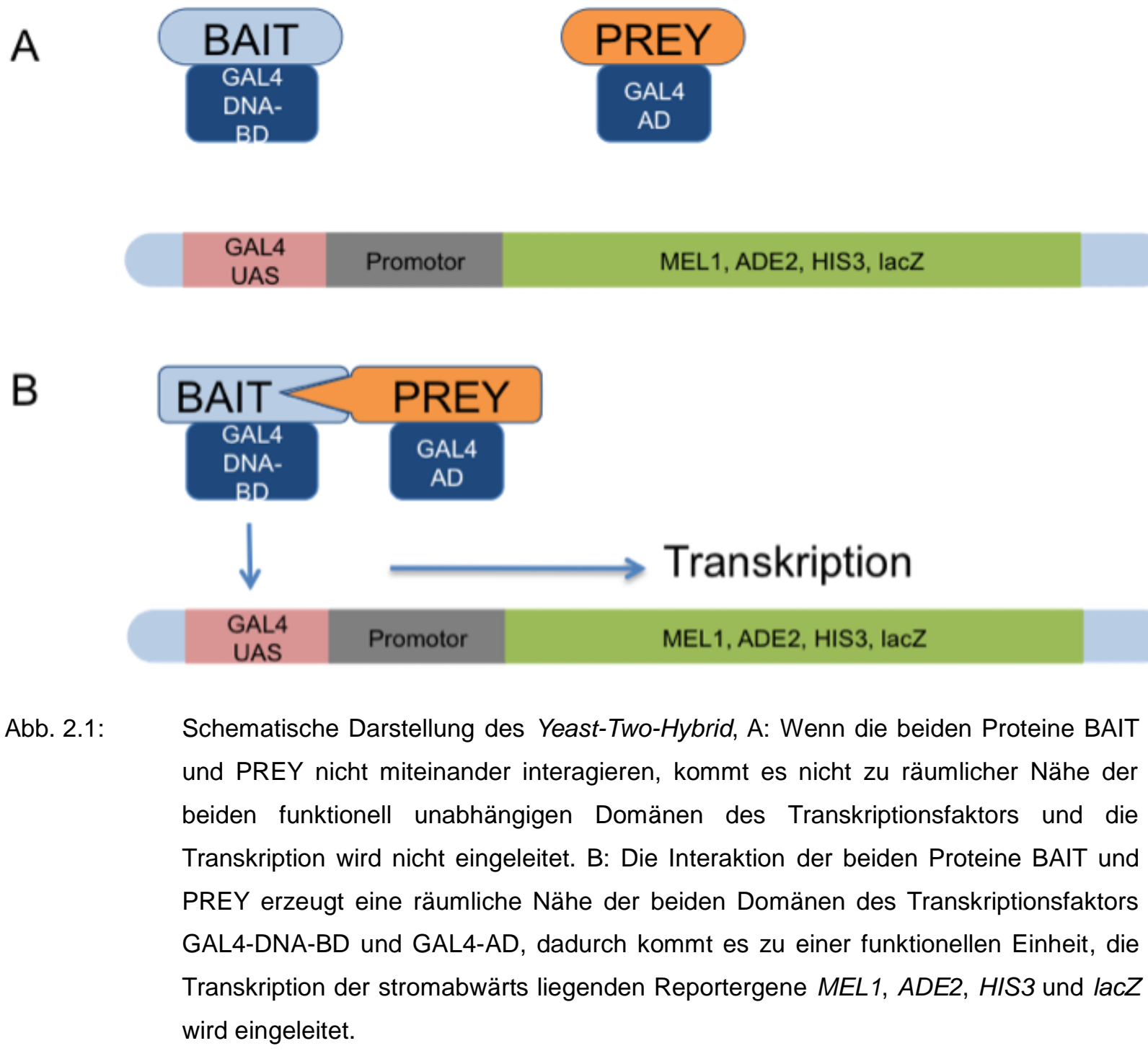

\subsubsection{Transformation kompetenter Hefezellen}

Für die Yeast-Two-Hybrid-Experimente wurde zunächst eine kleine Portion eines gefrorenen AH109-Hefestocks auf eine YPDA-Platte ausplattiert und für 3 Tage bei $30{ }^{\circ} \mathrm{C}$ inkubiert. $1 \mathrm{ml}$ YPDA-Nährlösung wurde dann mit einigen 2-3 $\mathrm{mm}$ großen Kolonien beimpft, durchmischt und dann zu einem Kolben mit $50 \mathrm{ml}$ YPDANährlösung hinzugegeben und über Nacht für $16-18 \mathrm{~h}$ bei $30^{\circ} \mathrm{C}$ inkubiert. Um eine $\mathrm{OD}_{600}$ von ungefähr 0,2 zu erreichen, wurden $300 \mathrm{ml}$ YPDA-Nährlösung mit bis zu 50 $\mathrm{ml}$ der Übernachtkultur von $\mathrm{AH} 109$ beimpft. Diese Kultur wurde $2-3 \mathrm{~h}$ bei $30^{\circ} \mathrm{C}$ bis zu einer $\mathrm{OD}_{600}$ von $0,5 \pm 0,1$ inkubiert. Für die Erstellung von kompetenten Zellen wurde 
die Kultur 5 min bei $1.000 \times$ g zentrifugiert, mit sterilem Wasser gewaschen und in 1,5 $\mathrm{ml} \mathrm{TE/Lithiumacetat-Lösung} \mathrm{resuspendiert.} \mathrm{Von} \mathrm{dieser} \mathrm{Suspension} \mathrm{wurden} 100 \mu \mathrm{l} \mathrm{mit}$ je 0,1 $\mu \mathrm{g}$ Plasmid-DNA der verschiedenen Konstrukte in den Vektoren pGADT7 und pGBKT7 und $100 \mu \mathrm{g}$ Lachsspermien-DNA $(10 \mu \mathrm{g} / \mu \mathrm{l})$ versetzt. Nach Zugabe von 600 $\mu \mathrm{l}$ PEG/Lithiumacetat-Lösung wurde der Ansatz $30 \mathrm{~min}$ bei $30^{\circ} \mathrm{C}$ geschüttelt. Nun wurden $70 \mu \mathrm{l}$ DMSO hinzugefügt und die Zellen 15 min einem Hitzeschock von $42{ }^{\circ} \mathrm{C}$ ausgesetzt, dann wurden die Zellen für 1-2 min auf Eis abgekühlt und kurz zentrifugiert. Das erhaltene Pellet wurde in $0,5 \mathrm{ml}$ TE-Puffer resuspendiert. $20 \mu \mathrm{l}$ dieser Suspension wurden als Tropfen auf einen Selektivnährboden gebracht und bei $30{ }^{\circ} \mathrm{C}$ für 3-4 Tage inkubiert.

\subsection{BiFC-Assay}

Die Interaktion zwischen den Proteinen CHD7 und CHD8 sollte durch einen

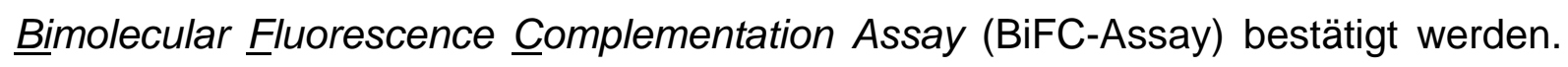
Es handelt sich hierbei um eine Methode zur Visualisierung und Lokalisierung von Protein-Proteininteraktionen direkt in der Zelle. Das Prinzip der Methode beruht darauf, dass die kodierende Sequenz eines fluoreszierenden Proteins, in diesem Fall EGFP, auf zwei Vektoren verteilt wird und dadurch in dem für die Fluoreszenz wichtigen Aminosäurenbereich von 157-158 getrennt ist (Ormö et al. 1996). Eine grüne Fluoreszenz kann nur auftreten, wenn die beiden getrennten $\mathrm{N}$ - und $\mathrm{C}$ terminalen Aminosäurebereiche in unmittelbarer räumlicher Nähe zueinander stehen. Die beiden Einzelfragmente des EGFP allein besitzen hingegen keine Fähigkeit zur Fluoreszenz. Werden die Einzelfragmente nun jeweils an die Proteine gekoppelt, deren Interaktion im Assay nachgewiesen werden soll, kommen sie nur bei einer Interaktion der Proteine in eine räumliche Nähe und besitzen wieder die Fähigkeit zur Fluoreszenz. Ein Vorteil der Methode besteht darin, dass auch schwächere Interaktionen zwischen Proteinen nachgewiesen werden können, da sich einmal interagierende EGFP-Fragmente nicht mehr voneinander trennen. Dadurch kann eine Interaktion mit einer höheren Sensitivität nachgewiesen werden (Kerppola 2008).

Der in dieser Arbeit durchgeführte BiFC-Assay wurde von Frau Prof. Dr. S. Hoyer- 
Fender (Abteilung Entwicklungsbiologie, Universität Göttingen) etabliert und bei einer Informationsveranstaltung im Institut für Humangenetik vorgestellt. Die Funktionalität des Assays wurde mit einigen bekannten Interaktionspartnern überprüft. Beispielsweise bestätigten Burnicka-Turek et al. (2010) mit diesem Assay eine Interaktion zwischen PELO und HAX1, EIF3G und SRPX. Die verwendeten Vektoren FPCA-V1 und FPCA-V2 wurden von Frau Prof. Dr. S. Hoyer-Fender hergestellt und freundlicherweise zur Verfügung gestellt.
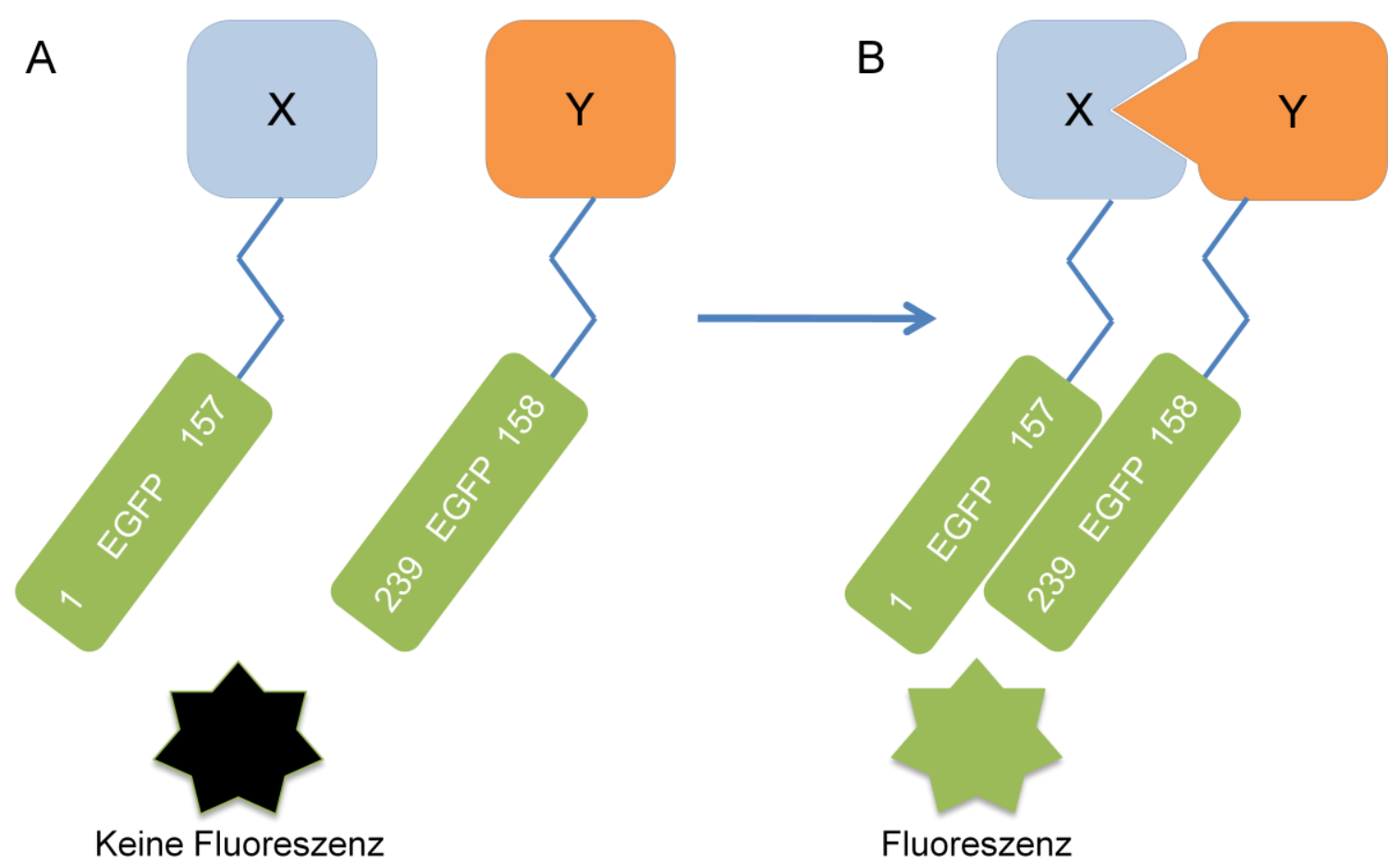

Abb 2.2: Schematische Darstellung des Prinzips beim BiFC-Assay. Die beiden auf eine Interaktion zu untersuchenden Kandidatengene $X$ und $Y$ werden mit dem $\mathrm{N}$ terminalen (AS 1-57) bzw. C-terminalen (AS 158-239) Teil des EGFP gekoppelt und überexprimiert. A: Die Kandidatenproteine interagieren nicht miteinander, das EGFP bleibt getrennt und es tritt keine Fluoreszenz auf. B: Die Kandidateproteine interagieren miteinander und bringen die $\mathrm{N}$ - und C-terminalen Teile des EGFP in eine räumliche Nähe, dadurch ist die Fähigkeit zur Fluoreszenz des EGFP wieder hergestellt, und es tritt ein Signal auf. 


\section{Ergebnisse}

\subsection{Familiärer Fall eines CHARGE-Syndroms}

Im Rahmen der Diagnostik wurde eine Familie identifiziert, in der zwei Kinder vom CHARGE-Syndrom betroffen sind. Die Eltern sind klinisch gesund. Die Diagnostik ergab bei beiden Kindern im Exon 34 des CHD7-Gens die Mutation c.7302dupA. Die Analyse des Exons 34 an DNA aus dem Blut der Eltern war unauffällig. Aufgrund dieser Konstellation kann es sich bei der Familie um ein Keimbahnmosaik bei einem der Eltern handeln. Linkage-Analysen zeigten, dass die Mutation der Kinder das väterliche Allel betrifft.

\subsubsection{Untersuchung verschiedener Zelltypen des Vaters zweier betroffener CHARGE-Kinder auf die Mutation c.7302dupA im CHD7-Gen}

Zum Nachweis eines somatischen oder Keimbahnmosaiks beim Vater wurde DNA aus Lymphozyten, Haarfollikelzellen, Schleimhautzellen sowie einem Spermienpool isoliert. Das Exon 34 des CHD7-Gens wurde amplifiziert und sequenziert. Die Sequenzierung ergab eine Wildtyp-Sequenz für das PCR-Produkt aus Lymphozyten, Haarfollikelzellen und Schleimhautzellen. Die Sequenzierung des PCR-Produktes aus DNA des Spermienpools zeigte einen Frameshift. Das heißt, in einem Teil der Spermien liegt die Mutation c.7302dupA im CHD7-Gen vor, in einem anderen Teil der Spermien liegt ein Normalbefund vor.

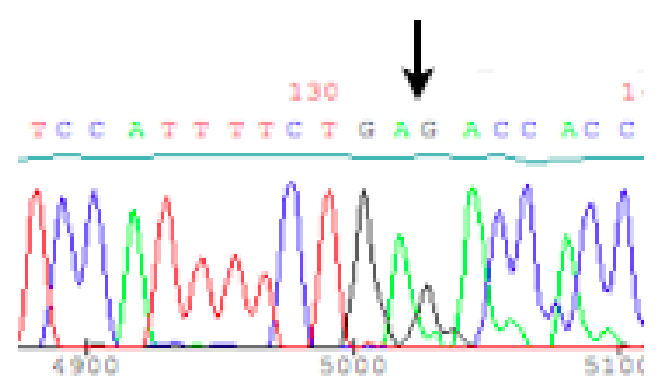

Abb. 3.1: Ausschnitt aus der Forward-Sequenz des Exon 34 vom CHD7-Gen („nested“ PCR). Der schwarze Pfeil kennzeichnet die Stelle, an der ein Frameshift beginnt. Der Frameshift kommt dadurch zustande, dass ein Teil der Spermien die normale Sequenz aufweist und in einem Teil der Spermien die Mutation c.7302dupA vorliegt. 


\subsubsection{Etablierung einer molekulargenetischen Analyse an Einzelspermien}

Für die molekulargenetische Analyse der Spermien war es zunächst nötig, einzelne Spermien aus dem Ejakulat zu isolieren. Das native Ejakulat wurde zweifach mit DPBS gewaschen und die pelletierten Spermien in DPBS resuspendiert. Anschließend wurde etwas von der Probe auf einen Objektträger ausgestrichen und getrocknet. Nun wurden mit Hilfe eines PALM-MicroLaser-Systems zunächst mehrere einzelne Spermien isoliert und in einem normalen E-Cup-Deckel, welcher zuvor mit $40 \mu \mathrm{l}$ Lysepuffer (DNeasy Blood \& Tissue Kit, QIAGEN) versetzt wurde, gesammelt. Die Spermien wurden zunächst aus dem E-Cup-Deckel in einen normalen 2-ml-E-Cup überführt, auf $100 \mu \mathrm{l}$ mit Lysepuffer aufgefüllt, gevortexed, bei $56{ }^{\circ} \mathrm{C}$ für $18 \mathrm{~h}$ inkubiert und dann die DNA nach dem „User-Developed Protocol 2 DNeasy Blood \& Tissue Kit (QIAGEN)“ isoliert. Das so gewonnene Lysat wurde auf $2 \mu$ vakuumzentrifugiert. Anschließend wurde eine Touch-Down-PCR mit folgendem Reaktionsansatz durchgeführt:

$\begin{array}{ll}2 \mu \mathrm{l} & \text { Template } \\ 2,5 \mu \mathrm{l} & \text { 10x ImmoBuffer } \\ 0,5 \mu \mathrm{l} & \text { dNTPs } \\ 0,75 \mu \mathrm{l} & \mathrm{MgCl}_{2} \\ 0,2 \mu \mathrm{l} & \text { Immolase DNA-Polymerase }(1 \mathrm{U} / \mu \mathrm{l}) \\ 0,5 \mu \mathrm{l} & \text { Primer: CHD7Ex34externF } \\ 0,5 \mu \mathrm{l} & \text { Primer: CHD7Ex34externR } \\ \text { ad. } 25 \mu \mathrm{l} & \mathrm{H}_{2} \mathrm{O} .\end{array}$

Für die Touch-Down-PCR wurde folgendes Programm (Programm: Touch-DownPCR 1) verwendet:

$\begin{array}{lll}94{ }^{\circ} \mathrm{C} & 5 \mathrm{~min} & \text { Initiale Denaturierung } \\ 94{ }^{\circ} \mathrm{C} & 60 \mathrm{sec} & \text { Denaturierung } \\ 65^{\circ} \mathrm{C} & 90 \mathrm{sec} 5 \text { Touch-Down-Zyklen } & \text { Annealing } \\ 72^{\circ} \mathrm{C} & 90 \mathrm{sec} & \text { Elongation }\end{array}$




$\begin{array}{lll}94{ }^{\circ} \mathrm{C} & 60 \mathrm{sec} & \text { Denaturierung } \\ 60{ }^{\circ} \mathrm{C} & 90 \mathrm{sec} 33 \text { Zyklen } & \text { Annealing } \\ 72{ }^{\circ} \mathrm{C} & 90 \mathrm{sec} & \text { Elongation }\end{array}$

$72{ }^{\circ} \mathrm{C} \quad 7 \mathrm{~min} \quad$ Finale Elongation.

Vom PCR-Produkt der ersten Touch-Down-PCR wurden $5 \mu \mathrm{l}$ in einen zweiten TouchDown-PCR-Ansatz mit internen Primern (F: CHD7Ex34internF; R: CHD7Ex34internR) eingesetzt. Der Ansatz sowie das PCR-Programm entsprachen dem der ersten Touch-Down-PCR. Das PCR-Produkt wurde durch eine Säule aufgereinigt (Millipore) und anschließend eine Sequenz-PCR durchgeführt. Die Sequenzierung ergab eine Wildtyp-Sequenz für CHD7.

Um das häufige Wechseln von E-Cups und mögliche Verunreinigungen in den einzelnen DNA-Isolationsschritten zu verhindern, wurde zur DNA-Isolation anstatt des Lysepuffers $30 \mu \mathrm{l}$ eines KOH/DTT-Gemisches (Cui et al. 1989) in den Deckel des E-Cups gegeben. Nach Hinzufügen der Spermien durch den PALM MicroLaser wurde der Ansatz für $10 \mathrm{~min}$ bei $65{ }^{\circ} \mathrm{C}$ inkubiert, bevor er mit $30 \mu \mathrm{l}$ Neutralisationspuffer versetzt und mit Hilfe einer Vakuumzentrifuge auf $3 \mu \mathrm{l}$ konzentriert wurde. Anschließend wurden zwei aufeinanderfolgende Touch-DownPCRs (s.o.) durchgeführt. In der PCR konnte kein PCR-Produkt amplifiziert werden, da die Salzkonzentration durch das neutralisierte KOH/DTT-Gemisch für die Polymerase zu hoch war. Eine Menge von ungefähr $20 \mu \mathrm{l}$ KOH/DTT im E-CupDeckel war jedoch zwingend notwendig, da die Fläche sonst nicht vollständig benetzt wird.

In einem weiteren Schritt wurden die DNA-Polymerasen Mango Taq (BIOLINE), Immolase (BIOLINE) sowie Robust Taq (PEQLAB) an unterschiedlichen Mengen $\mathrm{KOH} / \mathrm{DTT}$ mit und ohne Enhancer 1 bzw. Enhancer 2 (Robust Taq Kit) an genomischer DNA aus Blut verglichen, um eine DNA-Polymerase mit einer höheren Toleranz für die Salzkonzentration zu erhalten. 


\begin{tabular}{|c|c|c|c|c|c|}
\hline$\#$ & Polymerase & KOH/DTT & Enhancer 1 & Enhancer 2 & Template \\
\hline 1 & Immolase & $20 \mu \mathrm{l}$ & - & - & $0,5 \mu \mathrm{l}$ \\
\hline 2 & Immolase & $20 \mu \mathrm{l}$ & - & - & $0,5 \mu \mathrm{l}$ \\
\hline 3 & Immolase & $20 \mu \mathrm{l}$ & - & - & $0,5 \mu \mathrm{l}$ \\
\hline 4 & Mango Taq & $20 \mu \mathrm{l}$ & - & - & $0,5 \mu \mathrm{l}$ \\
\hline 5 & Mango Taq & $20 \mu \mathrm{l}$ & - & - & $0,5 \mu \mathrm{l}$ \\
\hline 6 & Mango Taq & $20 \mu \mathrm{l}$ & - & - & - \\
\hline 7 & Robust Taq & $20 \mu \mathrm{l}$ & - & - & $0,5 \mu \mathrm{l}$ \\
\hline 8 & Robust Taq & $20 \mu \mathrm{l}$ & $10 \mu \mathrm{l}$ & - & $0,5 \mu \mathrm{l}$ \\
\hline 9 & Robust Taq & $20 \mu \mathrm{l}$ & - & $2 \mu \mathrm{l}$ & $0,5 \mu \mathrm{l}$ \\
\hline 10 & Robust Taq & $20 \mu \mathrm{l}$ & - & - & $0,5 \mu \mathrm{l}$ \\
\hline 11 & Robust Taq & $20 \mu \mathrm{l}$ & $10 \mu \mathrm{l}$ & - & $0,5 \mu \mathrm{l}$ \\
\hline 12 & Robust Taq & $20 \mu \mathrm{l}$ & - & $2 \mu \mathrm{l}$ & $0,5 \mu \mathrm{l}$ \\
\hline 13 & Robust Taq & $20 \mu \mathrm{l}$ & - & - & - \\
\hline 14 & Immolase & $5 \mu \mathrm{l}$ & - & - & $0,5 \mu \mathrm{l}$ \\
\hline 15 & Immolase & $5 \mu \mathrm{l}$ & - & - & $0,5 \mu \mathrm{l}$ \\
\hline 16 & Immolase & $5 \mu \mathrm{l}$ & - & - & - \\
\hline 17 & Mango Taq & $5 \mu \mathrm{l}$ & - & - & $0,5 \mu \mathrm{l}$ \\
\hline 18 & Mango Taq & $5 \mu \mathrm{l}$ & - & - & $0,5 \mu \mathrm{l}$ \\
\hline 19 & Mango Taq & $5 \mu \mathrm{l}$ & - & - & - \\
\hline 20 & Robust Taq & $5 \mu \mathrm{l}$ & - & - & $0,5 \mu \mathrm{l}$ \\
\hline 21 & Robust Taq & $5 \mu \mathrm{l}$ & $5 \mu \mathrm{l}$ & - & $0,5 \mu \mathrm{l}$ \\
\hline 22 & Robust Taq & $5 \mu \mathrm{l}$ & - & $1 \mu \mathrm{l}$ & $0,5 \mu \mathrm{l}$ \\
\hline 23 & Robust Taq & $5 \mu \mathrm{l}$ & - & - & $0,5 \mu \mathrm{l}$ \\
\hline 24 & Robust Taq & $5 \mu \mathrm{l}$ & $5 \mu \mathrm{l}$ & - & $0,5 \mu \mathrm{l}$ \\
\hline 25 & Robust Taq & $5 \mu \mathrm{l}$ & - & $1 \mu \mathrm{l}$ & $0,5 \mu \mathrm{l}$ \\
\hline 26 & Robust Taq & $5 \mu \mathrm{l}$ & - & - & - \\
\hline 27 & Robust Taq & $5 \mu \mathrm{l}$ & $5 \mu \mathrm{l}$ & - & - \\
\hline 28 & Robust Taq & $5 \mu \mathrm{l}$ & - & $1 \mu \mathrm{l}$ & - \\
\hline
\end{tabular}

Tab. 3.1: Unterschiedliche Versuchsansätze mit unterschiedlichen DNA-Polymerasen, $\mathrm{KOH} / \mathrm{DTT}-M e n g e n$ sowie mit und ohne Enhancer 1 und 2, um die Toleranz der DNAPolymerase für unterschiedliche Salzkonzentrationen zu untersuchen. \#: Versuchsansatznummer 
Folgende PCR-Ansätze wurden durchgeführt:

$\begin{array}{ll}\text { Immolase-Ansatz: } \\ 5 \mu \mathrm{l} & 10 x \text { ImmoBuffer } \\ 1 \mu \mathrm{l} & \text { dNTPs } \\ 1,5 \mu \mathrm{l} & \mathrm{MgCl}_{2} \\ 0,4 \mu \mathrm{l} & \text { Immolase DNA-Polymerase }(1 \mathrm{U} / \mu \mathrm{l}) \\ 1 \mu \mathrm{l} & \text { Primer: CHD7Ex34externF } \\ 1 \mu \mathrm{l} & \text { Primer: CHD7Ex34externR } \\ \text { ad. } 50 \mu \mathrm{l} & \mathrm{H}_{2} \mathrm{O} . \\ & \\ \text { Mango-Taq-Ansatz: } \\ 5 \mu \mathrm{l} & 5 \times \text { Mango Taq Reaction Buffer } \\ 1 \mu \mathrm{l} & \text { dNTPs } \\ 1,5 \mu \mathrm{l} & \text { MgCl }_{2} \\ 2 \mu \mathrm{l} & \text { Mango Taq DNA-Polymerase } \\ 1 \mu \mathrm{l} & \text { Primer: CHD7Ex34externF } \\ 1 \mu \mathrm{l} & \text { Primer: CHD7Ex34externR } \\ \text { ad. } 50 \mu \mathrm{l} & \mathrm{H}_{2} \mathrm{O} .\end{array}$

Robust-Taq-Ansatz:

$\begin{array}{ll}10 \mu \mathrm{l} & \text { Puffer A } \\ 1 \mu \mathrm{l} & \text { dNTPs } \\ 0,2 \mu \mathrm{l} & \text { Robust Taq DNA-Polymerase } \\ 1 \mu \mathrm{l} & \text { Primer: CHD7Ex34externF } \\ 1 \mu \mathrm{l} & \text { Primer: CHD7Ex34externR } \\ \text { ad. } 50 \mu \mathrm{l} & \mathrm{H}_{2} \mathrm{O} .\end{array}$

Für die Touch-Down-PCR wurde das Programm Touch-Down-PCR 1 (Beschreibung des Programms siehe S. 39) verwendet. 


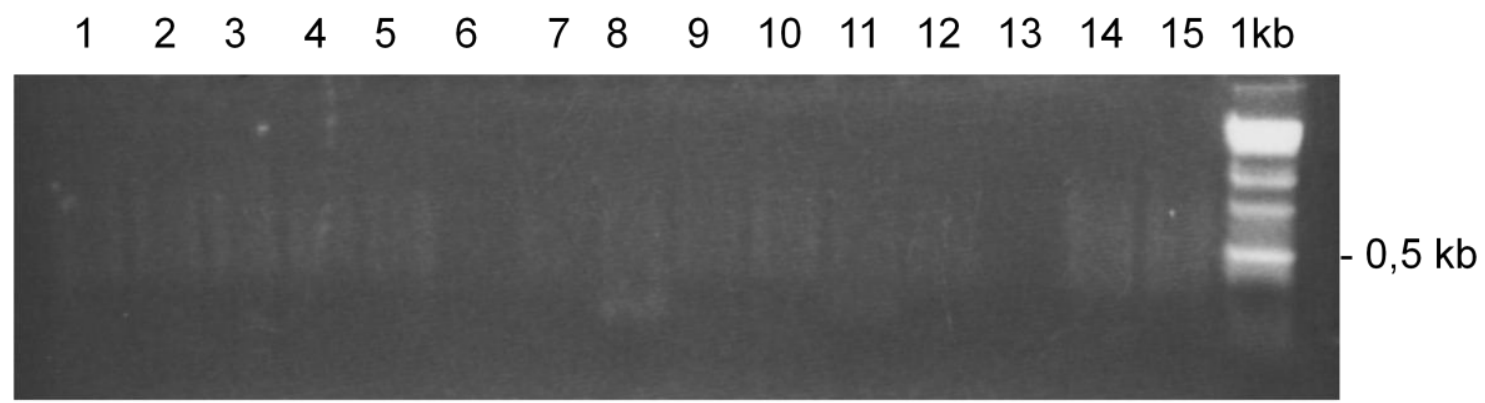

$\begin{array}{llllllllllllll}16 & 17 & 18 & 19 & 20 & 21 & 22 & 23 & 24 & 25 & 26 & 27 & 28 & 1 \mathrm{~kb}\end{array}$

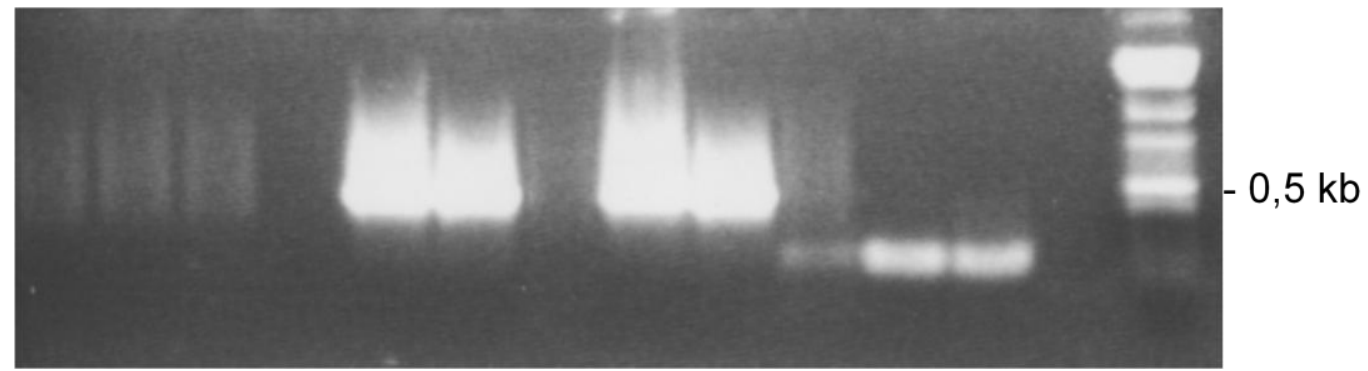

Abb 3.2: $\quad$ PCR-Produkte der Ansätze aus Tab 3.1 nach der Touch-Down-PCR 1. 1kb: DNA-Ladder.

Ein PCR-Produkt ließ sich lediglich in folgenden Ansätzen amplifizieren:

\begin{tabular}{|l|l|l|l|l|l|}
\hline$\#$ & Taq & KOH/DTT & Enhancer 1 & Enhancer 2 & Template \\
\hline 20,23 & Robust Taq & $5 \mu \mathrm{l}$ & - & - & $0,5 \mu \mathrm{l}$ \\
\hline 21,24 & Robust Taq & $5 \mu \mathrm{l}$ & $5 \mu \mathrm{l}$ & - & $0,5 \mu \mathrm{l}$ \\
\hline
\end{tabular}

Tab 3.2: Versuchsansätze der Tab 3.1, bei denen sich ein PCR-Produkt amplifizieren ließ. Die Versuchsansätze wurden zweimalig angesetzt.

Zur weiteren Eingrenzung der möglichen Menge an KOH/DTT-Gemisch und der Notwendigkeit von Zugabe des Enhancer 1 wurden weitere Versuchsansätze gewählt.

\begin{tabular}{|l|l|l|}
\hline$\#$ & KOH/DTT & Enhancer $\mathbf{1}$ \\
\hline 1 & $5 \mu \mathrm{l}$ & - \\
\hline 2 & $10 \mu \mathrm{l}$ & - \\
\hline 3 & $10 \mu \mathrm{l}$ & - \\
\hline 4 & $15 \mu \mathrm{l}$ & - \\
\hline
\end{tabular}




\begin{tabular}{|l|l|l|}
\hline 5 & $15 \mu \mathrm{l}$ & - \\
\hline 6 & $5 \mu \mathrm{l}$ & $10 \mu \mathrm{l}$ \\
\hline 7 & $10 \mu \mathrm{l}$ & $10 \mu \mathrm{l}$ \\
\hline 8 & $10 \mu \mathrm{l}$ & $10 \mu \mathrm{l}$ \\
\hline 9 & $15 \mu \mathrm{l}$ & $10 \mu \mathrm{l}$ \\
\hline 10 & $15 \mu \mathrm{l}$ & $10 \mu \mathrm{l}$ \\
\hline
\end{tabular}

Tab. 3.3: Versuchsansätze mit unterschiedlichen KOH/DTT-Mengen sowie mit und ohne Zugabe von Enhancer 1 zur weiteren Eingrenzung der möglichen Einsatzbedingungen der DNA-Polymerase Robust Taq.

Die weiteren Substanzen des PCR-Ansatzes entsprachen denen im obigen RobustTaq-Ansatz. Für die Touch-Down-PCR wurde folgendes PCR-Programm verwendet (Touch-Down-PCR 2):

$\begin{array}{llll}94^{\circ} \mathrm{C} & 5 \mathrm{~min} & & \text { Initiale Denaturierung } \\ 94{ }^{\circ} \mathrm{C} & 30 \mathrm{sec} & & \text { Denaturierung } \\ 65^{\circ} \mathrm{C} & 60 \mathrm{sec} & 5 \text { Touch-Down-Zyklen } & \begin{array}{l}\text { Annealing } \\ \text { Elongation }\end{array} \\ 72^{\circ} \mathrm{C} & 60 \mathrm{sec} & & \\ & & & \text { Denaturierung } \\ 94^{\circ} \mathrm{C} & 30 \mathrm{sec} & & \text { Annealing } \\ 60^{\circ} \mathrm{C} & 60 \mathrm{sec} & 33 \text { Zyklen } & \text { Elongation } \\ 72^{\circ} \mathrm{C} & 60 \mathrm{sec} & & \\ & & & \text { Finale Elongation. }\end{array}$




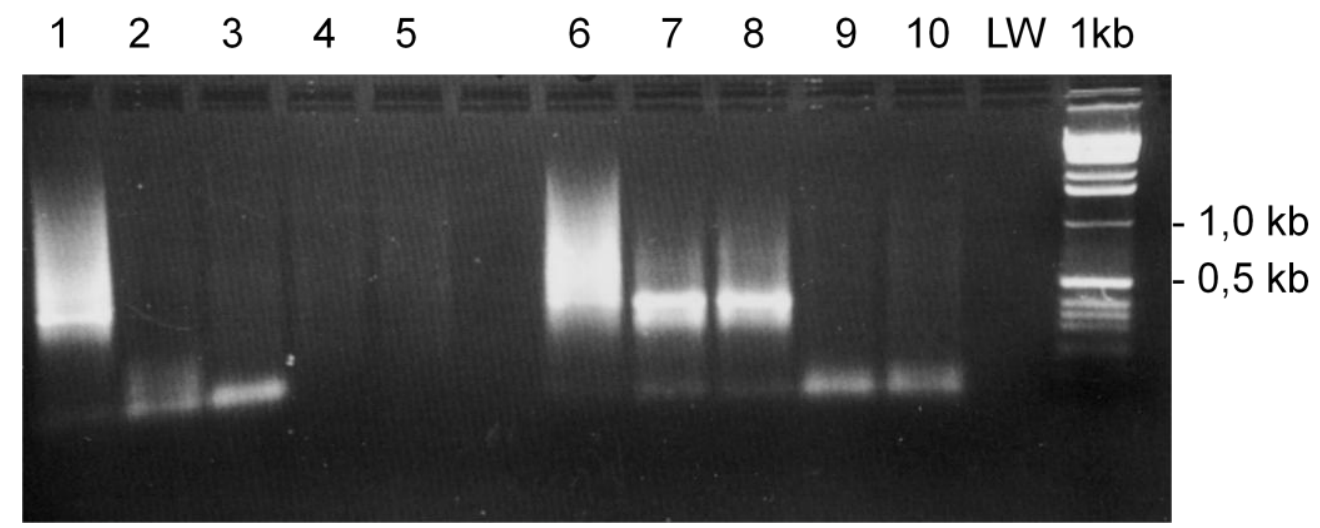

Abb. 3.3: PCR-Produkte aus Ansätzen mit verschiedenen KOH/DTT-Mengen sowie mit und ohne Enhancer 1, durchgeführt mit der Robust Taq Polymerase. Die Nummern 1-10 bezeichnen die Versuchsansätze nach Tab. 3.3, LW: Leerwert (PCR-Ansatz ohne DNA-Zugabe), 1kb: DNA-Ladder.

Ein PCR-Produkt mit der erwarteten Bandengröße ließ sich in folgenden Ansätzen amplifizieren:

\begin{tabular}{|l|l|l|}
\hline$\#$ & KOH/DTT & Enhancer $\mathbf{1}$ \\
\hline 1 & $5 \mu \mathrm{l}$ & \\
\hline 6 & $5 \mu \mathrm{l}$ & $10 \mu \mathrm{l}$ \\
\hline 7 & $10 \mu \mathrm{l}$ & $10 \mu \mathrm{l}$ \\
\hline 8 & $10 \mu \mathrm{l}$ & $10 \mu \mathrm{l}$ \\
\hline
\end{tabular}

Tab 3.4: $\quad$ Versuchsansätze der Tab 3.3, bei denen sich ein PCR-Produkt amplifizieren ließ.

Da die mögliche Menge des $\mathrm{KOH} / \mathrm{DTT}$-Gemisches, welche eine Amplifikation mittels PCR zulässt, für die komplette Benetzung des E-Cup-Deckels nicht ausreichte, musste eine alternative Möglichkeit zur Isolierung der Einzelspermien gewählt werden. Um zu untersuchen, welche Menge an Spermien für eine erfolgreiche PCR nötig ist, wurde eine Verdünnungsreihe der gewaschenen Spermien hergestellt. Dazu wurde die Konzentration der Spermien in einer Zählkammer unter dem Mikroskop bei 400-facher Auflösung bestimmt und 4 aufeinanderfolgende 1/10- Verdünnungen mit $\mathrm{H}_{2} \mathrm{O}$ angesetzt. Es wurde für jede Verdünnung ein PCR-Ansatz von $25 \mu \mathrm{l}$ sowie $50 \mu \mathrm{l}$ gewählt. 


\begin{tabular}{|l|lll|}
\hline$\#$ & Verdünnung & $\sim$ Anzahl Spermien/ $\boldsymbol{\mu l}$ & Ansatz \\
\hline 1 & nativ & $2,8 \times 10^{4}$ & $25 \mu \mathrm{l}$ \\
\hline 2 & nativ & $2,8 \times 10^{4}$ & $50 \mu \mathrm{l}$ \\
\hline 3 & $1 / 10$ & $2,8 \times 10^{3}$ & $25 \mu \mathrm{l}$ \\
\hline 4 & $1 / 10$ & $2,8 \times 10^{3}$ & $50 \mu \mathrm{l}$ \\
\hline 5 & $1 / 100$ & $2,8 \times 10^{2}$ & $25 \mu \mathrm{l}$ \\
\hline 6 & $1 / 100$ & $2,8 \times 10^{2}$ & $50 \mu \mathrm{l}$ \\
\hline 7 & $1 / 1.000$ & 28 & $25 \mu \mathrm{l}$ \\
\hline 8 & $1 / 1.000$ & 28 & $50 \mu \mathrm{l}$ \\
\hline 9 & $1 / 10.000$ & 2,8 & $25 \mu \mathrm{l}$ \\
\hline 10 & $1 / 10.000$ & 2,8 & $50 \mu \mathrm{l}$ \\
\hline
\end{tabular}

Tab 3.5: $\quad$ Versuchsansätze mit unterschiedlichen Verdünnungen der nativen Spermienlösung in $25 \mu \mathrm{l} \mathrm{bzw.} 50 \mu \mathrm{l}$ PCR-Ansätzen.

Jeweils $1 \mu \mathrm{l}$ der nativen Spermien bzw. der Verdünnungen wurde in $5 \mu \mathrm{KOH} / \mathrm{DTT}$ gegeben, für $10 \mathrm{~min}$ bei $65{ }^{\circ} \mathrm{C}$ inkubiert und mit $5 \mu \mathrm{l}$ Neutralisationslösung neutralisiert. Anschließend wurden folgende Ansätze für die PCR hergestellt:

\begin{tabular}{|l|l|l|}
\hline & Ansatz: $\mathbf{2 5} \boldsymbol{\mu l}$ & Ansatz: $\mathbf{5 0} \boldsymbol{\mu l}$ \\
\hline Puffer A & $5 \mu \mathrm{l}$ & $10 \mu \mathrm{l}$ \\
\hline dNTPs & $0,5 \mu \mathrm{l}$ & $1 \mu \mathrm{l}$ \\
\hline Robust Taq & $0,1 \mu \mathrm{l}$ & $0,2 \mu \mathrm{l}$ \\
\hline Primer: CHD7Ex34externF & $0,5 \mu \mathrm{l}$ & $1 \mu \mathrm{l}$ \\
\hline Primer: CHD7Ex34externR & $0,5 \mu \mathrm{l}$ & $1 \mu \mathrm{l}$ \\
\hline Enhancer 1 & $5 \mu \mathrm{l}$ & $10 \mu \mathrm{l}$ \\
\hline $\mathrm{H}_{2} \mathrm{O}$ & ad. $25 \mu \mathrm{l}$ & ad. $50 \mu \mathrm{l}$ \\
\hline
\end{tabular}

Tab 3.6: $\quad$ PCR-Ansätze für die Spermienverdünnungsreihe.

Für die Touch-Down-PCR wurde das Programm Touch-Down-PCR 2 gewählt, mit einer initialen Denaturierung der DNA für 2 min. 


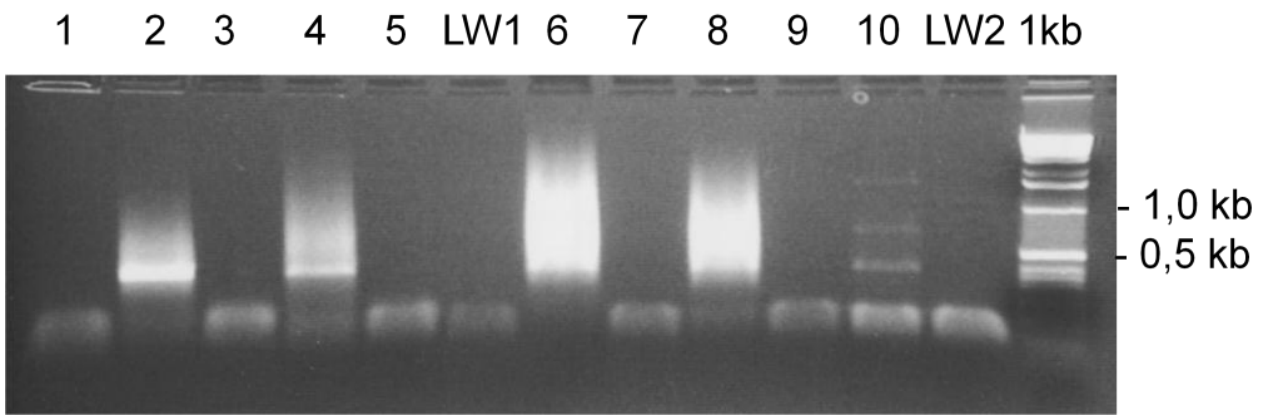

Abb. 3.4: PCR-Produkte unterschiedlicher Anzahl von Spermien in $25 \mu \mathrm{l}$ und $50 \mu \mathrm{l}$ PCRAnsätzen. Die Nummern 1-10 beziehen sich auf die Versuchsansätze nach Tab. 3.5, LW1 und LW2: Leerwerte, 1kb: DNA-Ladder.

Ein PCR-Produkt ließ sich in folgenden Ansätzen amplifizieren:

\begin{tabular}{|l|l|l|l|}
\hline$\#$ & Verdünnung & $\sim$ Anzahl Spermien/ $\mathbf{l l}$ & Ansatz \\
\hline 2 & Nativ & $2,8 \times 10^{4}$ & $50 \mu \mathrm{l}$ \\
\hline 4 & $1 / 10$ & $2,8 \times 10^{3}$ & $50 \mu \mathrm{l}$ \\
\hline 6 & $1 / 100$ & $2,8 \times 10^{2}$ & $50 \mu \mathrm{l}$ \\
\hline 8 & $1 / 1.000$ & 28 & $50 \mu \mathrm{l}$ \\
\hline
\end{tabular}

Tab 3.7: $\quad$ Versuchsansätze der Tab 3.6, bei der sich ein PCR-Produkt amplifizieren ließ.

Die PCR-Produkte wurden durch eine Säule aufgereinigt (Millipore) und anschließend eine Sequenz-PCR mit anschließender Sequenzierung durchgeführt. In jedem PCR-Produkt ließ sich die Mutation des Vaters der zwei betroffenen Kinder mit dem CHARGE-Syndrom als Frameshift im Hintergrund nachweisen. Die Fähigkeit des KOH/DTT-Gemisches, Spermien für die PCR zu lysieren, wurde somit bestätigt.

Die benötigte hohe Anzahl an Zyklen für die Amplifikation der niedrigen Ausgangskonzentration an DNA birgt eine hohe Gefahr für eine Kontamination der zu amplifizierenden DNA. Die Touch-Down-PCR mit den externen Primern besteht aus 20 Zyklen, die folgende Touch-Down-PCR mit in den internen Primern aus 20-22 Zyklen, so dass insgesamt 40-42 Amplifikationszyklen ausgeführt wurden. Die Präparation der Versuchsansätze wurde daher mit besonderer Sorgfalt unter 
weitestgehend sterilen Bedingungen durchgeführt. So wurden alle benötigten Pipetten und Spitzen, E-Cups, die $\mathrm{KOH}$ - und Neutralisationslösungen sowie das für die PCR benötigte $\mathrm{H}_{2} \mathrm{O}$ für 10 min unter UV-Licht bestrahlt und erst kurz vor der Verwendung aus dem sterilen UV-Schrank genommen.

Im nächsten Schritt wurde eine PCR an 10 Ansätzen von 28 Spermien (1/1.000Verdünnung) durchgeführt. Ein Leerwert wurde von Beginn des Versuchs an mitgeführt. Dazu wurden die E-Cups mit den Spermien und ein leeres E-Cup mit $5 \mu \mathrm{l}$ $\mathrm{KOH} / \mathrm{DTT}$ versetzt, für $10 \mathrm{~min}$ bei $65{ }^{\circ} \mathrm{C}$ inkubiert und durch Zugabe von $5 \mu \mathrm{l}$ Neutralisationslösung neutralisiert. Anschließend wurde nacheinander eine TouchDown-PCR mit externen (Primer: CHD7Ex34externF/R) und internen (Primer: CHD7Ex34internF/R) Primern durchgeführt.

\begin{tabular}{|c|c|}
\hline 1. Touch-Down-PCR (50 $\mu \mathrm{l})$ & 2. Touch-Down-PCR (25 $\mu \mathrm{l})$ \\
\hline $11 \mu \mathrm{l}$ aus dem Lyseansatz & $1 \mu \mathrm{l}$ Template aus 1. PCR \\
\hline $10 \mu \mathrm{l}$ Puffer A & $2,5 \mu \mathrm{l} 10 x$ ImmoBuffer \\
\hline $1 \mu \mathrm{ldNTPs}$ & $0,5 \mu \mathrm{ldNTPs}$ \\
\hline $0,2 \mu \mathrm{l}$ Robust Taq & $0,75 \mu \mathrm{l} \mathrm{MgCl} 2$ \\
\hline 1 l Primer: CHD7Ex34externF & $0,2 \mu \mathrm{l}$ Immolase DNA-Polymerase $(1 \mathrm{U} / \mu \mathrm{l})$ \\
\hline 1 l Primer: CHD7Ex34externR & 0,5 $\mu$ l Primer: CHD7Ex34internF \\
\hline $10 \mu \mathrm{l}$ Enhancer 1 & 0,5 $\mu \mathrm{l}$ Primer: CHD7Ex34internR \\
\hline ad. $50 \mu \mathrm{l} \mathrm{H} \mathrm{H}_{2} \mathrm{O}$ & ad. $25 \mu \mathrm{l} \mathrm{H} \mathrm{H}_{2}$ \\
\hline
\end{tabular}

Tab 3.8: $\quad$ PCR-Ansätze für die erste und zweite PCR an der 1/1.000 Spermienverdünnung.

Für die erste Touch-Down-PCR wurde das Programm Touch-Down-PCR 2 (s.o.) mit 2 min initialer Denaturierung und 5+15 Zyklen verwendet. Die zweite Touch-DownPCR wurde ebenso mit dem Programm Touch-Down-PCR 2 durchgeführt, hier wurde als initiale Denaturierung 7 min gewählt sowie 5+15 Zyklen für die Proben 1-5 und 5+17 Zyklen für die Proben 6-10 und den seit Beginn mitgeführten Leerwert. 


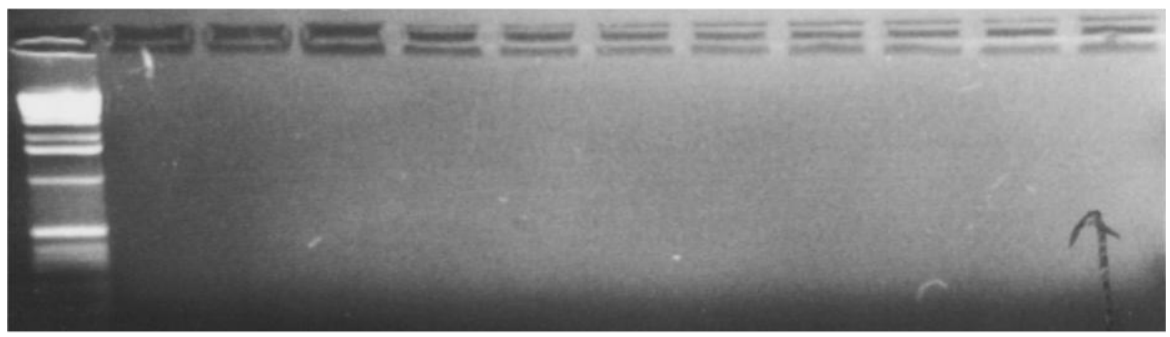

$\begin{array}{lllllllllllll}1 \mathrm{~kb} & 1 & 2 & 3 & 4 & 5 & 6 & 7 & 8 & 9 & 10 & \text { LW1 } & \text { LW2 }\end{array}$

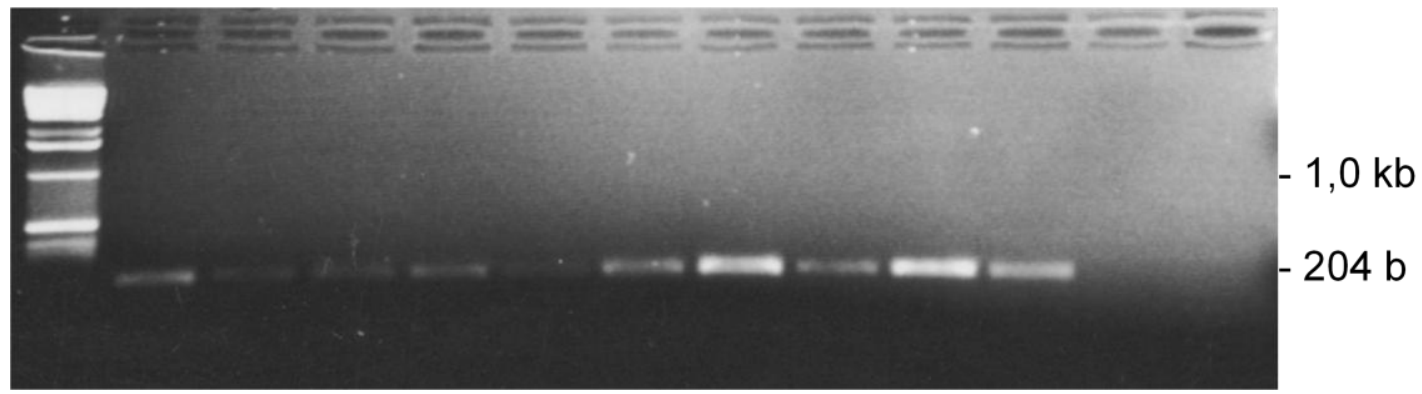

Abb 3.5: $\quad$ PCR-Produkte von 10 Ansätzen mit ungefähr 28 Spermien.

oben: 1. Touch-Down-PCR, die Nummern 1-10 beziehen sich auf die Versuchsansätze mit ungefähr 28 Spermien in jedem Ansatz.

unten: 2. Touch-Down-PCR die Nummern 1-10 beziehen sich auf die Versuchsansätze mit ungefähr 28 Spermien in jedem Ansatz.

LW: Leerwert aus der 1. PCR, LW1: Leerwert aus der 1. PCR, welcher auch in die 2. PCR eingesetzt wurde, LW2: Leerwert der 2. PCR, 1kb: DNA-Ladder.

Die Leerwerte zeigten keine Amplifikation von DNA, so dass von reinen PCRBedingungen ausgegangen werden konnte. Aufgrund der insgesamt relativ schwachen Banden der PCR-Produkte 1-10 wurde die zweite Touch-Down-PCR unter ansonsten gleichen Bedingungen mit 5+19 Zyklen erneut durchgeführt. Die PCR-Produkte wurden alle mittels Säule aufgereinigt (Millipore) und in eine SequenzPCR eingesetzt (5 $\mu$ l PCR Produkt; $4 \mu \mathrm{l}$ ET-Mix; $1 \mu$ l Primer: CHD7Ex34internR; PCR-Programm: Sequenzierprogramm). Die Sequenzierung ergab den Nachweis der Mutation als Frameshift in 6 von 10 Proben.

Im nächsten Schritt wurden 10 Ansätze einer Lysierung von 2,8 Spermien (1/10.000-Verdünnung) und eine Amplifizierung der DNA in zwei aufeinanderfolgenden Touch-Down-PCRs unter ansonsten gleichen Bedingungen wie beim vorherigen Versuchsansatz durchgeführt. Für die zweite Touch-Down-PCR 
wurden aufgrund der niedrigeren Spermien-Ausgangskonzentration in der ersten PCR 5+21 Zyklen gewählt.

Da nach der zweiten Touch-Down-PCR keine Banden der PCR-Produkte 1-10 nachweisbar waren, wurde die zweite Touch-Down-PCR unter ansonsten gleichen Bedingungen mit 5+26 Zyklen erneut durchgeführt.

Es ließ sich kein PCR-Produkt amplifizieren. Durch die möglichen Abweichungen in der Verdünnungsreihe und die Unmöglichkeit, die wirkliche Anzahl von Spermien in dem kompletten Ansatz zu bestimmen, konnte nicht mit Sicherheit davon ausgegangen werden, dass sich Spermien für die Amplifikation im Ansatz befanden.

Um eine genau Aussage über die Anzahl der sich im Versuchsansatz befindlichen Spermien treffen zu können, wurde eine Methode aus der Reproduktionsmedizin angewendet, mittels derer einzelne Spemien mit Hilfe einer Pipette unter dem Mikroskop isoliert werden können. Dazu wurde eine Petrischale mit Polyvinylpyrrolidon gefüllt und in dieses 10 Tropfen aus $5 \mu \mathrm{l}$ frisch angesetztem $\mathrm{KOH} / \mathrm{DTT}-G e m i s c h$ sowie ein Tropfen aus $5 \mu \mathrm{l}$ der aufbereiteten Spermien des zu untersuchenden Patienten eingebracht. Mit Hilfe des ICSI-Manipulators konnte nun aus dem Spermienpool eine definierte Anzahl an Spermien mit der ICSI-Pipette (Gynemed, Lensahn) aufgenommen und in die einzelnen Tropfen aus KOH/DTTGemisch eingesetzt werden. So wurden in einem ersten Versuch in vier Tropfen jeweils ein Spermium (\#1-4), in einem Tropfen fünf Spermien (\#5) sowie in einem Tropfen etwas von der Spermienlösung ohne ein einzelnes Spermium als Leerwert (LW) eingesetzt. Die einzelnen Tropfen wurden jeweils mit sterilen und frisch gezogenen Pasteurpipetten in einen kleinen PCR-Cup gesetzt und für $10 \mathrm{~min}$ bei $65{ }^{\circ} \mathrm{C}$ inkubiert und durch Zugabe von $5 \mu \mathrm{l}$ Neutralisationslösung neutralisiert. Anschließend wurde nacheinander eine Touch-Down-PCR mit externen (Primer: CHD7Ex34externF/R) und internen (Primer: CHD7Ex34internF/R) Primern angesetzt, wie oben beschrieben (s. Tab. 3.8). Für die zwei aufeinanderfolgenden Touch-Down-PCRs wurde ebenso das oben beschriebene Programm verwendet, mit 5+15 Zyklen für die erste und 5+19 Zyklen für die zweite Touch-Down-PCR. 


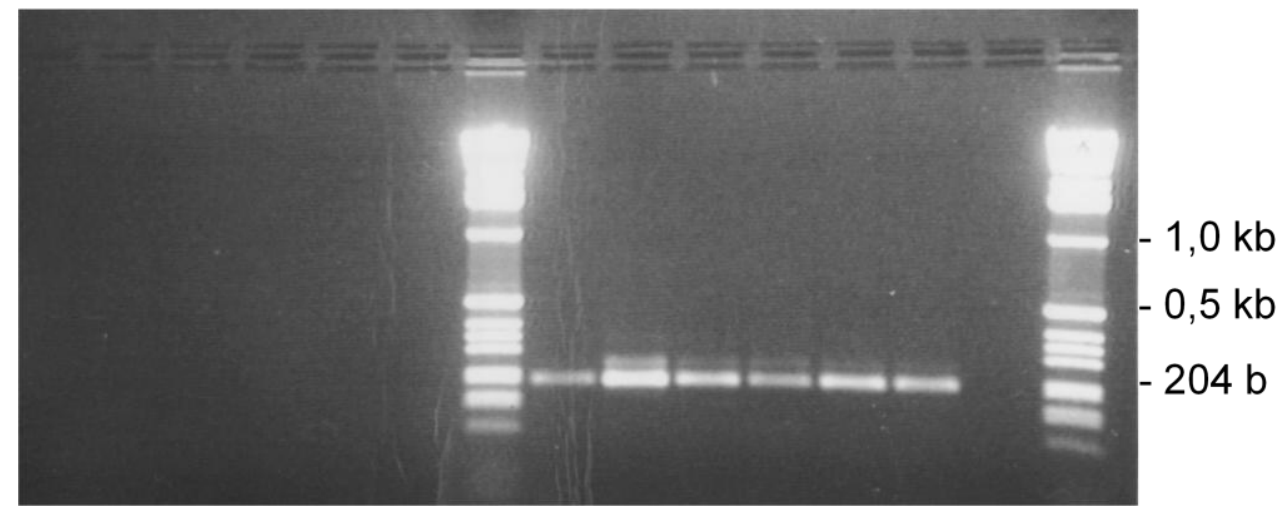

Abb 3.6: $\quad$ Links: 1. Touch-Down-PCR mit externen Primern. Für die Nummern 1-4 wurde eine PCR an jeweils einem Spermium durchgeführt, Nummer 5 zeigt das PCR-Produkt aus einem Pool von 5 Spermien.

Rechts: 2. Touch-Down-PCR mit internen Primern. Die Nummern 1-5 bezeichnen die PCR-Produkte aus einer PCR von jeweils $1 \mu$ l aus der 1. PCR.

LW: Leerwert, Spermienlösung ohne ein einzelnes sichtbares Spermium.

LW1: Leerwert aus der 1. PCR, welcher auch in die 2. PCR eingesetzt wurde.

LW2: Leerwert der 2. PCR, 1kb: DNA-Ladder.

Alle Ansätze ließen sich amplifizieren, der Leerwert mit der Spermienlösung ohne ein einzelnes Spermium zeigte eine Verunreinigung. Trotzdem wurden alle PCRProdukte mittels Säule aufgereinigt (Millipore) und in eine Sequenz-PCR eingesetzt (10 $\mu$ l PCR-Produkt; $4 \mu$ ET-Mix; $1 \mu$ Primer: CHD7Ex34internR; PCR-Programm: Sequenzierprgramm). Die Sequenzierung ergab den Nachweis der Mutation als Frameshift in der Probe mit den fünf Einzelspermien (\#5).

Die Verunreinigung des Leerwertes der Spermienlösung kam möglichweise durch spontan lysierte Spermien und die Freisetzung ihrer DNA zustande, bevor die einzelnen Spermien mit Hilfe des ICSI-Manipulators isoliert wurden. Um freigesetzte DNA aus der Spermienlösung zu entfernen und somit die Amplifikation nur eines DNA-Stranges aus einem Spermium zu ermöglichen, wurde die Spermienlösung vorbehandelt. Sie wurde dazu in $50 \mu$ Aliquots mit ungefähr 28.000 Spermien/ $\mu \mathrm{l}$ aufgeteilt. $\mathrm{Zu}$ einem Aliquot wurde dann DPBS bis zu einem Gesamtvolumen von $500 \mu \mathrm{l}$ hinzugefügt. Die Probe wurde daraufhin mit $2 \mu \mathrm{l}$ DNAse I (1 unit//l, SigmaAldrich, Taufkirchen) behandelt und für $5 \mathrm{~min}$ bei Raumtemperatur inkubiert. Die 
Inaktivierung der DNAse erfolgte durch Erhitzung auf $70{ }^{\circ} \mathrm{C}$ für $10 \mathrm{~min}$. Nun wurde DPBS bis zu einem Gesamtvolumen von $1 \mathrm{ml}$ hinzugegeben und der Ansatz für 5 min mit 1.500 x g zentrifugiert. Der Überstand wurde verworfen und das Spermienpellet in $30 \mu \mathrm{l}$ DPBS resuspendiert. Die so vorbehandelten Spermien wurden, entsprechend der obigen Beschreibung, mit Hilfe von ICSI-Pipetten (Gynemed, Lensahn) und eines ICSI-Manipulators einzeln isoliert, lysiert und eine Amplifikation der DNA mit anschließender Sequenzierung durchgeführt.
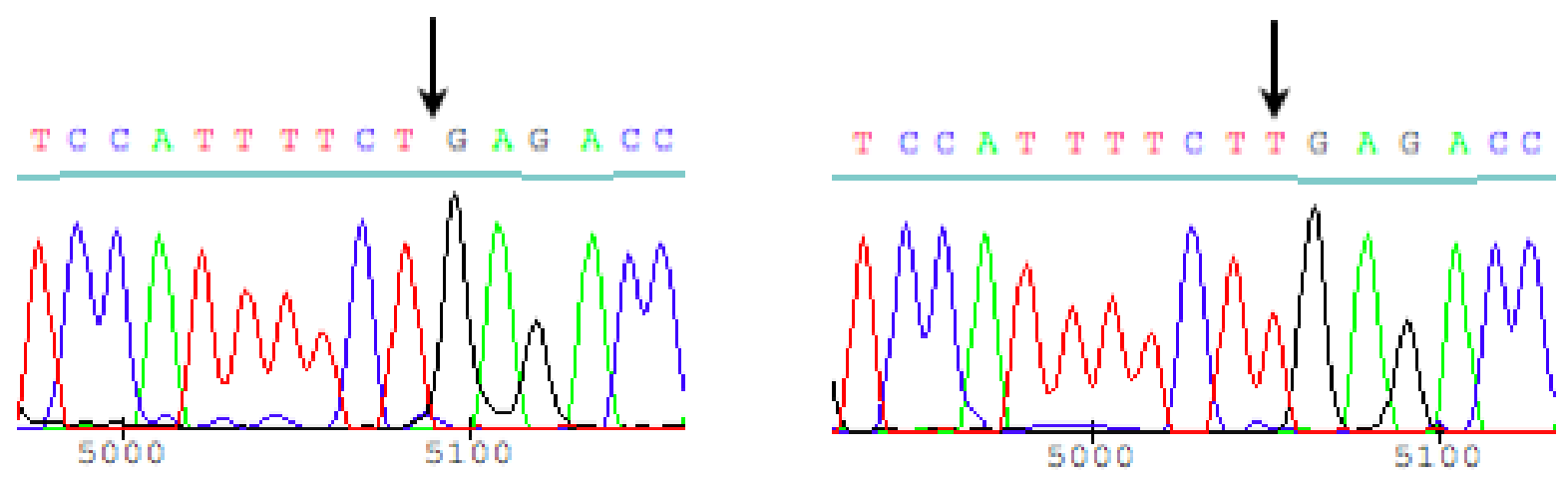

Abb. 3.7: $\quad$ Ausschnitt aus der Forward-Sequenz des Exons 34 des CHD7-Gen („nested“ PCR). Die linke Sequenz zeigt eine Wildtypsequenz in einem Einzelspermium.

Die rechte Sequenz zeigt die Duplikation c.7302dupA in einem Einzelspermium. Der schwarze Pfeil kennzeichnet die Stelle der Mutation.

\section{Zusammenfassung Einzelspermienanalyse}

\begin{tabular}{|c|c|}
\hline Arbeitsschritt & Beschreibung \\
\hline Vorbereiten der & 1. Aufteiligung der Spermienlösung auf $50 \mu \mathrm{l}$ Aliquots \\
\hline \multirow[t]{8}{*}{ Spermienlösung } & 2. Zugabe von DPBS ad. $500 \mu \mathrm{l}$ \\
\hline & 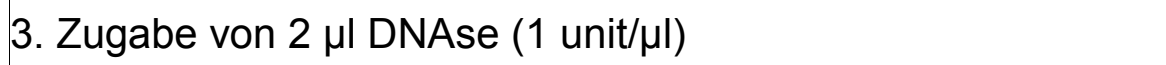 \\
\hline & 4. Inkubation $5 \min (\mathrm{RT})$ \\
\hline & 5. Inaktivierung der DNAse durch Erhitzen auf $70^{\circ} \mathrm{C}$ für $10 \mathrm{~min}$ \\
\hline & 6. Zugabe von DPBS ad. $1 \mathrm{ml}$ \\
\hline & 7. Zentrifugation für 5 min bei $1.500 \times \mathrm{g}$, Verwerfen des \\
\hline & Überstandes \\
\hline & 8. Lösung des Spermienpellets in $30 \mu$ IPBS \\
\hline
\end{tabular}




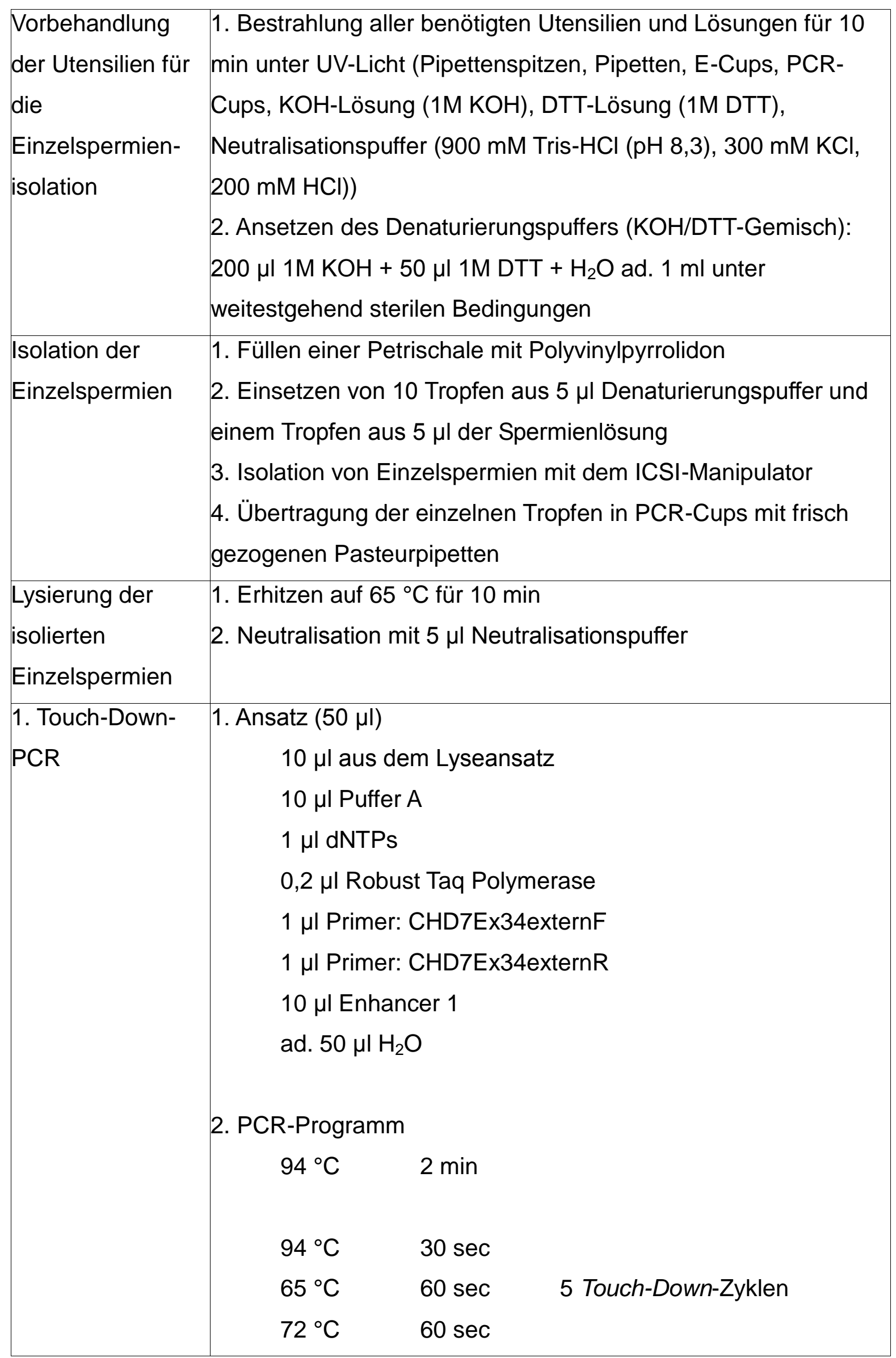




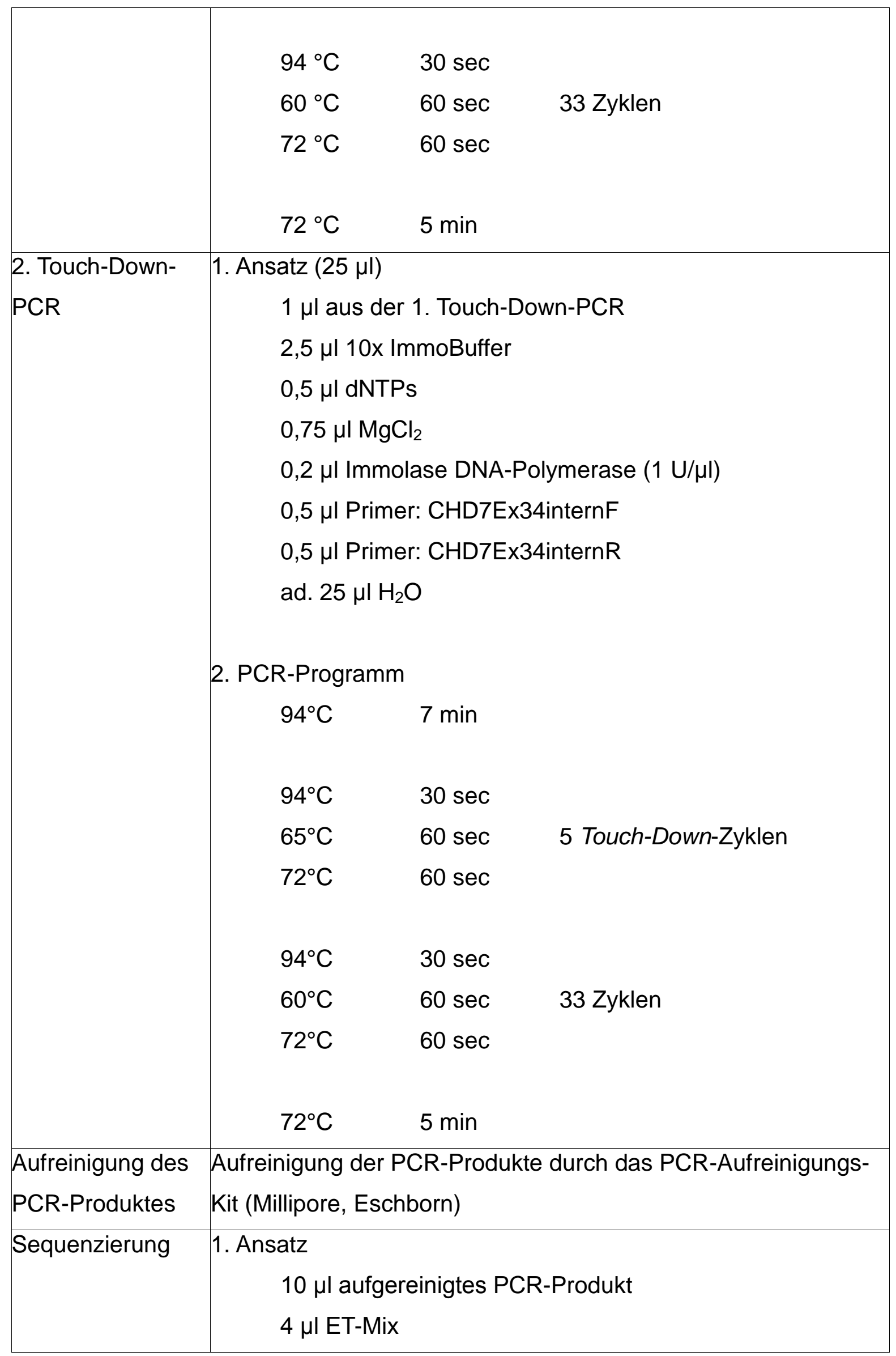




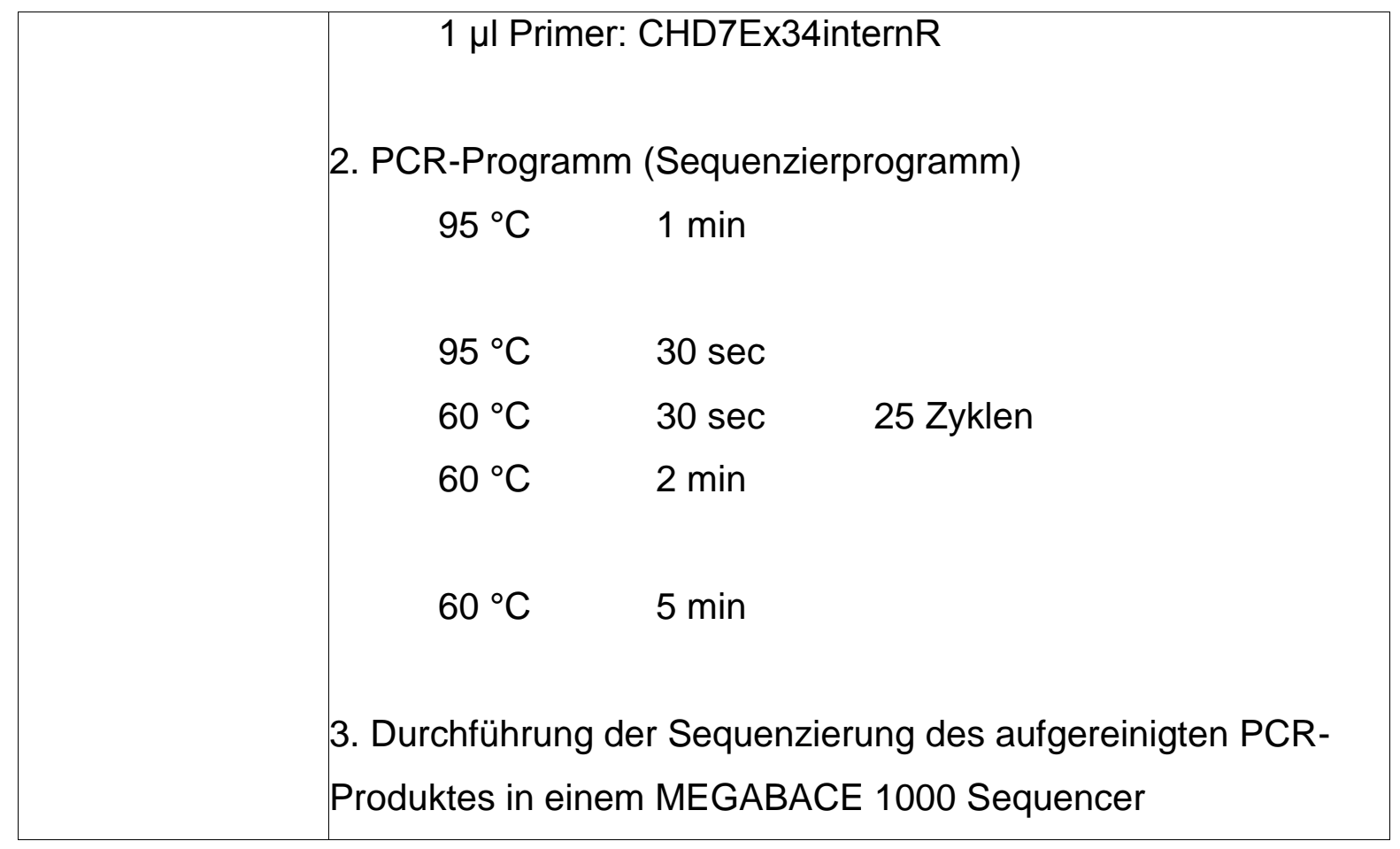

Tab 3.9: Zusammenfassung der Arbeitsschritte zur Durchführung einer PCR an Einzelspermien.

\subsubsection{Untersuchung von Einzelspermien zur Mosaikbestimmung}

Um eine Aussage über das Verhältnis zwischen Spermien mit dem Wildtypallel und dem mutierten Allel beim Vater der beiden vom CHARGE-Syndrom betroffenen Kinder zu treffen, wurden entsprechend der oben beschriebenen Versuchsdurchführung (Tab 3.9) 59 Einzelspermien genotypisiert. Für jede Petrischale mit 10 Einzelspermien wurde dabei ein Leerwert mit der Spermienlösung ohne ein einzelnes Spermium mitgeführt. Bei Kontamination dieses Leerwertes gingen die Ergebnisse der kompletten Petrischale nicht in die Auswertung ein. Die Mutation c.7302dupA ließ sich in 16 von 59 Einzelspermien nachweisen. In der Stichprobe tragen annähernd $27 \%$ der väterlichen Spermien die Mutation c.7302dupA im CHD7-Gen. 


\subsection{CHD7-Interaktionsstudien}

In Vorarbeiten (Koszucka 2008) wurde mit dem Plasmid CHD7-CR1-3-pGBKT7 (AS 1591-2181), welches die drei konservierten Regionen CR1-CR3 und die SANTDomäne des CHD7-Proteins (s. Abb. 3.8) enthält, ein Yeast-Two-Hybrid-LibraryScreen mit der Matchmaker human fetal brain cDNA library zur Identifikation von Interaktionspartnern durchgeführt. Dieses Teilstück des CHD7-Gens wurde dafür in den Vektor pGBKT7 kloniert (BAIT). Das Konstrukt CHD7-CR1-3-pGBKT7 (AS 15912181) wurde in AH109-Hefezellen auf Toxizität und Autoaktivierung überprüft. Im Yeast-Two-Hybrid-Library-Screen und anschließender Klonidentifizierung wurde CHD8 als putativer Interaktionspartner erkannt (PREY). Eine Teilsequenz des CHD8Gens befindet sich im Vektor pGADT7-Rec der Matchmaker human fetal brain cDNA library, eine Autoaktivierung des leeren BAIT-Vektors (pGBKT7) wurde ausgeschlossen.

\subsubsection{Verwendete Konstrukte}

Für die folgenden direkten Yeast-Two-Hybrid-Experimente wurden Konstrukte zum Teil aus Vorarbeiten von Koszucka (2008) übernommen, andere Konstrukte neu erstellt. Die nachstehende Tabelle gibt Auskunft über die verwendeten Konstrukte.

\begin{tabular}{|c|c|c|c|c|}
\hline \multirow[b]{2}{*}{ Konstrukt } & \multirow[b]{2}{*}{ Vektor } & \multirow{2}{*}{$\begin{array}{c}\text { Insert } \\
\text { Aminosäure } \\
\text { n-bereich/ } \\
\text { Datenbank- } \\
\text { Nr. }\end{array}$} & \multicolumn{2}{|c|}{ Beschreibung } \\
\hline & & & Template/ Primer & $\begin{array}{l}\text { Verwendete } \\
\text { Restriktions- } \\
\text { enzyme }\end{array}$ \\
\hline $\begin{array}{l}\text { pGBKT7- } \\
\text { CHD7-CR1- } \\
\left.3^{*}\right)\end{array}$ & pGBKT7 & $\begin{array}{l}1591-2181 / \\
\text { NP_060250.2 }\end{array}$ & \multicolumn{2}{|c|}{$\begin{array}{l}\text { enthält die drei konservierten Regionen } \\
\text { CR1-CR3 und die SANT-Domäne des } \\
\text { CHD7 }\end{array}$} \\
\hline & & & $\begin{array}{l}\text { humane cDNA/ } \\
\text { chd7NdelF und } \\
\text { chd7EcoRIR }\end{array}$ & $\begin{array}{l}\text { Ndel und } \\
\text { EcoRI aus } \\
\text { pGEM-T } \\
\text { Easy }\end{array}$ \\
\hline
\end{tabular}




\begin{tabular}{|c|c|c|c|c|}
\hline \multirow{2}{*}{$\begin{array}{l}\text { pGBKT7- } \\
\text { CHD7-CR1 } \\
\left.{ }^{\star}\right)\end{array}$} & \multirow[t]{2}{*}{ pGBKT7 } & \multirow[t]{2}{*}{$\begin{array}{l}1593-1768 / \\
\text { NP_060250.2 }\end{array}$} & \multicolumn{2}{|c|}{$\begin{array}{l}\text { enthält die konservierte Region CR1 des } \\
\mathrm{CHD7}\end{array}$} \\
\hline & & & $\begin{array}{l}\text { humane cDNA/ } \\
\text { chd7CR1NcolF und } \\
\text { chd7CR1EcoRIR }\end{array}$ & $\begin{array}{l}\text { Ncol und } \\
\text { EcoRI aus } \\
\text { pGEM-T } \\
\text { Easy }\end{array}$ \\
\hline $\begin{array}{l}\text { pGBKT7- } \\
\text { CHD7-CR2 }\end{array}$ & pGBKT7 & $\begin{array}{l}\text { 1701-1948/ } \\
\text { NP_060250.2 }\end{array}$ & \multicolumn{2}{|c|}{$\begin{array}{l}\text { enthält die konservierte Region CR2 des } \\
\text { CHD7 }\end{array}$} \\
\hline *) & & & $\begin{array}{l}\text { humane cDNA/ } \\
\text { chd7CR2EcoRIF und } \\
\text { chd7CR2SallR }\end{array}$ & $\begin{array}{l}\text { Ncol und } \\
\text { EcoRI aus } \\
\text { pGEM-T } \\
\text { Easy }\end{array}$ \\
\hline $\begin{array}{l}\text { pGBKT7- } \\
\text { CHD7-CR3 }\end{array}$ & pGBKT7 & $\begin{array}{l}\text { 1950-2172/ } \\
\text { NP_060250.2 }\end{array}$ & \multicolumn{2}{|c|}{$\begin{array}{l}\text { enthält die konservierte Region CR3 des } \\
C H D 7 \text { und die SANT-Domäne }\end{array}$} \\
\hline *) & & & $\begin{array}{l}\text { humane cDNA/ } \\
\text { chd7CR3NcolF und } \\
\text { chd7EcoRIR }\end{array}$ & $\begin{array}{l}\text { Ncol und } \\
\text { EcoRI aus } \\
\text { pGEM-T } \\
\text { Easy }\end{array}$ \\
\hline $\begin{array}{l}\text { pGBKT7- } \\
\text { CHD7- }\end{array}$ & pGBKT7 & $\begin{array}{l}\text { 1950-2042/ } \\
\text { NP_060250.2 }\end{array}$ & \multicolumn{2}{|c|}{$\begin{array}{l}\text { enthält den n-terminalen Teil des } \\
\text { Konstruktes pGBKT7-CHD7-CR3 }\end{array}$} \\
\hline CR3n & & & $\begin{array}{l}\text { pGBKT7-CHD7-CR3/ } \\
\text { chd7CR3NcolF und } \\
\text { chd7CRUeNEcoRIR }\end{array}$ & $\begin{array}{l}\text { Ncol und } \\
\text { EcoRI aus } \\
\text { pGEM-T } \\
\text { Easy }\end{array}$ \\
\hline $\begin{array}{l}\text { pGBKT7- } \\
\text { CHD7- }\end{array}$ & pGBKT7 & $\begin{array}{l}2039-2172 / \\
\text { NP_060250.2 }\end{array}$ & \multicolumn{2}{|c|}{$\begin{array}{l}\text { enthält den c-terminalen Teil des } \\
\text { Konstruktes pGBKT7-CHD7-CR3 }\end{array}$} \\
\hline CR3c & & & $\begin{array}{l}\text { pGBKT7-CHD7-CR3 } \\
\text { chd7CR3UeCNcolF und } \\
\text { chd7EcoRIR }\end{array}$ & $\begin{array}{l}\text { Ncol und } \\
\text { EcoRI aus } \\
\text { pGEM-T } \\
\text { Easy }\end{array}$ \\
\hline $\begin{array}{l}\text { pGBKT7- } \\
\text { CHD7- }\end{array}$ & pGBKT7 & $\begin{array}{l}\text { 2039-2172; } \\
\text { Trp2091Arg/ }\end{array}$ & \multicolumn{2}{|c|}{$\begin{array}{l}\text { wie Konstrukt pGBKT7-CHD7-CR3c, } \\
\text { enthält Missense-Mutation Trp2091Arg }\end{array}$} \\
\hline
\end{tabular}




\begin{tabular}{|c|c|c|c|c|}
\hline $\begin{array}{l}\text { CR3C- } \\
\text { Trp2091Arg } \\
\text { *) }\end{array}$ & & NP_060250.2 & & \\
\hline \multirow{2}{*}{$\begin{array}{l}\text { pGBKT7- } \\
\text { CHD7-CR3- } \\
\text { Trp2091Arg }\end{array}$} & \multirow[t]{2}{*}{ pGBKT7 } & \multirow{2}{*}{$\begin{array}{l}\text { 1950-2172; } \\
\text { Trp2091Arg/ } \\
\text { NP_060250.2 }\end{array}$} & \multicolumn{2}{|c|}{$\begin{array}{l}\text { wie Konstrukt pGBKT7-CHD7-CR3, } \\
\text { enthält Missense-Mutation Trp2091Arg }\end{array}$} \\
\hline & & & $\begin{array}{l}\text { pGBKT7-CHD7-CR3 } \\
\text { und pGBKT7-CHD7- } \\
\text { CR3c-Trp2091Arg/ } \\
\text { Verdau und Ligation }\end{array}$ & $\begin{array}{l}\text { AfIII und } \\
\text { EcoRI aus } \\
\text { dem } \\
\text { Template }\end{array}$ \\
\hline \multirow[t]{2}{*}{$\begin{array}{l}\text { pGBKT7- } \\
\text { CHD7- } \\
\text { CR3b *) }\end{array}$} & \multirow[t]{2}{*}{ pGBKT7 } & \multirow[t]{2}{*}{$\begin{array}{l}\text { 1962-2099/ } \\
\text { NP_060250.2 }\end{array}$} & \multicolumn{2}{|c|}{$\begin{array}{l}\text { enthält die konservierte Region CR3 des } \\
C D H 7-G e n s \text { und die SANT-Domäne } \\
\text { ohne C- und N- terminale Überhänge }\end{array}$} \\
\hline & & & $\begin{array}{l}\text { humane cDNA/ } \\
\text { chd7SANTNcolF und } \\
\text { chd7SANTCR3EcoRIR }\end{array}$ & $\begin{array}{l}\text { Ncol und } \\
\text { EcoRI aus } \\
\text { pGEM-T } \\
\text { Easy }\end{array}$ \\
\hline $\begin{array}{l}\text { pGBKT7- } \\
\text { CHD7- }\end{array}$ & pGBKT7 & $\begin{array}{l}\text { 1962-2099; } \\
\text { His2096Arg/ }\end{array}$ & \multicolumn{2}{|c|}{$\begin{array}{l}\text { wie Konstrukt pGBKT7-CHD7-CR3b, } \\
\text { enthält Missense-Mutation His2096Arg }\end{array}$} \\
\hline $\begin{array}{l}\text { CR3b- } \\
\text { His2096Arg } \\
\left.{ }^{\star}\right)\end{array}$ & & NP_060250.2 & $\begin{array}{l}\text { humane cDNA/ } \\
\text { chd7SANTNcolF und } \\
\text { chd7SANTCR3His2096 } \\
\text { ArgEcoRIR }\end{array}$ & $\begin{array}{l}\text { Ncol und } \\
\text { EcoRI aus } \\
\text { pGEM-T } \\
\text { Easy }\end{array}$ \\
\hline pGBKT7- & pGBKT7 & $1962-2021 /$ & \multicolumn{2}{|c|}{ enthält die SANT-Domäne des CHD7 } \\
\hline $\begin{array}{l}\text { CHD7- } \\
\text { SANT *) }\end{array}$ & & NP_060250.2 & $\begin{array}{l}\text { humane cDNA/ } \\
\text { chd7SANTNcolF und } \\
\text { chd7SANTEcoRIR }\end{array}$ & $\begin{array}{l}\text { Ncol und } \\
\text { EcoRI aus } \\
\text { pGEM-T } \\
\text { Easy }\end{array}$ \\
\hline \multirow[t]{2}{*}{$\begin{array}{l}\text { pGADT7- } \\
\text { CHD8 *) }\end{array}$} & pGADT7 & $\begin{array}{l}1789-2091 / \\
\text { NP_065971.2 }\end{array}$ & \multicolumn{2}{|c|}{$\begin{array}{l}\text { enthält den Teil des CHD8 aus dem } \\
\text { Yeast-Two-Hybrid-Library-Screen }\end{array}$} \\
\hline & & & pGADT7-Rec-CHD8 & \\
\hline \multirow[t]{2}{*}{$\begin{array}{l}\text { pGBKT7- } \\
\text { CHD8 }\end{array}$} & pGBKT7 & $\begin{array}{l}1789-2091 / \\
\text { NP_065971.2 }\end{array}$ & \multicolumn{2}{|c|}{$\begin{array}{l}\text { enthält den Teil des CHD8 aus dem } \\
\text { Yeast-Two-Hybrid-Library-Screen }\end{array}$} \\
\hline & & & pCMV-Myc-CHD8 & Mfel und Sfil \\
\hline
\end{tabular}




\begin{tabular}{|c|c|c|c|c|}
\hline & & & (siehe Abb. 3.14) & $\begin{array}{l}\text { (pCMV-Myc- } \\
\text { CHD8) } \\
\text { EcoR/ und } \\
\text { Sfil } \\
\text { (pGBKT7) }\end{array}$ \\
\hline \multirow[t]{2}{*}{$\begin{array}{l}\text { pGADT7- } \\
\text { CHD7-CR1- } \\
3\end{array}$} & \multirow[t]{2}{*}{ pGADT7 } & \multirow[t]{2}{*}{$\begin{array}{l}\text { 1591-2181/ } \\
\text { NP_060250.2 }\end{array}$} & \multicolumn{2}{|c|}{$\begin{array}{l}\text { enthält die drei konservierten Regionen } \\
\text { CR1-CR3 und die SANT-Domäne des } \\
\text { CHD7 }\end{array}$} \\
\hline & & & pGBKT7-CHD7-CR1-3 & $\begin{array}{l}\text { EcoRl und } \\
\text { Ndel aus } \\
\text { pGBKT7- } \\
\text { CHD7-CR1-3 }\end{array}$ \\
\hline
\end{tabular}

*) Konstrukt wurde aus Vorarbeiten von Koszucka (2008) übernommen.

Tab 3.10: Verwendete Konstrukte für die direkten Yeast-Two-Hybrid-Experimente.

\subsubsection{Direkter Yeast-Two-Hybrid-Assay von CHD7 und seinen Teilstücken mit einem CHD8-Teilstück}

In einem ersten gerichteten Yeast-Two-Hybrid-Experiment wurde das Plasmid pGBKT7-CHD7-CR1-3 gegen das im Yeast-Two-Hybrid-Library-Screen entdeckte Plasmid pGADT7-CHD8 getestet. Dabei zeigte sich eine Interaktion durch das Wachstum auf -LTHA-Mangelmedium. Im nächsten Schritt wurde $\mathrm{CHD7}$ in die drei konservierten Regionen CR1, CR2 und CR3 unterteilt und die entsprechenden Plasmide hergestellt und sequenziert. Diese Plasmide, pGBKT7-CHD7-CR1 (Abb. 3.8 a), pGBKT7-CHD7-CR2 (Abb. 3.8 b) und pGBKT7-CHD7-CR3 (Abb. 3.8 c) wurden wiederum gegen das Plasmid pGADT7-CHD8 getestet. 


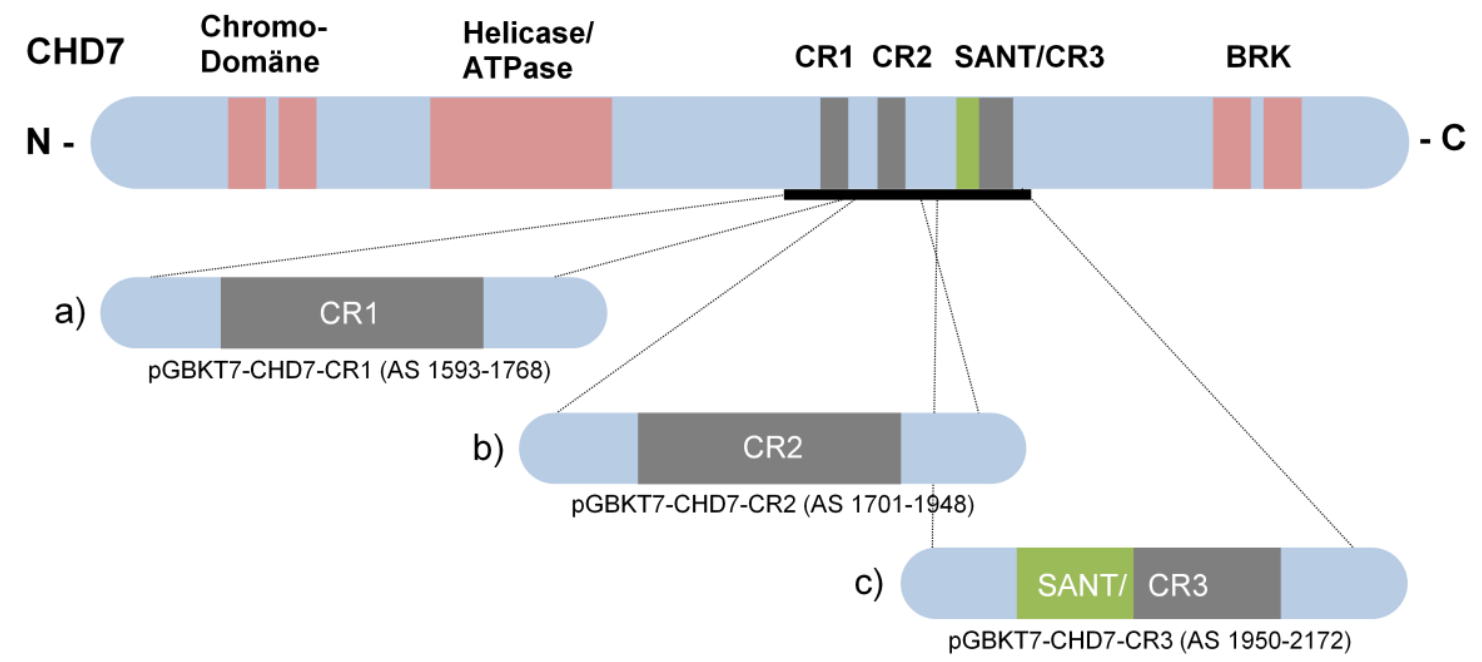

Abb. 3.8: Schematische Darstellung des CHD7-Proteins und der Bait-Konstrukte für den direkten Yeast-Two-Hybrid. CHD7 besteht aus zwei N-terminalen Chromodomänen, gefolgt von einer SWI2/SNF2-artigen ATPase/Helicase-Domäne, drei konservierten Regionen (CR1-CR3), einer SANT-Domäne und zwei BRK-Domänen. Die drei Plasmide pGBKT7-CHD7-CR1 (a), pGBKT7-CHD7-CR2 (b) und pGBKT7-CHD7-CR3 (c) teilen das Plasmid pGBKT7-CHD7-CR1-3 (schwarzer Balken) in drei Teile.

Es zeigte sich eine schwache Interaktion in Form eines Wachstums auf -LTHAMangelmedium mit dem Plasmid pGBKT7-CHD7-CR3.

\subsubsection{Eingrenzung der Interaktionsstelle}

Um eine genauere Aussage über den Ort der Protein-Proteininteraktion zwischen CHD7 und CHD8 machen zu können, wurden neue Konstrukte erstellt und getestet. Diese wurden aus Vorarbeiten (Koszucka 2008) übernommen. Da sich eine Interaktion mit dem Plasmid pGBKT7-CHD7-CR3 (Abb. 3.8 c) zeigte, wurde dieses Plasmid als Ausgang für eine nähere Unterteilung desselben benutzt. So wurde das Konstrukt pGBKT7-CHD7-CR3b (Abb. 3.9 b) erstellt, ohne die C- und N-terminalen Überhänge, sowie das Konstrukt pGBKT7-CHD7-SANT (Abb. 3.9 d), welches nur die SANT-Domäne enthält. Außerdem wurde ein Konstrukt pGBKT7-CHD7-CR3bHis2096Arg (Abb. 3.9 c) erstellt, welches dem Konstrukt pGBKT7-CHD7-CR3b entspricht, jedoch die Missense-Mutation His2096Arg enthält, welche bei einem Patienten mit CHARGE-Syndrom gefunden wurde. Als Positivkontrollen wurden in 
diesem direkten Yeast-Two-Hybrid die Konstrukte pGBKT7-CHD7-CR1-3 und pGBKT7-CHD7-CR3 mitgeführt. Für die Negativkontrolle wurde das Konstrukt pGBKT7-CHD7-CR1 verwendet, da sich hier keine Interaktion zeigte.

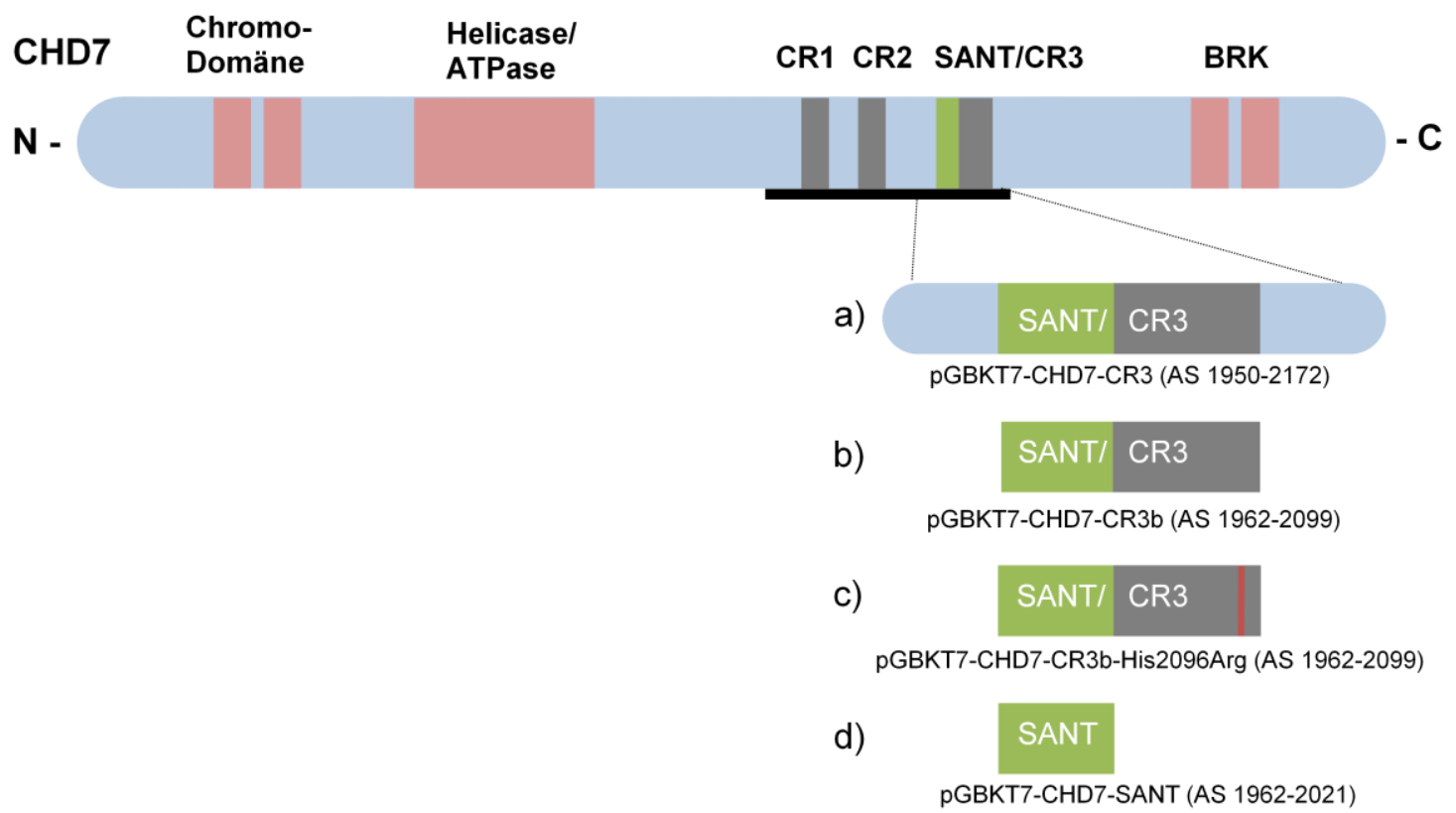

Abb 3.9: $\quad$ Schematische Darstellung des CHD7-Proteins und der Bait-Konstrukte für den direkten Yeast-Two-Hybrid. Das Plasmid pGBKT7-CHD7-CR3b (b) entspricht dem Plasmid pGBKT7-CHD7-CR3 (a) ohne die $\mathrm{N}$ - und C-terminalen Überhänge. Das Plasmid pGBKT7-CHD7-CR3b-His2096Arg (c) entspricht dem Plasmid pGBKT7CHD7-CR3b (b) mit der Missense-Mutation His2096Arg. Im Plasmid pGBKT7-CHD7SANT (d) befindet sich die SANT-Domäne des CHD7.

Eine Interaktion zwischen zwei Proteinen zeigt sich im direkten Yeast-Two-Hybrid durch Wachstum auf -LTHA Mangelmedium sowie einem blauen Farbumschlag nach Zugabe von X- $\alpha-G a l$. Eine Interaktion zeigte sich bei den Doppeltransfektionen in den Positivkontrollen mit den Konstrukten pGADT7-CHD8 mit pGBKT7-CHD7-CR1-3 (Abb. 3.10 \#1) sowie bei pGADT7-CHD8 mit pGBKT7-CHD7-CR3 (Abb. 3.10 \#3). Mit der verwendeten Negativkontrolle sowie den anderen Konstrukten, pGBKT7-CHD7CR3b (Abb. 3.10 \#4), pGBKT7-CHD7-CR3b-His2096Arg (Abb. 3.10. \#5) sowie pGBKT7-CHD7-SANT (Abb. 3.10 \#6) zeigte sich im direkten Yeast-Two-Hybrid in der Doppeltransfektion mit dem Konstrukt pGADT7-CHD8 keine Interaktion. 

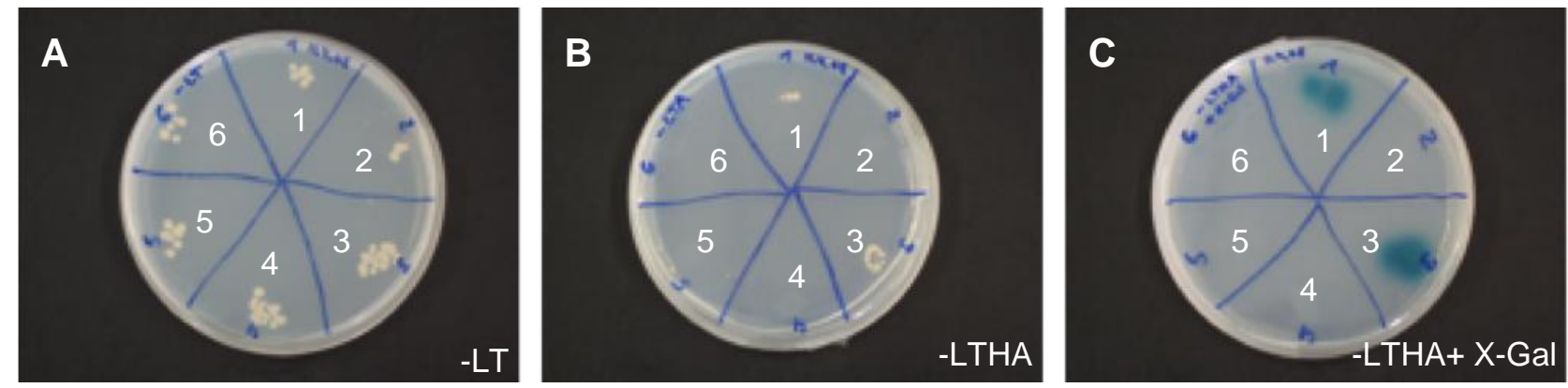

Abb. 3.10: Direkter Yeast-Two-Hybrid zur näheren Eingrenzung der Interaktionsstelle, Doppeltransfektionen von den Konstrukten pGADT7-CHD8 mit 1. pGBKT7-CHD7CR1-3, 2. pGBKT7-CHD7-CR1, 3. pGBKT7-CHD7-CR3, 4. pGBKT7-CHD7-CR3b, 5. pGBKT7-CHD7-CR3b-His2096Arg und 6. pGBKT7-CHD7-SANT. A: Wachstum der Hefekolonien auf einem SD -LT-Mangelmedium (Transfektionskontrolle).

B: Wachstum der interagierenden Konstrukte auf SD -LTHA-Mangelmedium. \#1 pGADT7-CHD8 mit pGBKT7-CHD7-CR1-3 und \#3 pGADT7-CHD8 mit pGBKT7CHD7-CR3. C: Wachstum der interagierenden Konstrukte \#1 und \#3 auf SD -LTHA + $\mathrm{X}-\alpha$-Gal-Mangelmedium.

\subsubsection{Eingrenzung der Interaktion im CR3-Teil des CHD7-Gens}

Mit dem Konstrukt pGBKT7-CHD7-CR3 zeigte sich eine Interaktion mit pGADT7CHD8. Hingegen zeigte sich mit dem Konstrukt pGBKT7-CHD7-CR3b, welches sich vom pGBKT7-CHD7-CR3-Konstrukt nur durch das Fehlen der N- und C-terminalen Überhänge unterscheidet, keine Interaktion mit pGADT7-CHD8. Daraus kann geschlossen werden, dass sich die Interaktion mit $C H D 8$ in den Überhängen N-bzw. C-terminal des CR3-Teils des CHD7-Gens befinden muss. Daher wurden neue Konstrukte erstellt, die das Konstrukt pGBKT7-CHD7-CR3 in ein vorderes (pGBKT7CHD7-CR3n (Abb. 3.11 b)) und ein hinteres (pGBKT7-CHD7-CR3c (Abb. $3.11 \mathrm{c}$ )) Stück aufteilen. Zudem wurde eine weitere bei einem CHARGE-Syndrom Patienten beobachtete Missense-Mutation Trp2091RArg in das hintere Stück eingefügt und das Konstrukt pGBKT7-CHD7-CR3c-Trp2091Arg (Abb. 3.11 d) erstellt. Die Wirkung der Missense-Mutation auf die Interaktion wurde untersucht. 


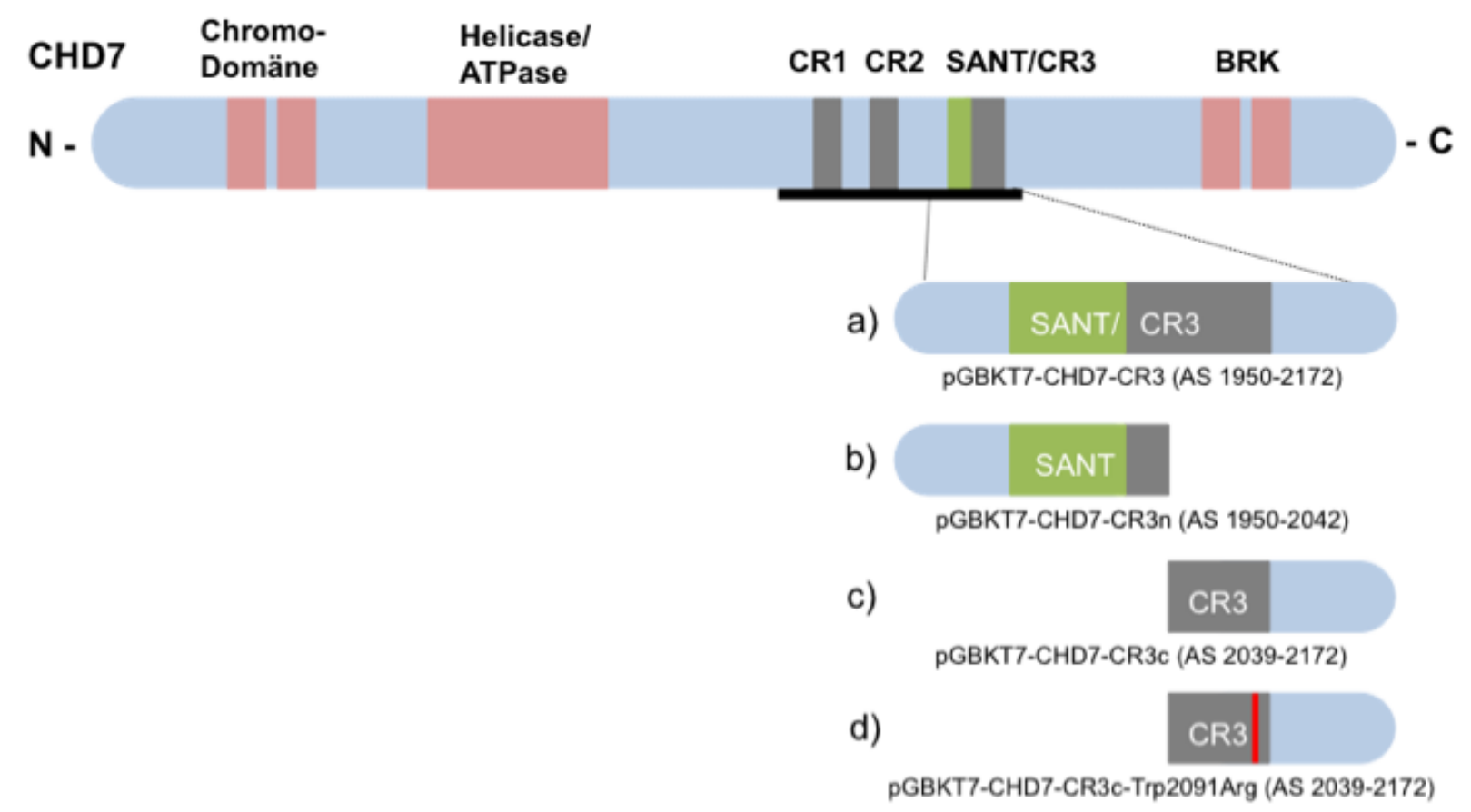

Abb 3.11: Schematische Darstellung des CHD7-Proteins und der Bait-Konstrukte für den direkten Yeast-Two-Hybrid zur näheren Eingrenzung der Interaktion im CR3-Teil des CHD7. Das Plasmid pGBKT7-CHD7-CR3n (b) besteht aus dem N-terminalen Teil des Plasmids pGBKT7-CHD7-CR3 (a) mit dem Aminosäurebereich 1950-2042. Das Plasmid pGBKT7-CHD7-CR3c (c) besteht aus dem C-terminalen Teil des Plasmids pGBKT7-CHD7-CR3 (a) mit dem Aminosäurebereich 2039-2172. Im Plasmid pGBKT7-CHD7-CR3c-Trp2091Arg (d) mit dem Aminosäurebereich 2039-2172 befindet sich die Missense-Mutation Trp2091Arg.

Im direkten Yeast-Two-Hybrid ließ sich keine Interaktion des Konstruktes pGADTCHD8 mit den Konstrukten pGBKT7-CHD7-CR3n, pGBKT7-CHD7-CR3c und pGBKT7-CHD7-CR3cTrp2091Arg nachweisen. Aufgrund dieses Ergebnisses liegt die Vermutung nahe, dass die einzelnen Teilstücke von ihrer Größe zu klein für einen Interaktionsnachweis waren.

\subsubsection{Interaktion von CHD7 mit der Missense-Mutation Trp2091Arg mit CHD8}

Um die Auswirkung der Missense-Mutation Trp2091Arg auf die Interaktion zu untersuchen, wurde diese nun in das mit CHD8 interagierende Konstrukt pGBKT7CHD7-CR3 eingefügt und das Konstrukt pGBKT7-CHD7-CR3-Trp2091Arg erstellt. Durch die Missense-Mutation Trp2091Arg tritt im direkten Yeast-Two-Hybrid zwischen den Konstrukten pGADT7-CHD8 und pGBKT7-CHD7CR3-Trp2091Arg keine Interaktion mehr auf. 

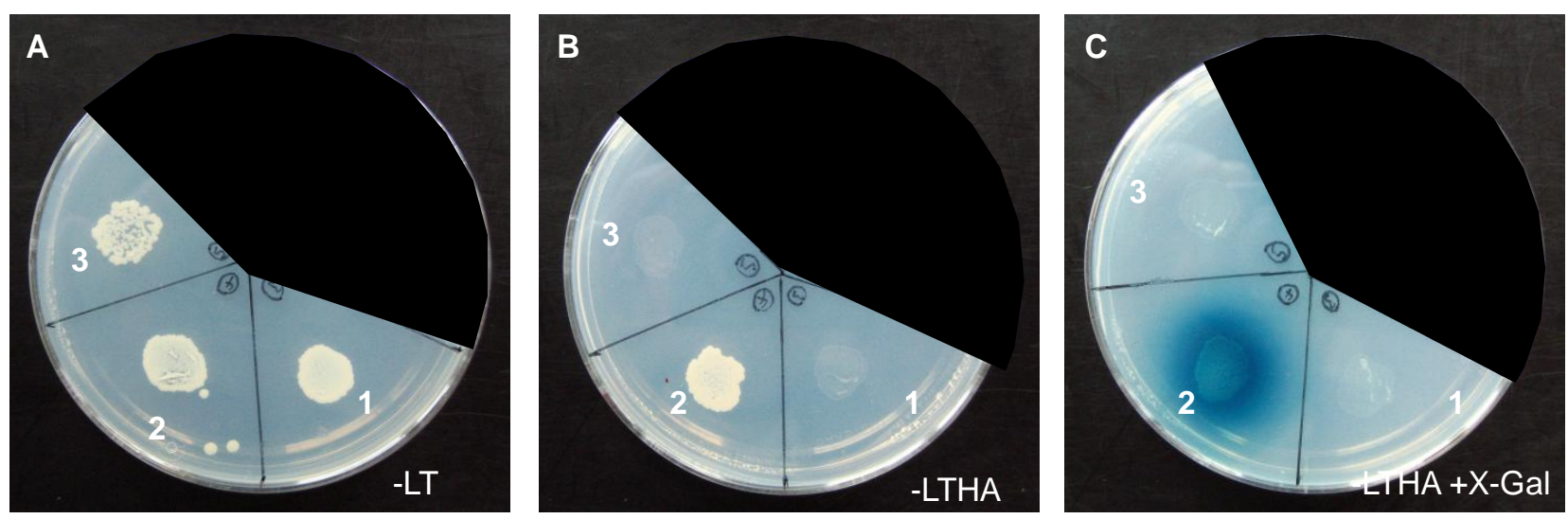

Abb. 3.12: Direkter Yeast-Two-Hybrid zur Untersuchung der Auswirkung der Missense-Mutation Trp2091Arg im CHD7-Gen auf die Interaktion mit CHD8, Doppeltransfektionen von den Konstrukten pGADT7-CHD8 mit 1. pGBKT7-CHD7-CR1 (Negativkontrolle), 2. pGBKT7-CHD7-CR3 (Positivkontrolle) und 3. pGBKT7-CHD7-CR3-Trp2091Arg.

A: Wachstum der Hefekolonien auf einem SD -LT-Mangelmedium (Transfektionskontrolle). B: Wachstum der interagierenden Konstrukte auf SD - LTHAMangelmedium. C: Wachstum des interagierenden Konstruktes 2. auf SD -LTHA + X$\alpha$-Gal-Mangelmedium.

\subsubsection{Direkter Yeast-Two-Hybrid-Assay von CHD7 und CHD7 sowie CHD8 und CHD8}

In einem weiteren direkten Yeast-Two-Hybrid wurde die Interaktion zwischen CHD7 und CHD7 sowie zwischen CHD8 und CHD8 untersucht. Dazu wurden zwei neue Konstrukte erstellt, zum einen das Konstrukt pGADT7-CHD7-CR1-3 (Tab 3.10), zum anderen das Konstrukt pGBKT7-CHD8 (Tab 3.10). Für die Erstellung des Konstruktes pGADT7-CHD7-CR1-3 wurde der leere Vektor pGADT7 sowie das Konstrukt pGBKT7-CHD7-CR1-3 (Tab. 3.10) mit den Restriktionsenzymen EcoRI und Ndel verdaut. Das Insert aus dem Vektor pGBKT7-CHD7-CR1-3 sowie der verdaute leere Vektor pGADT7 wurden auf ein Gel aufgetragen und extrahiert (QIAEX II Gel Extraction Kit, QIAGEN), nachfolgend ligiert und in DH5a-E.coli transformiert und durch eine Midi-Präparation isoliert. Als Template für das Konstrukt pGBKT7-CHD8 diente das Konstrukt pCMV-Myc-CHD8 (Abb. 3.14)). Es wurde mit den Restriktionsenzymen Mfel und Sfil verdaut, auf ein Gel aufgetragen und das Insert extrahiert (QIAEX II Gel Extraction Kit, QIAGEN). Der leere Vektor pGBKT7 wurde mit den Enzymen EcoRI und Sfil verdaut und ebenso auf ein Gel aufgetragen und extrahiert. Das Insert aus dem Konstrukt pCMV-Myc-CHD8 wurde mit dem 
leeren, verdauten Vektor pGBKT ligiert, in DH5a-E.coli transformiert und durch eine Midi-Präparation isoliert.

Im direkten Yeast-Two-Hybrid ließ sich eine Interaktion der Teilstücke von CHD8 mit CHD8 nachweisen. Die CHD7 Teilstücke zeigten untereinander keine Interaktion.
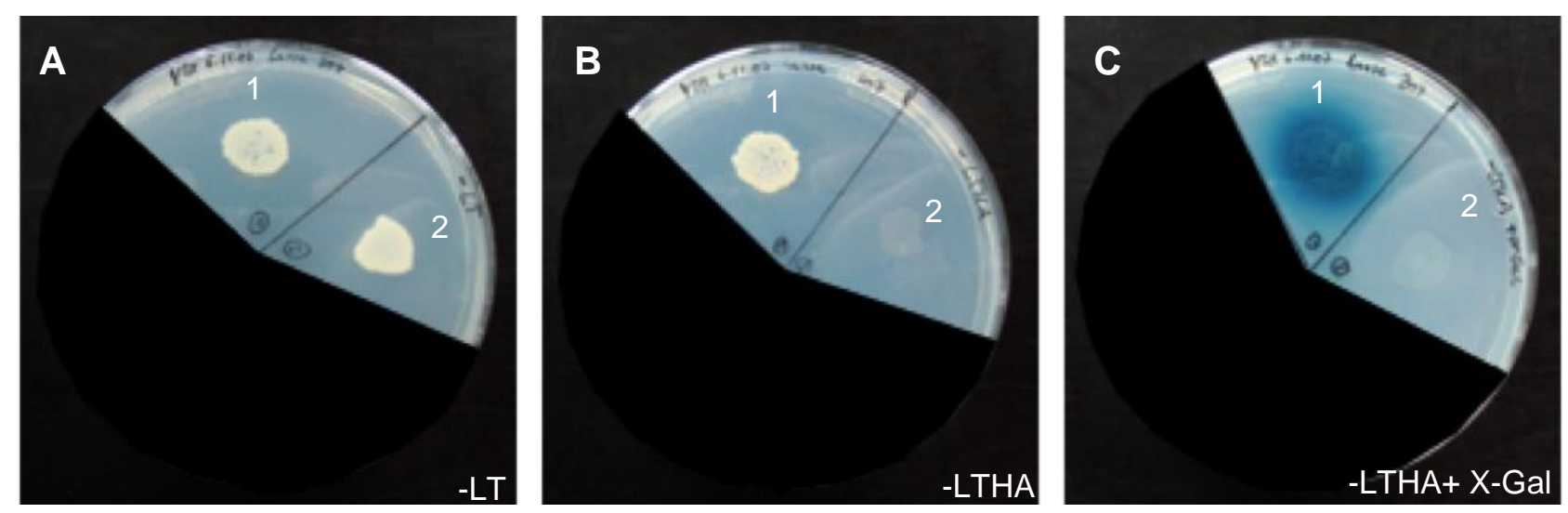

Abb. 3.13: Direkter Yeast-Two-Hybrid zur Untersuchung der Interaktionen zwischen CHD7 und CHD7 sowie zwischen CHD8 und CHD8, Doppeltransfektionen von den Konstrukten \#1 pGADT7-CHD8 und pGBKT8-CHD8 sowie \#2 pGADT7-CHD7-CR1-3 und pGBKT7-CHD7-CR1-3.

A: Wachstum der Hefekolonien auf einem SD -LT-Mangelmedium (Transfektionskontrolle). B: Wachstum der Hefekolonien mit den interagierenden Konstrukten (\#1) auf SD -LTHA-Mangelmedium. C: Wachstum der Hefekolonien mit den interagierenden Konstrukten (\#1) auf SD -LTHA + X-a-Gal-Mangelmedium. 


\subsubsection{Ko-Lokalisation der Proteine CHD7 und CHD8}

Die für die Ko-Lokalisation verwendeten Plasmide pCMV-HA-CHD7 und pCMV-MycCHD8 wurden aus unveröffentlichten Vorarbeiten (Koszucka 2008) übernommen. Die Herstellung der Konstrukte erfolgte wie in Abb. 3.14 beschrieben.

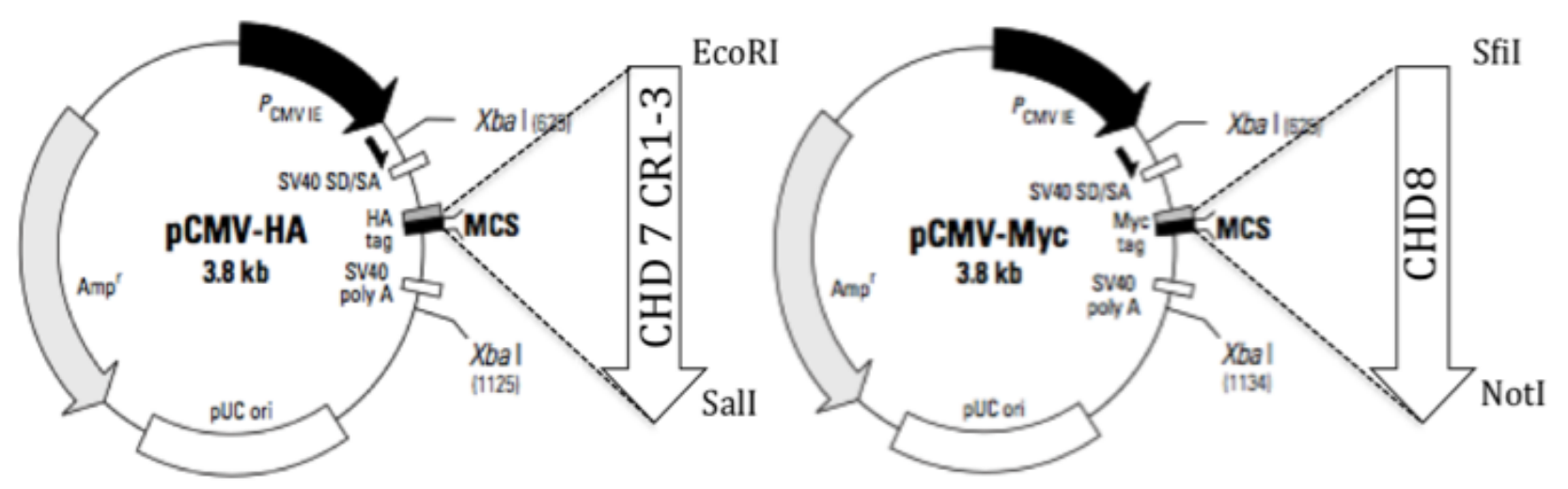

Abb. 3.14: Schemazeichnung der für die Ko-Lokalisation benutzten Konstrukte pCMV-HA-CHD7 (links) und pCMV-Myc-CHD8 (rechts) (Quelle der Vektorgrafiken: www.clontech.com). Der CR1-3 Teil (AS 1593-2178, NP_060250.2) von CHD7 wurde in den Vektor pCMVHA kloniert und sequenziert. Als Vorlage für eine PCR mit Primern mit den Restriktionsschnittestellen EcoRI und Sall diente das Plasmid pGBKT7-CHD7-CR1-3 (Tab. 3.10). Das CHD8-Insert (AS 1789-2302, NP_065971.2) wurde an humaner cDNA amplifiziert, in den Vektor pGEM-T Easy kloniert, mit den Restriktionsenzymen Sfil und Notl verdaut und anschließend in den pCMV-Myc Vektor kloniert und sequenziert (Abb. modifiziert nach Clontech Vektor-Informationen).

Die Auswahl der Zelllinie für die Ko-Lokalisation erfolgte aufgrund der Expression von CHD8 in NIH3T3-Zellen (Ishihara et al. 2006).

Die NIH3T3-Zellen wurden mit jeweils 0,5 $\mu$ gNA der Konstrukte pCMV-HA-CHD7 und pCMV-Myc-CHD8 kotransfiziert und für $24 \mathrm{~h}$ bei $37^{\circ} \mathrm{C}$ inkubiert. Nach dem Waschen der Objektträger mit DPBS wurden die Zellen mit $4 \%$ iger Paraformaldehyd-Lösung fixiert und nochmals mit DPBS gewaschen. Daraufhin erfolgte eine Markierung der HA- bzw. Myc-tags der verwendeten Plasmide mit den Antikörpern anti-HA (Kaninchen) und anti-c-Myc (Maus). Die Objekträger wurden erneut mit DPBS gewaschen und mit Antikörpern gegen die FC-Teile der ersten Antikörpermarkierung beimpft. Dafür wurden die Antikörper anti-Kaninchen Cy3 
(Schaf) (C2306, Sigma-Aldrich) sowie anti-Maus FITC (Ziege) (F0257, SigmaAldrich) verwendet. Die Objekträger wurden zur Färbung der Kerne mit Vectashield/DAPI eingedeckt.
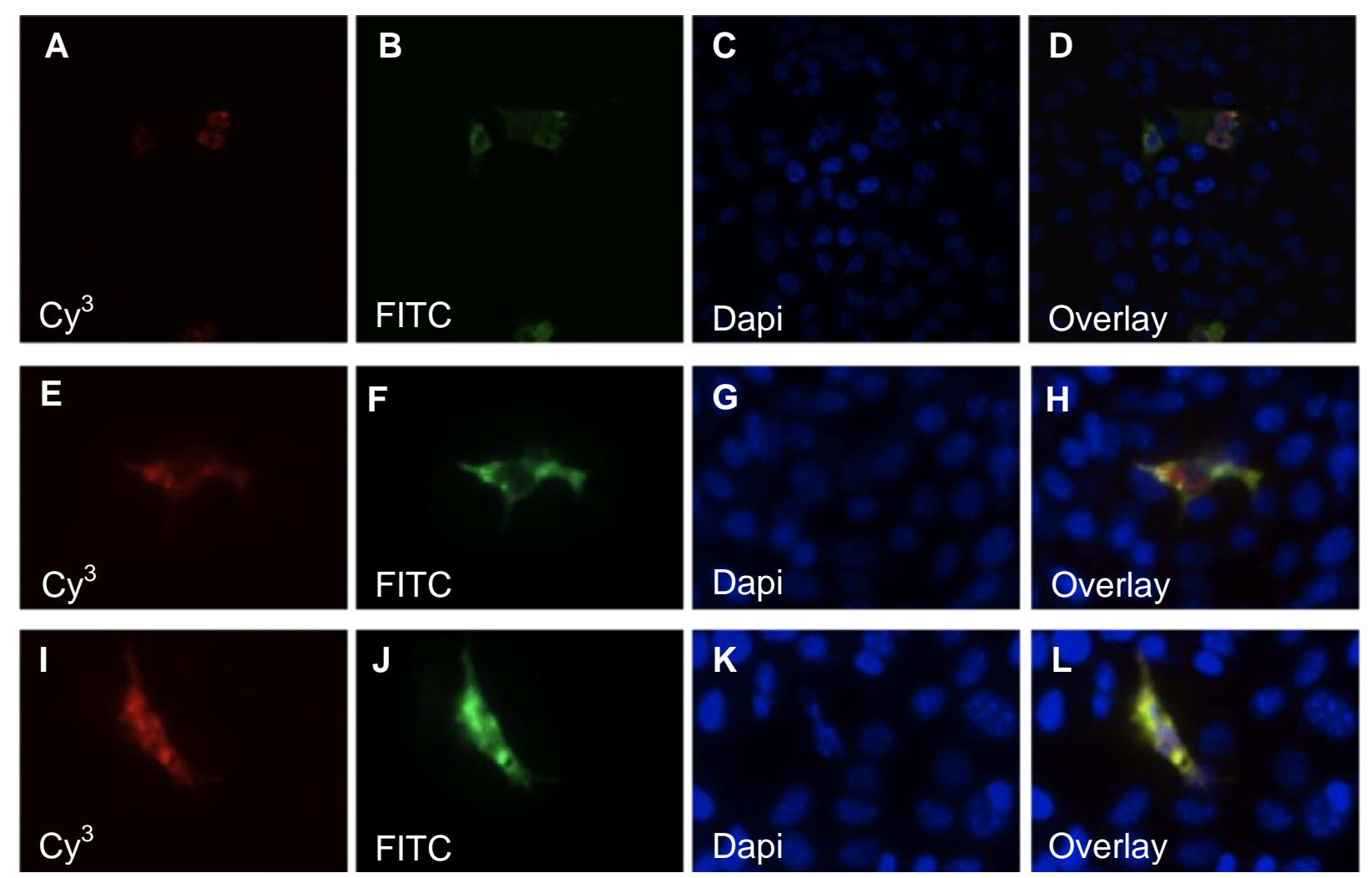

Abb. 3.15: Subzelluläre Ko-Lokalisation der Proteine CHD7, markiert mit den Antikörpern anti-HA und anti-Kaninchen $\mathrm{Cy}^{3}$ und $\mathrm{CHD} 8$, markiert mit den Antikörpern anti-Myc und antiMaus FITC, in NIH3T3-Zellen unter dem Fluoreszenzmikroskop. A-D: Das CHD7-HA Fusionsteilstück kolokalisiert im Nukleus mit dem CHD8-Myc Fusionsteilstück. E-H: Die Ko-Lokalisation findet auch im Zytoplasma statt. I-L: Gleichzeitge Ko-Lokalisation im Nukleus und im Zytoplasma.

Eine Ko-Lokalisation der beiden Fusionsproteine von CHD7 und CHD8 ließ sich unter dem Fluoreszenzmikroskop sowohl im Nukleus, im Zytoplasma als auch in beiden Zellkompartimenten gleichzeitig nachweisen. Auffällig ist, dass bei einer KoLokalisation im Nukleus die Kerne eine andere Struktur zeigen als bei einer KoLokalisation im Zytoplasma. 


\subsubsection{Nachweis der Interaktion von CHD7 und CHD8 mit Hilfe des BiFC-Assays}

Für die Durchführung des BiFC-Assays wurden die auf eine Interaktion zu untersuchenden Genabschnitte in die beiden Vektoren FPCA-V1 und FPCA-V2 einkloniert. Der Vektor FPCA-V1 enthält den C-terminalen Bereich des EGFP (Aminosäure 158-239), N-terminal wurde der offene Leserahmen des CR1-3 Teil aus CHD7 einkloniert. Ein Spacer trennt die beiden Sequenzen, damit die Tertiärstruktur besser ausgebildet werden kann. Das Konstrukt wurde bereits in Vorarbeiten (Koszucka 2008) erstellt und übernommen. Zur Überprüfung des Leserahmens und dem Ausschluss von Mutationen wurde es sequenziert. Für die Erstellung des zweiten Konstruktes wurde zunächst eine PCR an einem aus Vorarbeiten übernommenem Plasmid mit $C H D 8$ im Vektor pGEM-T Easy durchgeführt. Hierfür wurden Primer verwendet, die eine Restriktionsschnittstelle für die Klonierung in den Vektor FPCA-V2 enthalten (Primer: chd8FPCA-V2KpnIF und chd8FPCA-V2BgIIIR). Das so erhaltene PCR-Produkt wurde erneut in den Vektor pGEM-T Easy zwischenkloniert. Anschließend wurde das Produkt sequenziert und ein fehlerfreies Plasmid ausgewählt, vermehrt und das Insert für den FPCA-V2-Vektor mit Hilfe der Restriktionsenzyme $\mathrm{Kpnl}$ und Bglll aus dem Vektor pGEM-T Easy herausgeschnitten und in den mit den Restriktionsenzymen KpnI und Bglll verdauten Vektor FPCA-V2 hineinkloniert. Zur Kontrolle des Leserahmens wurde das Konstrukt erneut sequenziert. Tab. 3.11 und Abb. 3.16 geben einen Überblick über die für den BiFCAssay verwendeten Konstrukte.

\begin{tabular}{|c|c|c|c|c|}
\hline \multirow[b]{2}{*}{ Konstrukt } & \multirow[b]{2}{*}{ Vektor } & \multirow{2}{*}{$\begin{array}{c}\text { Insert } \\
\text { Aminosäuren- } \\
\text { bereich/ } \\
\text { Datenbank- } \\
\mathrm{Nr} .\end{array}$} & \multicolumn{2}{|c|}{ Beschreibung } \\
\hline & & & Template/ Primer & $\begin{array}{c}\text { Verwendete } \\
\text { Restriktions- } \\
\text { enzyme }\end{array}$ \\
\hline \multirow[t]{2}{*}{$\begin{array}{l}\text { FPCA-V1- } \\
\text { CHD7CR1-3 } \\
\left.{ }^{*}\right)\end{array}$} & \multirow[t]{2}{*}{ FPCA-V1 } & \multirow[t]{2}{*}{$\begin{array}{l}\text { 1596-2178/ } \\
\text { NP_060250.2 }\end{array}$} & \multicolumn{2}{|c|}{$\begin{array}{l}\text { enthält die drei konservierten Regionen } \\
\text { CR1-CR3 und die SANT-Domäne des } \\
\text { CHD7 }\end{array}$} \\
\hline & & & $\begin{array}{l}\text { humane cDNA/ } \\
\text { chd7FPCA-V1EcoRIF } \\
\text { chd7FLCA-V1SallR }\end{array}$ & EcoRI und Sall \\
\hline
\end{tabular}




\begin{tabular}{|c|c|c|c|c|}
\hline \multirow{2}{*}{$\begin{array}{l}\text { FPCA-V2- } \\
\text { CHD8 }\end{array}$} & \multirow[t]{2}{*}{ FPCA-V2 } & \multirow{2}{*}{$\begin{array}{l}\text { 1791-2302/ } \\
\text { NP_065971.2 }\end{array}$} & \multicolumn{2}{|c|}{ enthält einen Teil des $C H D 8$-Gens } \\
\hline & & & $\begin{array}{l}\text { humane cDNA/ } \\
\text { chd8FPCA-V2KpnIF } \\
\text { chd8FPCA-V2BgllI }\end{array}$ & Kpnl und BgIII \\
\hline
\end{tabular}

*) Konstrukt wurde aus Vorarbeiten von Koszucka (2008) übernommen

Tab. 3.11: $\quad$ Verwendete Konstrukte für den BiFC-Assay.

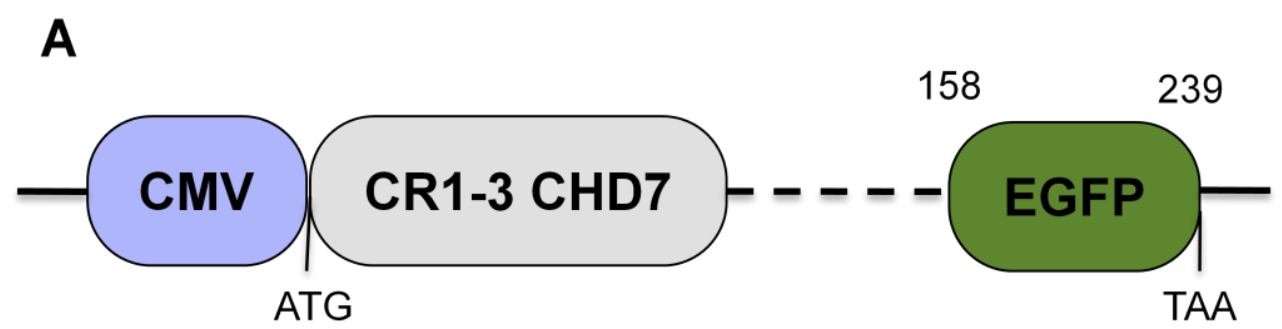

B

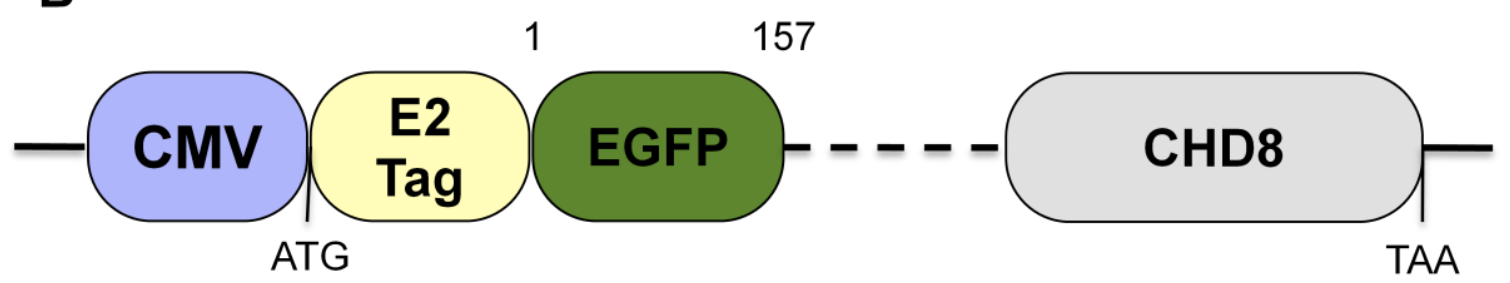

Abb. 3.16: $\quad$ Schematische Darstellung der im BiFC-Assay verwendeten Konstrukte (Prof. Dr. S. Hoyer-Fender). A: Der Vektor FPCA-V1 enthält den C-terminalen Bereich des EGFP (Aminosäure 158-239). Der offene Leserahmen des CR1-3 Teil vom CHD7 (AS 15962178) wurde N-terminal des EGFP mit einem Spacer einkloniert. B: Der Vektor FPCAV2 enthält den N-terminalen Bereich des EGFP (Aminosäure 1-157) gekoppelt an einen E2-Tag zur Detektion mit einem E2-spezifischen Antikörper. Der offene Leserahmen des CHD8 (AS 1791-2302) wurde so einkloniert, dass es im resultierenden Fusionsprotein C-terminal von EGFP liegt.

Für die Durchführung des BiFC-Assay wurden HeLa-Zellen verwendet. Die HeLaZellen wurden mit jeweils $0,5 \mu \mathrm{g}$ DNA der Konstrukte FPCA-V1-CHD7 und FPCA-V2CHD8 kotransfiziert und für $24 \mathrm{~h}$ bei $37^{\circ} \mathrm{C}$ inkubiert. Nach dem Waschen der Objektträger mit DPBS wurden die Zellen mit 4 \%iger Paraformaldehyd-Lösung fixiert, nochmals mit DPBS gewaschen und mit Vectashield/DAPI eingedeckt. In Abb. 3.17 ist ein grünes Signal in den kotransfizierten HeLa-Zellen zu beobachten, welches sowohl nur im Zytoplasma, nur im Nukleus als auch in beiden Zellkompartimenten gleichzeitig lokalisiert ist. 

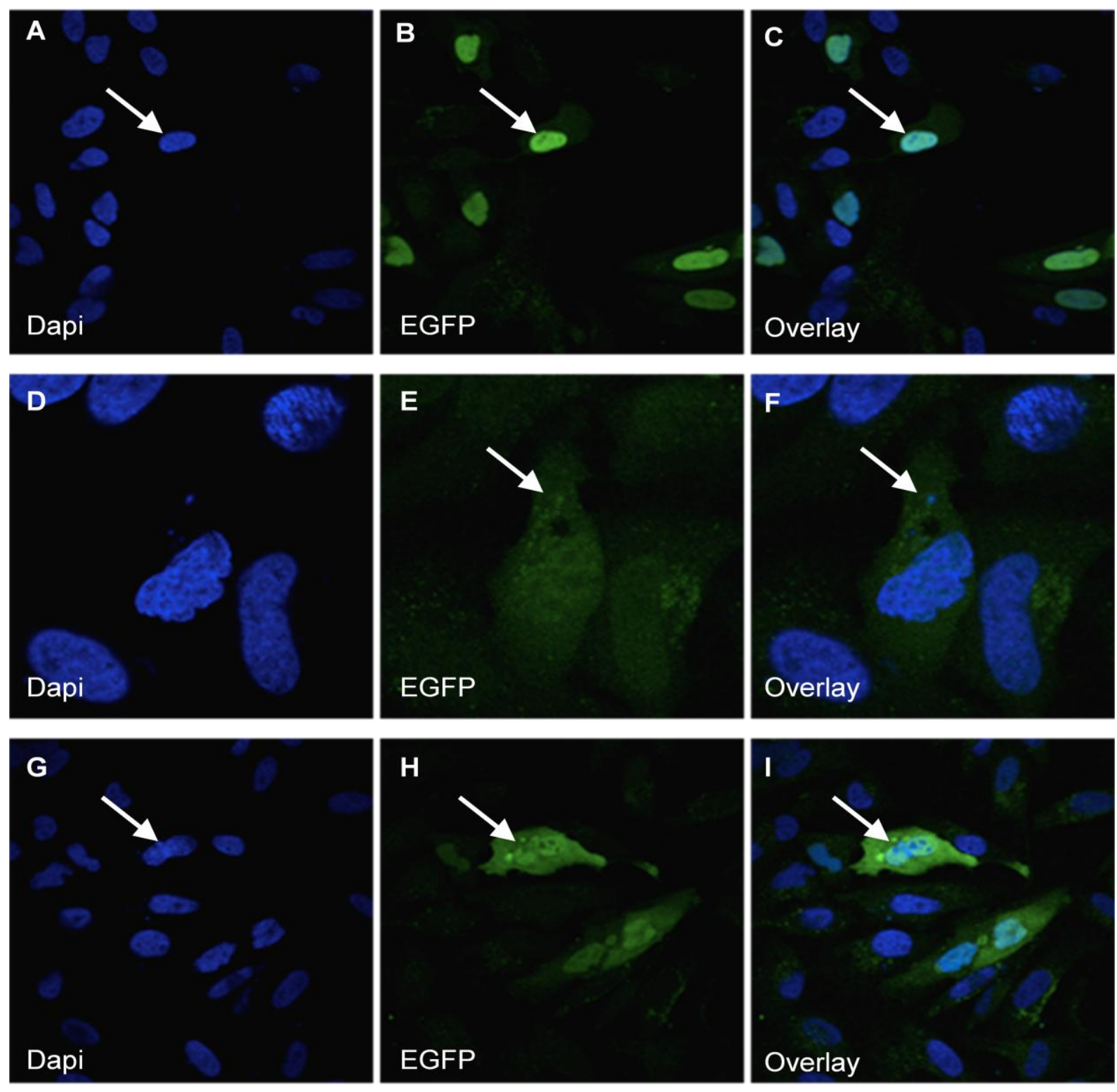

Abb. 3.17: Nachweis der Interaktion von CHD7 und CHD8 mit Hilfe des BiFC-Assays. HeLaZellen wurden auf Glasobjektträgern mit den Konstrukten FPCA-V1-CHD7 und FPCAV2-CHD8 kotransfiziert und für $24 \mathrm{~h}$ inkubiert. Die Zellen wurden anschließend mit 4 \%igem Paraformaldehd fixiert und die Kerne mit Vectashield/DAPI blau eingefärbt. Die Bilder der grün fluoreszierenden Zellen wurden mit 600facher Vergrößerung aufgenommen. A-C: CHD7 und CHD8 interagieren im Nukleus (Pfeil). D-F: Die Interaktion zeigt sich auch im Zytoplasma (Pfeil). G-I: Gleichzeitige Interaktion im Zytoplasma und im Nukleus (Pfeil). 


\section{Diskussion}

\subsection{Familiärer Fall eines CHARGE-Syndroms}

Im Rahmen dieser Arbeit wurde eine Familie untersucht, in der zwei Kinder an einem CHARGE-Syndrom leiden. Ein Geschwisterkind ist gesund. Die Eltern zeigen keinerlei Auffälligkeiten. In einer in Vorarbeiten durchgeführten Linkage-Analyse konnte die bei beiden betroffenen Kindern identifizierte Mutation c.7302dupA im CHD7-Gen dem väterlichen Allel zugeordnet werden (Pauli et al. 2009).

\subsubsection{Nachweis eines Gonadenmosaiks bei familiärem CHARGE-Syndrom}

Die vorliegende Arbeit weist ein Gonadenmosaik beim Vater als Ursache des CHARGE-Syndroms bei zwei betroffenen Geschwisterkindern nach. Die beiden betroffenen Kinder tragen dieselbe Mutation c.7302dupA, ein weiteres Geschwisterkind ist gesund.

In unterschiedlichen väterlichen Geweben (Haare, Lymphozyten und Mundschleimhaut) konnte keine Mutation nachgewiesen werden. Der Vater ist klinisch unauffällig, daher ist ein Mosaik der väterlichen Keimbahn wahrscheinlich. Ein Gonadenmosaik kann den Ursprung in einer Urkeimzelle haben, welche sich im Rahmen der Keimzellentwicklung weiter teilt und die Mutation damit an die Keimzellen überträgt. Soriano und Jaenisch (1986) gehen von dem Vorliegen von mindestens drei Urkeimzellen für die Keimzellentwicklung im 4- bis 16-Zell Stadium der Embryonalentwicklung aus.

In dieser Arbeit wurde die Mutation c.7302dupA an aus Ejakulat isolierter DNA nachgewiesen.

Im Ejakulat können sich neben Spermien auch noch weitere Zellen wie Lymphozyten (Gil et al. 1995) oder möglicherweise Urothel befinden, so dass eine Zuordnung der Mutation zu Zellen der Keimbahn nicht sicher möglich ist. Um sicherzustellen, dass Spermien und keine anderen Zellen für die DNA Analyse selektiert wurden, und zur näheren Quantifizierung des Mosaiks wurden mittels eines ICSI-Manipulators Einzelspermien isoliert und eine Methode etabliert, mittels derer die Mutation in 16 von 59 Spermien nachgewiesen werden konnte, in 43 Spermien lag die Wildtyp- 
Sequenz vor. In der untersuchten Stichprobe tragen ungefähr $27 \%$ der Spermien des Vaters der beiden betroffenen Kinder die Mutation c.7302dupA im CHD7-Gen.

Die Inzidenz für das CHARGE-Syndrom wird auf bis zu 1:8.500 Lebendgeburten geschätzt (Issekutz et al. 2005). Die meisten der Patienten mit CHARGE-Syndrom wurden als sporadische Fälle beschrieben. Autosomal dominant vererbte Fälle sind selten, da sich aufgrund der Schwere des Krankheitsbildes die meisten Patienten nicht fortpflanzen. Es wurden jedoch auch familiäre Fälle beschrieben (Mitchell et al. 1985, Metlay et al. 1987), wobei in diesen Fällen der betroffene Elternteil eine milde Klinik aufweist (Jongmans et al. 2008). Teilweise handelt es sich bei diesen Fällen um ein somatisches Mosaik, bei dem ein Teil der somatischen Zellen und ein Teil der Keimzellen die Mutation tragen. Abhängig vom Zeitpunkt des Auftretens der Mutation in der Embryonalentwicklung sind dabei unterschiedliche Gewebe in unterschiedlich starker Ausprägung betroffen.

Die genaue Frequenz an Gonadenmosaiken beim CHARGE-Syndrom ist bis heute nicht bekannt, sie wird aufgrund von Fallbeschreibungen derzeit in der Literatur mit $3 \%$ angegeben (Lalani et al. 2006, Wincent et al. 2008, Jongmans et al. 2008). Bei diesen Fallbeschreibungen handelt es sich um klinisch gesunde Eltern, die mehr als ein betroffenes Kind haben, und bei denen keine Mutation im CHD7-Gen in den Lymphozyten molekulargenetisch nachgewiesen werden konnte.

In dieser Arbeit wird zum ersten Mal bei einem familiären CHARGE-Fall ein Gonadenmosaik beim Vater bestätigt und gleichzeitig eine Aussage über den Anteil der Spermien mit der c.7302dupA-Mutation getroffen.

\subsubsection{Gonadenmosaike bei anderen Erkrankungen}

Es gibt Berichte über Familien mit mehr als einem betroffenen Kind mit einer bestimmten autosomal dominanten Erkrankung bei unauffälligen Eltern. In den meisten Fällen wird das Vorliegen eines Gonadenmosaiks lediglich vermutet (Hall JG 1988). Ein Mosaik kann sich auf die Keimzellen beschränken oder aber gleichzeitig in somatischen Zellen und in Keimzellen vorliegen. Würde nur eine Progenitorzelle vorliegen, läge eine Mutation in jeder prämeiotischen Keimzelle vor und somit trügen 50 \% der Spermien die Mutation. Soriano und Jaenisch zeigten 1986 in Mäusen mit retroviralen Sonden, dass sich die Zellen, aus denen sich der Embryo in der 
Blastozyste entwickelt, intensiv durchmischen, bevor sie sich zum endgültigen Gewebe differenzieren. Somatische Gewebe basieren dabei auf mindestens acht Stammzellen, drei oder mehr Zellen sollen dabei die Keimzellen bilden und werden dazu vor der somatischen Differenzierung separiert. Ein Hinweis für das Vorliegen von mehreren Zellen für die Keimzelldifferenzierung ergibt sich auch aus den Befunden in einer Familie, in der die von Neurofibromatose Typ 2 betroffene Mutter ein somatisches und Gonadenmosaik hat und den selben Haplotyp auf ihre zwei Kinder überträgt, bei denen jedoch nur eines die Mutation trägt (Bijlsma et al. 1997). Cohn et al. beschrieben 1990 ein Gonadenmosaik bei der Osteogenesis imperfecta mit einem mutationstragenden von acht Spermien und schlossen daher auf das Vorliegen von mindestens vier Progenitorzellen in der Keimzelldifferenzierung.

Abhängig vom Grad und der Art des Mosaiks können die Träger asymptomatisch sein oder verschiedene Ausprägungen der Erkrankung zeigen. Es wurde gezeigt, dass die Frequenz somatischer Mosaike und der Keimzellmosaike zwischen verschiedenen Erkrankungen variiert (Zlotogora 1998). So wird die Mosaikfrequenz beim Noonan-Syndrom auf unter $1 \%$ geschätzt (Elalaoui et al. 2010), während sie bei der Osteogenesis imperfecta 16 \% erreichen kann (Pyott et al. 2011). Tab. 4.1 gibt einen Überblick über die Frequenz somatischer Mosaike und der Keimzellmosaike bei autosomal dominanten Erkrankungen.

\begin{tabular}{|c|c|c|}
\hline Erkrankung & Mosaikfrequenz & Quelle \\
\hline Noonan-Syndrom & $<1 \%$ & Elalaoui et al. 2010 \\
\hline von-Hippel-Lindau & $4-4,8 \%$ & $\begin{array}{c}\text { Sgambati et al. 2000, } \\
\text { Evans et al. 1998 }\end{array}$ \\
\hline Tuberöse Sklerose & $6 \%$ & Rose et al. 1999 \\
\hline Alagille-Syndrom & $8,2 \%$ & Giannakudis et al. 2001 \\
\hline Retinoblastom & $10 \%$ & Lemmers et al. 2004 \\
\hline Fazioskapulohumerale & $13 \%$ & Pyott et al. 2011 \\
\hline Muskeldystrophie & $16 \%$ & \\
\hline
\end{tabular}

Tab 4.1: $\quad$ Überblick über die in der Literatur angegebenen Frequenzen von somatischen Mosaiken und Keimzellmosaiken autosomal dominanter Erkrankungen. 


\subsubsection{Quantitative Bestimmung von Gonadenmosaiken im Vergleich}

In der vorliegenden Arbeit wurde ein Gonadenmosaik für das CHARGE-Syndrom in der Familie nachgewiesen. Es wurde eine Methode zum Nachweis der Mutation im CHD7-Gen in der DNA einzelner Spermien etabliert. Einzelne Spermien wurden dazu mit einem Mikromanipulator mit ICSI-Pipetten isoliert, die DNA extrahiert und an dieser DNA eine PCR in zwei Schritten durchgeführt, sowie das Produkt sequenziert. Auch bei anderen Erkrankungen wurden Gonadenmosaike beobachtet und quantifiziert, Tab. 4.2 gibt einen Überblick über die in der Literatur beschriebenen quantifizierten paternalen Gonadenmosaike. Sippel et al. (1998) haben ein Gonadenmosaik beim Retinoblastom mit einem Anteil von ungefähr $5 \%$ mutationstragender Spermien beschrieben. Namikawa et al. (1995) quantifizieren ein väterliches Gonadenmosaik bei der Osteogenesis imperfecta mit ungefähr $43 \%$ der Spermien. Zwischen dieses Spektrum ordnet sich das in dieser Arbeit festgestellte Mosaik mit $27 \%$ mutationstragenden Spermien ein.

\begin{tabular}{|c|c|c|c|c|}
\hline Erkrankung & Gen & Mosaik & $\begin{array}{c}\text { Anteil } \\
\text { mutationstragender } \\
\text { Spermien }\end{array}$ & Quelle \\
\hline $\begin{array}{l}\text { Osteogenesis } \\
\text { imperfecta }\end{array}$ & COL1A1 & gonosomal & $12,5 \%$ & $\begin{array}{c}\text { Cohn et al. } \\
1990\end{array}$ \\
\hline Kniest-Syndrom & COL2A1 & gonosomal & $40 \%$ & $\begin{array}{c}\text { Edwards et } \\
\text { al. } 1992\end{array}$ \\
\hline $\begin{array}{l}\text { von-Willebrand- } \\
\text { Syndrom Typ IIB }\end{array}$ & VWF & gonadal & $5 \%$ & $\begin{array}{c}\text { Murray et al. } \\
1992\end{array}$ \\
\hline $\begin{array}{c}\text { Neurofibromatose } \\
\text { Typ } 1\end{array}$ & NF1 & gonadal & $10 \%$ & $\begin{array}{c}\text { Lázaro et al. } \\
1994\end{array}$ \\
\hline $\begin{array}{l}\text { Osteogenesis } \\
\text { imperfecta }\end{array}$ & COL1A1 & gonosomal & $43 \%$ & $\begin{array}{c}\text { Namikawa et } \\
\text { al. } 1995\end{array}$ \\
\hline $\begin{array}{l}\text { Osteogenesis } \\
\text { imperfecta }\end{array}$ & COL1A2 & gonosomal & $40 \%$ & $\begin{array}{l}\text { Lund et al. } \\
\qquad 1996\end{array}$ \\
\hline $\begin{array}{c}\text { Osteogenesis } \\
\text { imperfecta }\end{array}$ & COL1A1 & gonadal & $37,5 \%$ & $\begin{array}{c}\text { lida et al. } \\
1996\end{array}$ \\
\hline
\end{tabular}




\begin{tabular}{|c|c|c|c|c|}
\hline Retinoblastom & RB1 & gonadal & $5 \%$ & $\begin{array}{c}\text { Sippel et al. } \\
1998\end{array}$ \\
\hline Morbus Fabry & GLA & gonadal & $25 \%$ & $\begin{array}{c}\text { Dobrovolný } \\
\text { et al. 2005 }\end{array}$ \\
\hline SCN & ELA2 & gonosomal & $33 \%$ & $\begin{array}{c}\text { Malcov et al. } \\
2010\end{array}$ \\
\hline
\end{tabular}

Tab. 4.2: Überblick über die in der Literatur beschriebenen Quantifizierungen mutationstragender Spermien. Bei der in dieser Arbeit untersuchten Stichprobe des familiären CHARGE-Falles beträgt der Anteil der Spermien mit der Mutation c.7302dupA im CHD7-Gen $27 \%$.

\subsubsection{Konsequenzen für die Genetische Beratung und Ausblick}

In der Literatur wird aufgrund der bis dato beschriebenen Fälle mit CHARGESyndrom zusammen mit den familiären Fällen ein Wiederholungsrisiko von ungefähr $3 \%$ für ein Geschwisterkind eines am CHARGE-Syndrom erkrankten Kindes angegeben (Jongmans et al. 2008). Bei den in dieser Arbeit untersuchten 59 Einzelspermien tragen 16 die Mutation c.7302dupA und würden im Falle einer mit einem solchen Spermium befruchteten Eizelle zum CHARGE-Syndrom führen können. Ungeachtet einer aufgrund dieser Mutation eventuell vorliegenden Benachteiligung dieser Spermien in der Konkurrenz um die Befruchtung der Eizelle ist das Wiederholungsrisiko in dieser untersuchten Familie deutlich erhöht, es ist also bei Kenntnis eines Gonadenmosaiks wesentlich höher zu bewerten als die allgemeine Angabe in der Literatur. Beim Karsch-Neugebauer-Syndrom, bei dem ebenso ein autosomal-dominanter Erbgang angenommen wird, wurden von zehn in der Literatur beschriebenen Fällen vier auf das eventuelle Vorliegen eines Gonadenmosaiks zurückgeführt (Wong et al. 1998).

In der gängigen Praxis der humangenetischen Beratung werden die Eltern betroffener Kinder mit CHARGE-Syndrom durch eine DNA-Analyse von Lymphozyten untersucht. Lässt sich die Mutation des betroffenen Kindes in diesen Analysen bei den Eltern nicht nachweisen, wird die Mutation als de novo klassifiziert. Ein vorhandenes Gonadenmosaik bleibt dabei unentdeckt. Auch ein somatisches Mosaik kann sich der Detektion entziehen, da der Grad des Mosaiks in den 
unterschiedlichen Geweben variiert und die Mutation somit in den Lymphozyten fehlen kann. Die Häufigkeit eines Gonadenmosaiks beim CHARGE-Syndrom könnte zu niedrig geschätzt werden, da möglicherweise eine signifikante Anzahl an Mutationen fälschlicherweise als de novo klassifiziert wurde. Studien mit großen Kohorten an CHARGE-Patienten und deren Eltern sind nötig, um die Prävalenz von Gonadenmosaiken beim CHARGE-Syndrom näher einzugrenzen. Der quantitative Nachweis eines väterlichen Gonadenmosaiks ist, im Gegensatz zum Nachweis eines mütterlichen Gonadenmosaiks, an aus Spermien isolierter DNA mit relativ geringem Aufwand zu führen, ein Protokoll wurde im Rahmen dieser Arbeit aufgestellt. Es gibt keine genauen Studien zur Häufigkeit von Gonadenmosaiken beim CHARGESyndrom. In einer Studie an 30 Familien konnte die das CHARGE-Syndrom verursachende Mutation in 92,3\% der Fälle dem väterlichen Allel zugeordnet werden (Pauli et al. 2012), daher ist die Untersuchung auf ein väterliches Gonadenmosaik in Zukunft zu empfehlen. Studien mit mehr CHARGE-Familien sind nötig, um das bevorzugte Auftreten der Mutation in der väterlichen Keimbahn zu bestätigen. In weiteren Arbeiten ist es interessant, an großen Kohorten von CHARGE-Patienten zu untersuchen, ob bei den Vätern ein Gonadenmosaik vorliegt. Möglicherweise liegen auch Mosaike mit einem geringeren Grad als dem in der Stichprobe dieser Arbeit festgestellten Mosaik von $27 \%$ der Keimzellen vor. In diesem Fall können dem betroffenen CHARGE-Kind weitere gesunde Geschwister folgen. Das Wiederholungsrisiko liegt dabei jedoch deutlich über dem Risiko eines CHARGESyndroms im Gesamtkollektiv von 1:8.500 Geburten. Weitere Untersuchungen könnten in der genetischen Beratung im Hinblick auf das Wiederholungsrisiko nach der Geburt des ersten Kindes mit dem CHARGE-Syndrom hilfreich sein. Hier gilt es, zum einen Informationen über die generelle Häufigkeit von paternalen Gonadenmosaiken beim CHARGE-Syndrom zu erlangen und zum anderen in der individuellen Beratung über die Untersuchung der Spermien eine Quantifizierung des Mosaiks und damit einen Hinweis auf das Wiederholungsrisiko zu ermöglichen. Der Nachweis eines Gonadenmosaiks kann z.B. eine Entscheidungshilfe für die ratsuchende Familie zur Inanspruchenahme einer Präimplantationsdiagnostik sein. 


\subsection{CHD7-Interaktionsstudien}

Mutationen im CHD7-Gen können zum CHARGE-Syndrom führen (Vissers et al. 2004). Eine Mutation im CHD7-Gen wird jedoch nur in ca. 58 \% (Lalani et al. 2006) bzw. 64 \% (Jongmans et al. 2006) der Fälle gefunden. Die anderen Fälle erfüllen die klinischen Kriterien des CHARGE-Syndroms, eine Mutation lässt sich jedoch bislang nicht nachweisen (Lalani et al. 2006). CHD7 wurde im Rahmen von großen Multiprotein-Komplexen nachgewiesen (Bajpai et al. 2010). Es ist möglich, dass auch Mutationen in CHD7-Interaktionspartnern zum CHARGE-Syndrom führen. Ziel dieser Arbeit war es daher auch, das in einem Yeast-Two-Hybrid-Library-Screen identifizierte, mögliche Kandidatenprotein CHD8 für das CHARGE-Syndrom auf seine Interaktion mit CHD7 zu untersuchen und eine mögliche Interaktionsstelle näher einzugrenzen.

Im direkten Yeast-Two-Hybrid wurde die Interaktion zwischen CHD7- und CHD8Teilstücken bestätigt und eine Autoaktivierung ausgeschlossen. Die Interaktionsstelle im CHD7-Protein ließ sich in weiteren direkten Yeast-Two-Hybrid-Experimenten auf den Bereich der SANT-Domäne mit dem CR3-Teil sowie $\mathrm{N}$ - und C-terminalen Überhängen eingrenzen (s. Abb 3.9). Eine weitere Eingrenzung, etwa auf die SANTDomäne allein, die SANT-Domäne und den CR3-Teil ohne $\mathrm{N}$ - und C-terminale Überhänge oder $\mathrm{N}$ - und $\mathrm{C}$-terminale Hälften des interagierenden Konstruktes gelang nicht. Möglicherweise sind die $\mathrm{N}$ - und $\mathrm{C}$-terminalen Überhänge in der Interaktion der beiden Proteine involviert. Die fehlende Interaktion bei Aufteilung der Konstrukte auf den N-bzw. C-terminalen Teil könnte ihre Ursache darin haben, dass die erstellten Konstrukte zu klein für einen Interaktionsnachweis sind.

Im Rahmen der Ko-Lokalisation wurde der offene Leserahmen des CR1-3-Teils vom CHD7-Gen in den Vektor pCMV-HA und ein Teilstück des CHD8-Gens in den Vektor pCMV-Myc einkloniert. Nach Markierung des HA- bzw. Myc-Tags mit spezifischen Antikörpern und Visualisierung mittels fluoreszierender Sekundärantikörper ließ sich die Proteinexpression in der Zelle unter dem Mikroskop lokalisieren. CHD7 und CHD8 zeigten dabei eine in verschiedenen Zellen unterschiedliche Ko-Lokalisation, beschränkt auf das Zytoplasma, den Zellkern und in manchen Zellen gleichzeitig in beiden Zellkompartimenten.

Desweiteren wurde ein BiFC-Assay mit dem CHD8-Teil aus dem direkten YeastTwo-Hybrid und dem CR1-3-Teil des CHD7 zum Interaktionsnachweis durchgeführt. 
Über den Nachweis eines Fluoreszenzsignals ließ sich die Interaktion zwischen den beiden Konstrukten nachweisen. Mit Hilfe dieser Methode gelang der direkte Interaktionsnachweis in eukaryoten Zellen. Analog zur Ko-Lokalisation ließ sich die Interaktion im Nukleus, im Zytoplasma sowie in beiden Zellkompartimenten gleichzeitig nachweisen. Das endogene Protein befindet sich im Kern. Durch die Transfektion und die anschließende Überexpression der Konstrukte erklärt sich die Lokalisation im Zytoplasma und in beiden Kompartimenten.

\subsubsection{CHD7 und CHD8 enthaltende Proteinkomplexe}

CHD8 ist neben CHD7 und anderen CHDs ein Mitglied der Subgruppe III der CHDProteine. Es zeichnet sich durch zwei $\mathrm{N}$-terminale Chromodomänen und eine SWI2/SNF2-artige ATPase/Helikase-Domäne aus. Es folgen, spezifisch für die Mitglieder der Subgruppe III, drei konservierte Regionen (CR1-CR3), eine SANTDomäne und zwei BRK-Domänen (Flaus et al. 2006).

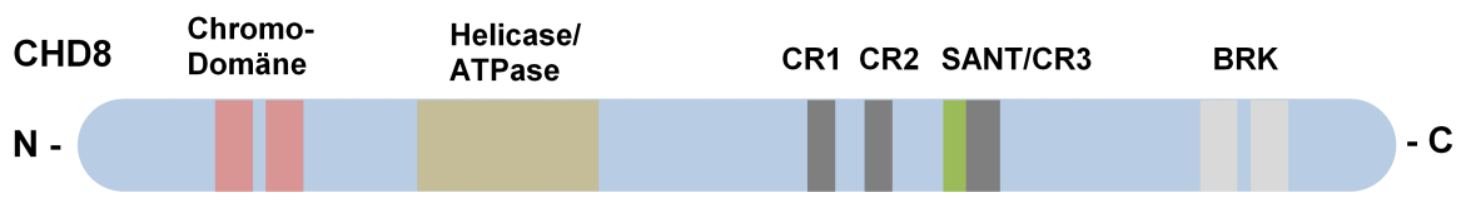

Abb 4.1: Schematische Darstellung der Struktur des humanen CHD8 mit zwei N-terminalen Chromodomänen, einer Helicase/ATPase-Domäne, drei konservierten Regionen (CR1-CR3) sowie einer SANT- und zwei C-terminalen BRK-Domänen (nach Yuan et al. 2007).

Es wurde gezeigt, dass CHD8 mit humanem Staf (ZNF143), einem Zink-Finger Transkriptionsfaktor, interagiert, der die Expression des U6-Gens kontrolliert (Yuan et al. 2007). Des Weiteren wurde CHD8 mit Komponenten des MLL1-WDR5Komplexes aufgereinigt (Dou et al. 2005, Thompson et al. 2008) und eine direkte Interaktion mit beta-Catenin nachgewiesen. CHD8 spielt dabei eine Rolle in der Regulation von beta-Catenin-Zielgenen (Thompson et al. 2008). Das Chd8 der Maus bindet mit seiner BRK-Domäne Ctcf, ein Insulator-Binding-Protein, welches eine Rolle in der Regulation der Genexpression durch Blockade von Expressionsverstärkern und der epigenetischen Regulierung spielt (Ishihara et al. 
2006). Mit seiner Tandem-Chromodomäne bindet CHD8 in vitro spezifisch an Histon $\mathrm{H} 3$, welches am Lysin 4 di-methyliert ist, außerdem wurde eine Assoziation mit der RNA Polymerase II (Pol II) und eine Kontrollfunktion der Expression des Cyclin E2 und der Thymidylatsynthetase beschrieben (Rodríguez-Paredes et al. 2009).

In der Fliege Drosophila melanogaster stellt kismet das einzige zu der Subgruppe III der CHD-Genfamilie verwandte Gen dar. Kismet codiert für zwei Isoformen, ein großes Protein mit einem Molekulargewicht von 574 kDa (Kis-L) und eine kleine Isoform mit $225 \mathrm{kDa}$ (Kis-S) (Daubresse et al. 1999, Therrien et al. 2000). Kis-L ist eng verwandt mit dem humanen $C H D 7$ und anderen Subgruppe-III-Genen. Kis- $L$ gehört zur Trithoraxgruppe, und es wurde für dieses Protein eine wichtige Rolle in der Körpersegmentation und Identifikation der einzelnen Segmente in DrosophilaLarven nachgewiesen (Daubresse et al. 1999). Des Weiteren wurde postuliert, dass $K i s-L$ in einem frühen Schritt der Transkriptionselongation durch die Pol II beteiligt ist, da es mit den meisten Pol-II-Sites kolokalisiert ist (Srinivasan et al. 2005, 2008; Rodríguez-Paredes et al. 2009). Srinivasan et al. beobachteten 2005 eine reduzierte Aktivität der Elongation durch Pol II und der Elongationsfaktoren SPT6 und CHD1 in kismet-mutierten Larven. Im Gegensatz zu Drosophila führt die Ausschaltung von CHD8 im Säugetier nicht generell zu einem niedrigeren Level an Ser2phosphorylierter Pol II. Daher wurde vorgeschlagen, dass beim Säugetier die Funktion von kismet durch diverse andere Mitglieder der CHD-Subgruppe-III-Familie übernommen wird. Die Ausschaltung eines Subgruppen-Mitglieds führt demnach zu einem genspezifischen, jedoch nicht zu einem generellen Effekt (Rodríguez-Paredes et al. 2009). Kismet wird für einen Repressionsmechanismus der hedgehogExpression in den anterioren Zellen der Imaginalscheibe benötigt. Für das kismetHomolog CHD8 konnte im Krallenfrosch ebenfalls eine Bedeutung in der Regulation des Hedgehog-Signalweges nachgewiesen werden (Terriente-Félix et al. 2011).

In der vorliegenden Arbeit wurde gezeigt, dass Teilbereiche der beiden Mitglieder $\mathrm{CHD} 7$ und $\mathrm{CHD} 8$ der CHD-Subgruppe-III miteinander interagieren. Eine weitere Interaktion innerhalb einer Subgruppe wurde bisher für die Mitglieder der Subgruppe II, CHD3 und CHD4, nachgewiesen (Marfella und Imbalzano 2007). In Drosophila gibt es nur ein zur Subgrupe II verwandtes Gen namens Mi-2, welches für zwei unterschiedliche Transkripte kodiert, dMi-2a und dMi-2b (Khattak et al. 2002). Beim Säugetier bilden CHD3 und CHD4 zusammen eine Kernkomponente des NuRDKomplexes, einem ATP-abhängigen Chromatin-remodeling-Komplex, welcher zudem 
noch eine Histon-Deacetylase-Aktivität besitzt (Xue et al. 1998; Hall JA und Georgel 2007). Hypothetisch könnte CHD7 demnach mit CHD8 eine Kernkomponente eines Komplexes bilden, der eine ähnliche Funktion wie kismet aufweist, das einzige zur Subgruppe III verwandte Gen von Drosophila.

\subsubsection{Mögliche Bedeutung von Mutationen im CHD8-Gen für die Pathogenese des CHARGE-Syndroms}

In einer Arbeit über drei Kinder, die durch Entwicklungsverzögerung, kognitive Beeinträchtigung und andere als beim CHARGE-Syndrom auftretende Dysmorphien (weiter Augenabstand, kurze Nase mit flachem Nasenrücken, langes Philtrum, prominenter Kupidobogen der Oberlippe, prominente Unterlippe sowie Ohrmuscheldysplasien) auffielen, wurde eine Mikrodeletion auf dem Chromosom 14q11.2 gefunden. Die minimal überlappende Region von ungefähr 35 kb enthält nur SUPT16H und das CHD8-Gen. Daraus folgte die Annahme, dass eine Haploinsuffizienz des CHD8 eine Rolle in der Ausprägung des beobachteten Phänotyps spielt (Zahir et al. 2007). Da sich der Phänotyp bei den beschriebenen Patienten mit der Mikrodeletion vom Phänotyp des CHARGE-Syndroms unterscheidet, kommt eine heterozygote Deletion des $\mathrm{CHD} 8$ als ursächlicher Mechanismus für das CHARGE-Syndrom eher nicht in Betracht. Vielmehr können Veränderungen der Nukleotid-Sequenz, hier insbesondere Missense-Mutationen, zu einem stärker ausgeprägten oder anderen Phänotyp führen als Deletionen des gesamten Gens. Das durch die Mutation im CHD8-Gen veränderte Protein kann dabei einen negativen Effekt auf seinen Interaktionspartner ausüben und so zur Ausprägung des Phänotyps führen.

Batsukh et al. untersuchten 2010 die Sequenz des CHD8-Gens bei 25 CHD7negativen CHARGE-Patienten. Es fanden sich keine pathogenen Mutationen im CHD8-Gen, große Exon -Deletionen oder -Duplikationen des CHD8-Gens können jedoch nicht ausgeschlossen werden. Die Resultate dieser Arbeit und der Untersuchungen von Batsukh et al. (2010) können CHD8 als Kandidatengen für das CHARGE-Syndrom weder bestätigen noch ausschließen. Untersuchungen mit größeren Kohorten an CHD7-negativen CHARGE-Syndrom-Patienten sind nötig, um die Bedeutung von CHD8 für die Pathogenese des CHARGE-Syndroms näher herauszuarbeiten. 


\subsubsection{Einfluss der Missense-Mutationen p.Trp2091Arg und p.His2096Arg im CHD7 auf die Interaktion mit CHD8}

In den meisten Fällen finden sich bei den CHD7-positiven CHARGE-SyndromPatienten Nonsense-Mutationen, gefolgt von Frameshift-Mutationen, die zu einem vorzeitigen Stop der Aminosäurekette führen (Lalani et al. 2006). MissenseMutationen, die zu einem veränderten Protein führen, machen nur etwa $11 \%$ der Mutationen aus (Lalani et al. 2006). Um einen möglichen Effekt zweier MissenseMutationen (p.Trp2091Arg und p.His2096Arg) im CHD7 vom CHARGE-Syndrom betroffener Patienten auf die Interaktion mit CHD8 zu untersuchen, wurden die Mutationen in die in Abbildung 4.2 gezeigten Konstrukte des direkten Yeast-TwoHybrid einkloniert und ihre Auswirkung auf die Interaktion mit CHD8 mittels direktem Yeast-Two-Hybrid untersucht.

Die Patientin mit der Missense-Mutation p.Trp2091Arg ist von einem atypischen CHARGE-Syndrom betroffen und zeigt bilaterale Kolobome, einen Mikrophthalmus des rechten Auges, einen Mikrozephalus sowie eine mentale Retardierung und eine einseitige Schwerhörigkeit. Während sich im direkten Yeast-Two-Hybrid der Konstrukte pGBKT7-CHD7-CR3 und pGADT7-CHD8 eine Interaktion nachweisen ließ, entfiel diese nach Einfügen der Mutation p.Trp2091Arg in das Konstrukt pGBKT7-CHD7-CR3 (s. Abb. 4.2).

Auch die Auswirkung der in der Literatur beschriebenen Mutation p.His2096Arg im CHD7 (Lalani et al. 2006) auf die Interaktion mit CHD8 wurde in dieser Arbeit untersucht. Die Mutation wurde in das Konstrukt pGBKT7-CHD7-CR3b einkloniert, es zeigte sich keine Interaktion mit CHD8. Da sich jedoch auch mit dem WildtypKonstrukt keine Interaktion mit CHD8 zeigte, war dieses neu erstellte Konstrukt nicht geeignet, einen Wegfall der Interaktion nachzuweisen (s. Abb. 4.2). In weiterführenden Arbeiten der Arbeitsgruppe wurde die Missense-Mutation p.His2096Arg, analog zur Mutation p.Trp2091Arg in dieser Arbeit, in das in der Wildtyp-Sequenz mit CHD8 interagierende Konstrukt pGBKT7-CHD7-CR3 eingefügt. Es konnte ein Wegfall der Interaktion durch diese Missense-Mutation im direkten Yeast-Two-Hybrid beobachtet werden (Batsukh et al. 2010). 

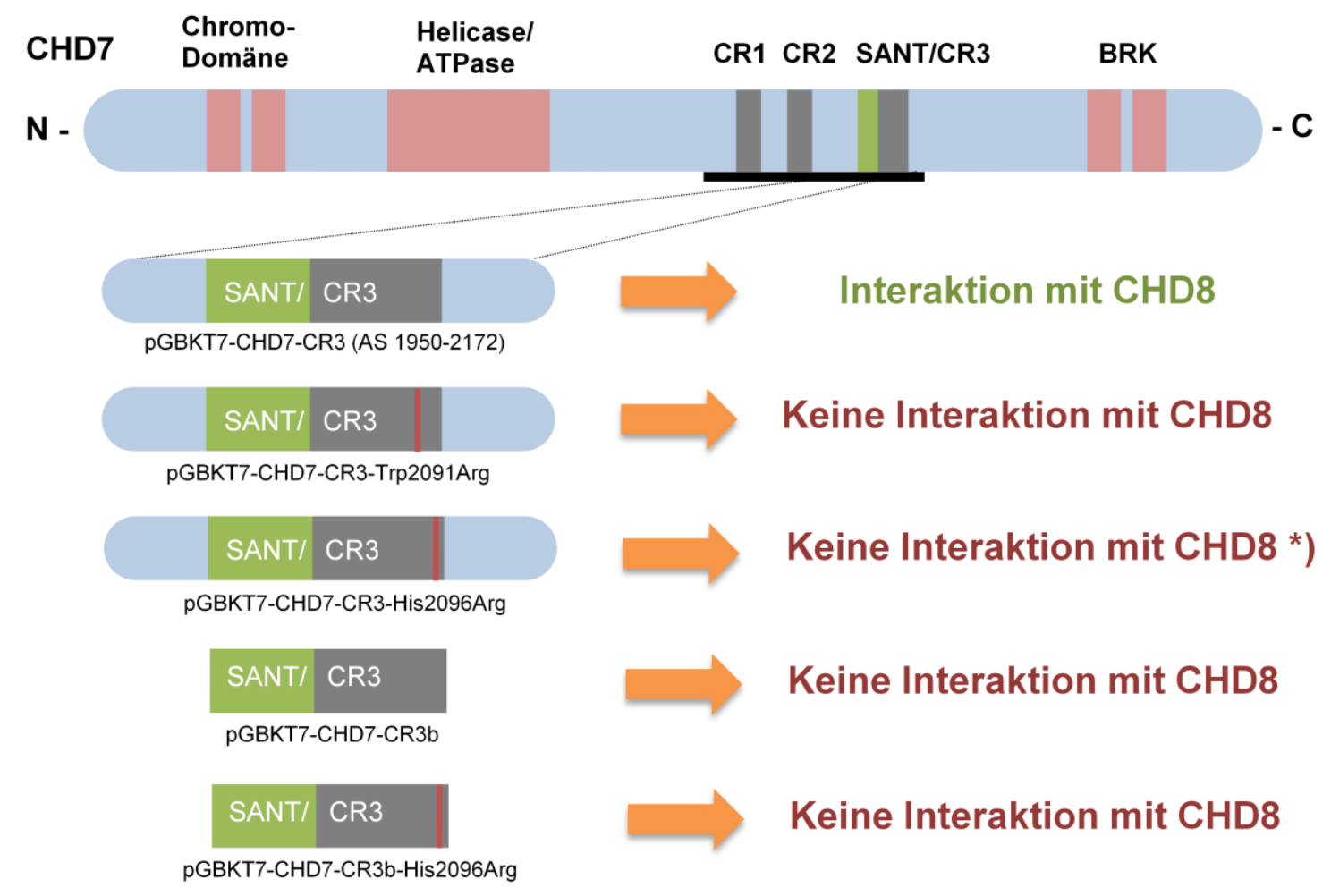

Abb. 4.2: $\quad$ Dargestellt ist der Einfluss der Missense-Mutationen p.Trp2091Arg und p.His2096Arg auf die Interaktion zwischen CHD7 und CHD8 im direkten Yeast-Two-Hybrid. Die Mutationen führen zu einem Wegfall der Interaktion zwischen CHD7 und CHD8.

*) Das Konstrukt pGBKT7-CHD7-CR3-His2096Arg wurde in einer Folgearbeit erstellt und gegen $\mathrm{CHD} 8$ getestet, auch hier ließ sich der Wegfall der Mutation gegenüber dem Konstrukt ohne Mutation (pGBKT7-CHD7-CR3) nachweisen (Batsukh et al. 2010).

Der Wegfall der Interaktion zwischen CHD7 und CHD8 durch eine MissenseMutation im $\mathrm{CHD7}$, die zu einem atypischen CHARGE-Syndrom führt, erhärtet die Hypothese, dass CHD7 und CHD8 physiologisch interagieren und eine Störung dieser Interaktion zum CHARGE Syndrom führen kann. Batsukh et al. untersuchten 2010 in Weiterführung dieser Arbeit die beschriebenen Missense-Mutationen und ihre Auswirkung auf die Interaktion durch eine Ko-Immunopräzipitation. Hier bestand weiterhin eine Interaktion der beiden Proteine. Während direkte Yeast-Two-Hybrid Experimente nur Interaktionen zwischen zwei Proteinen zeigen, können durch die Ko-Immunopräzipitation auch Linker-Proteine zwischen CHD7 und CHD8 detektiert werden. Sie schlossen daraus, dass CHD7 und CHD8 Komponenten eines größeren Komplexes sind. So wurde gezeigt, dass Chd8 der Maus mit Ctcf über seine BRKDomäne interagiert (Ishihara et al. 2006). Auch für das humane CHD7 wurde eine 
Interaktion mit CTCF über seine BRK-Domänen beobachtet (Allen et al. 2007). In Zusammenfassung der Ergebnisse dieser Arbeit und eigener Ergebnisse postulieren Batsukh et. al (2010), dass CHD7 und CHD8 sowohl direkt als auch indirekt interagieren. Einerseits kommt es im direkten Yeast-Two-Hybrid durch MissenseMutationen im CHD7 zu einer Unterbrechung der Interaktion mit CHD8, andererseits führen Missense-Mutationen im CHD7 in der Ko-Immunopräzipitation nicht zu einer Unterbrechung der Interaktion - ein möglicher Hinweis für die Interaktion über LinkerProteine.

\subsubsection{Ausblick auf weitere Untersuchungen zur Interaktion zwischen CHD7 und CHD8}

In Vorarbeiten wurde CHD8 als potentieller Interaktionspartner des CHD7 identifiziert. In dieser Arbeit konnte die Interaktion im Yeast-Two-Hybrid, in der KoLokalisation sowie im BiFC-Assay bestätigt werden. In weiteren Arbeiten der Arbeitsgruppe wurde die Interaktion auch in der Ko-Immunopräzipitation nachgewiesen (Batsukh et al. 2010). Der Nachweis einer zum CHARGE-Syndrom führenden Mutation im CHD8 bei CHD7-negativen CHARGE-Patienten gelang auch in diesen weiterführenden Arbeiten bei einer Analyse an 25 Patienten nicht. Es sind weitere Untersuchungen an einem größeren Kollektiv an CHD7-negativen CHARGEPatienten nötig, um diesen Aspekt zu klären.

Interessant wären Untersuchungen zu den Linker-Proteinen, welche eine Rolle in der Interaktion zwischen CHD7 und CHD8 spielen könnten. Möglicherweise können auch Mutationen in den diesen Proteinen zugrunde liegenden Genen ursächlich für das CHARGE-Syndrom sein. Diese zu identifizieren und Auswirkungen von Mutationen auf die Interaktion näher zu untersuchen, könnte zur weiteren Aufklärung der Pathogenese des CHARGE-Syndroms beitragen.

Weitere Untersuchungen sind nötig, um einen eventuellen Gesamtkomplex mit CHD7 und CHD8 aufzuklären. CHD7 interagiert mit dem BAF- und PBAF-Komplex (polybromo- and BRG1-associated factor-containing complex) (Bajpai et al. 2010). CHD8 ist eine Komponente des WAR-Komplexes (bestehend aus RbPB5, ASH2L und WDR5), welcher die Genexpression von HOXA2 reguliert (Yates et al. 2010). Gibt es gemeinsame Komponenten des PBAF- und des WAR-Komplexes? Bilden diese beiden Komplexe zusammen einen großen Komplex? Es wäre interessant zu 
untersuchen, welche weiteren Gene von diesem Komplex reguliert werden und ob es hier einen Zusammenhang mit den multiplen Fehlbildungen beim CHARGE-Syndrom gibt. 


\section{Zusammenfassung}

Das CHARGE-Syndrom ist ein autosomal dominant vererbtes Dysmorphiesyndrom. In den meisten Fällen handelt es sich um sporadische Fälle. Nur für ca. 58 \% (Lalani et al. 2006) bzw. 64 \% (Jongmans et al. 2006) der Betroffenen konnte als Ursache eine Mutation im CHD7-Gen nachgewiesen werden, bei einem großen Teil der Erkrankten lässt sich jedoch keine Genmutation nachweisen. In dieser Arbeit wurde eine Familie untersucht, in der zwei Kinder mit der Mutation c.7302dupA vom CHARGE-Syndrom betroffen sind. Die erste Aufgabe dieser Arbeit war es, ein vermutetes Gonadenmosaik zu bestätigen und eine Methode zu etablieren, um dieses zu quantifizieren. Im zweiten Teil dieser Arbeit ging es um die Bestätigung von $\mathrm{CHD} 8$ als Interaktionspartner von $\mathrm{CHD} 7$ und die nähere Eingrenzung der Interaktionsstelle.

Die für das CHARGE-Syndrom der beiden Geschwister im untersuchten familiären Fall ursächliche Mutation c.7302dupA ließ sich in den Spermien nachweisen. Ein Gonadenmosaik konnte somit bestätigt werden.

Eine Methode zur DNA-Analyse an Einzelspermien wurde etabliert, mittels derer der Grad des Mosaiks näher bestimmt werden konnte. In einer Stichprobe des untersuchten Falles trugen 16 von 59 der untersuchten Einzelspermien die Mutation c.7302dupA. Aus diesem Ergebnis lässt sich ein deutlich erhöhtes Wiederholungsrisiko bei einem weiteren Kind ableiten.

Eine Interaktion von CHD7 mit CHD8 konnte durch einen direkten Yeast-Two-Hybrid nachgewiesen werden. Bestätigt wurde dieses Ergebnis durch den Nachweis der KoLokalisation der beiden Proteine sowie durch ein Signal in einem bimolekularen Fluoreszenzkomplement-Assay. Im direkten Yeast-Two-Hybrid ließ sich die Interaktionsstelle im CHD7 auf den AS Bereich 1950-2172 mit den Domänen SANT und CR3 mit distalen und proximalen Überhängen eingrenzen. Eine nähere Eingrenzung der Interaktionsstelle gelang nicht.

Durch das Einfügen einer bei einem CHARGE-Patienten identifizierten MissenseMutation p.Trp2091Arg in den entsprechenden CHD7-Abschnitt ließ sich keine Interaktion mit CHD8 im direkten Yeast-Two-Hybrid mehr nachweisen. Die Bedeutung dieser Missense-Mutation beim Wegfall der Interaktion zwischen CHD7 und CHD8 als Ursache für das CHARGE-Syndrom ist in diesem Fall anzunehmen. 


\section{Literaturverzeichnis}

Allen MD, Religa TL, Freund SM, Bycroft M (2007): Solution structure of the BRK domains from CHD7 J Mol Biol $\underline{371}(5), 1135-1140$

Altschul SF, Gish W, Miller W, Myers EW, Lipman DJ (1990): Basic local alignment search tool J Mol Biol 215(3), 403-10

Aramaki M, Udaka T, Kosaki R, Makita Y, Okamoto N, Yoshihashi H, Oki H, Nanao K, Moriyama N, Oku S et al. (2006): Phenotypic spectrum of CHARGE syndrome with CHD7 mutations J Pediatr 148(3), 410-414

Ausubel FM, Brent R, Kingston RE, Moore DD, Seidman JG, Smith JA, Struhl K: Current Protocols in Molecular Biology Greene Publishing Associates and WileyInterscience, New York 1994

Bajpai R, Chen DA, Rada-Iglesias A, Zhang J, Xiong Y, Helms J, Chang CP, Zhao Y, Swigut T, Wysocka J (2010): CHD7 cooperates with PBAF to control multipotent neural crest formation Nature $\underline{463}(7283), 958-962$

Batsukh T, Pieper L, Koszucka AM, von Velsen N, Hoyer-Fender S, Elbracht M, Bergman JE, Hoefsloot LH, Pauli S (2010): CHD8 interacts with CHD7, a protein which is mutated in CHARGE syndrome Hum Mol Genet 19(14), 2858-2866

Becker PB, Hörz W (2002): ATP-dependent nucleosome remodeling Annu Rev Biochem 71, 247-273

Bijlsma EK, Wallace AJ, Evas DGR (1997): Misleading linkage results in an NF2 presymptomatic test owing to mosaicism J Med Genet $\underline{34}$ (11), 934-936

Blake KD, Davenport SL, Hall BD, Hefner MA, Pagon RA, Wiliams MS, Lin AE, Graham JM Jr (1998): CHARGE association: an update and review for the primary pediatrician Clin Pediatr (Phila) $\underline{37}$ (3), 159-173 
Bosman EA, Penn AC, Ambrose JC, Kettleborough R, Stemple DL, Steel KP (2005): Multiple mutations in mouse Chd7 provide models for CHARGE syndrome Hum $\mathrm{Mol}$ Genet 14(22), 3464-3476

Burnicka-Turek O, Kata A, Buyandelger B, Ebermann L, Kramann N, Burfeind P, Hoyer-Fender S, Engel W, Adham IM (2010): Pelota interacts with HAX1, EIF3G and SRPX and the resulting protein complexes are associated with the actin cytoskeleton BMC Cell Biol 11, 28

Cavalli G, Paro R (1998): Chromo-domain proteins: linking chromatin structure to epigenetic regulation Curr Opin Cell Biol 10(3), 354-360

Chien A, Edgar DB, Trela JM (1976): Deoxyribonucleotid acid polymerase from the extreme thermophile Thermus aquaticus J Bacteriol $\underline{127(3), 1550-1557}$

Cohn DH, Starman BJ, Blumberg B, Byers PH (1990): Recurrence of lethal osteogenesis imperfecta due to parental mosaicism for a dominant mutation in a human type I collagen gene (COLIAI) Am J Hum Genet $\underline{46}$ (3), 591-601

Cui XF, Li HH, Goradia TM, Lange K, Kazazian HH, Galas D, Arnheim N (1989): Single-sperm typing: determination of genetic distance between the $\mathrm{G}$ gamma-globin and parathyroid hormone loci by using the polymerase chain reaction and allelespecific oligomers Proc Natl Acad Sci U S A 866(23), 9389-9393

Daubresse G, Deuring R, Moore L, Papoulas O, Zakrajsek I, Waldrip WR, Scott MP, Kennison JA, Tamkun JW (1999): The Drosophila kismet gene is related to chromatin-remodeling factors and is required for both segmentation and segment identity Development $\underline{126}(6), 1175-1187$

Deardorff MA, Kaur M, Yaeger D, Rampuria A, Korolev S, Pie J, Gil-Rodríguez C, Arnedo M, Loeys B, Kline AD et al. (2007): Mutations in cohesin complex members SMC3 and SMC1A cause a mild variant of cornelia de Lange syndrome with

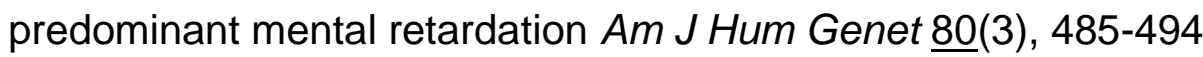


Delmas V, Stokes DG, Perry RP (1993): A mammalian DNA-binding protein that contains a chromodomain and an SNF2/SW12-like helicase domain Proc Natl Acad Sci U S A $\underline{90}(6), 2414-2418$

Dobrovolný R, Dvoráková L, Ledvinová J, Magage S, Bultas J, Lubanda JC, Poupetová H, Elleder M, Karetová D, Hrebícek M (2005): Recurrence of Fabry disease as a result of paternal germline mosaicism for alpha-galactosidase a gene mutation Am J Med Genet A 134A(1), 84-87

Don RH, Cox PT, Wainwright BJ, Baker K, Mattick JS (1991): ,Touchdown' PCR to circumvent spurious priming during gene amplification Nucleic Acids Res 19(14), 4008

Dou Y, Milne TA, Tackett AJ, Smith Er, Fukuda A, Wysocka J, Allis CD, Chait BT, Hess JL, Roeder RG (2005): Physical association and coordinate function of the $\mathrm{H} 3$ K4 methyltransferase MLL1 and the H4 K16 acetyltransferase MOF Cell 121(6), 873885

Edwards MJ, Wenstrup RJ, Byers PH, Cohn DH (1992): Recurrence of lethal osteogenesis imperfecta due to parental mosaicism for a mutation in the COL1A2 gene of type I collagen. The mosaic parent exhibits phenotypic features of a mild form of the disease Hum Mutat 1 (1), 47-54

Elalaoui SC, Kraoua L, Liger C, Ratbi I, Cavé H, Sefiani A (2010): Germinal mosaicism in Noonan syndrome: A family with two affected siblings of normal parents Am J Med Genet A 152A(11), 2850-2853

Evans DG, Wallace AJ, Wu CL, Trueman L, Ramsden RT, Strachan T (1998): Somatic mosaicism: a common cause of classic disease in tumor-prone syndromes? Lessons from type 2 neurofibromatosis Am J Hum Genet $\underline{63}$ (3), 727-736

Fields S, Song O (1989): A novel genetic system to detect protein-protein interactions Nature $\underline{340}(6230), 245-246$ 
Flanagan JF, Blus BJ, Kim D, Clines KL, Rastinejad F, Khorasanizadeh S (2007): Molecular implications of evolutionary differences in CHD double chromodomains $J$ Mol Biol $\underline{369}(2)$, 334-342

Flaus A, Martin DM, Barton GJ, Owen-Hughes T (2006): Identification of multiple distinct Snf2 subfamilies with conserved structural motifs Nucleic Acids Res 34(10), 2887-2905

Giannakudis J, Röpke A, Kujat A, Krajewska-Walasek M, Hughes H, Fryns JP, Bankier A, Amor D, Schlicker M, Hansmann I (2001): Parental mosaicism of JAG1 mutations in families with Alagille syndrome Eur J Hum Genet $\underline{9}(3), 209-216$

Gil T, Castilla JA, Hortas ML, Molina J, Redondo M, Samaniego F, Garrido F, Vergara F, Herruzo A (1995): CD4+ cells in human ejaculates Hum Reprod 10(11), 2923-2927

Hall BD (1979): Choanal atresia and associated multiple anomalies J Pediatr 95(3), 395-398

Hall JA, Georgel PT (2007): CHD proteins: a diverse familiy with strong ties Biochem

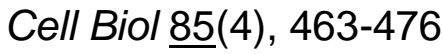

Hall JG (1988): Somatic mosaicism: observations related to clinical genetics $A m$ J Hum Genet $\underline{43}(4)$, 355-363

Hamosh A, Scott AF, Amberger JS, Bocchini CA, McKusick VA (2005): Online Mendelian Inheritance in Man (OMIM), a knowledgebase of human genes and genetic disorders Nucleic Acids Res 33(Database issue):D514-7

Hanahan D (1983): Studies on transformation of Escherichia coli with plasmids $\mathrm{J} \mathrm{Mol}$ Biol $\underline{166}(4), 557-580$ 
Hittner HM, Hirsch NJ, Kreh GM, Rudolph AJ (1979): Colobomatous microphthalmia, heart disease, hearing loss and mental retardation-a syndrome $J$ Pediatr Ophthalmol Strabismus $\underline{16}(2), 122-128$

Ho L, Crabtree GR (2010): Chromatin remodelling during developement Nature $\underline{463}(7280), 474-484$

Hurd EA, Capers PL, Blauwkamp MN, Adams ME, Raphael Y, Poucher HK, Martin DM (2007): Loss of Chd7 function in gene-trapped reporter mice is embryonic letal and associated with severe defects in multiple developing tissues Mamm Genome 18(2), 94-104

lida T, Suzumori K, Ikuta K, Tanemura M, Yagami Y, Okamoto T, Hata A (1996): Identification of a Gly862 to Ser substitution in the type I collagen gene from a single spermatozoon Mol Hum Reprod 2(2), 131-134

Ishihara K, Ishimura M, Nakao M (2006): CTCF-dependent chromatin insulator is linked to epigenetic remodelling $\mathrm{Mol}$ Cell $\underline{23}(5), 733-742$

Issekutz KA, Graham JM Jr, Prasad C, Smith IM, Blake KD (2005): An epidemiological analysis of CHARGE syndrome: preliminary results from a canadian study Am J Med Genet A $\underline{133 A}$ (3), 309-317

Jainchill JL, Aaronson SA, Todaro GJ (1969): Murine sarcoma and leukemia viruses: assay using clonal lines of contact-inhibited mouse cells $J$ Virol $\underline{4}(5), 549-553$

Jongmans MC, Admiraal RJ, van der Donk KP, Vissers LE, Baas AF, Kapusta L, van Hagen JM, Donnai D, de Ravel TJ, Veltman JA et al. (2006): CHARGE syndrome: the phenotypic spectrum of mutations in the CHD7 gene J Med Genet $\underline{43}(4)$, 306-314

Jongmans MC, Hoefsloot LH, van der Donk KP, Admiraal RJ, Magee A, van de Laar I, Hendriks Y, Verheij JB, Walpole I, Brunner HG, van Ravenswaaij CM (2008): Familial CHARGE syndrome and the CHD7 gene: a recurrent missense mutation, intrafamilial recurrence and variability $A m J$ Med Genet $A$ 146A(1), 43-50 
Kerppola TK (2008): Bimolecular fluorescence complementation (BiFC) analysis as a probe of proteininteractions in living cells Annu Rev Biophys 37, 465-487

Khattak S, Lee BR, Cho SH, Ahnn J, Spoerel NA (2002): Genetic characterization of Drosophila Mi-2 ATPase Gene 293(1-2), 107-114

Koszucka AM: Persönliche Mitteilung, Göttingen 2008

Lalani SR, Safiullah AM, Fernbach SD, Harutyunyan KG, Thaller C, Peterson LE, McPherson JD, Gibbs RA, White LD, Hefner M et al. (2006): Spectrum of CHD7 mutations in 110 individuals with CHARGE syndrome and genotype-phenotype correlation Am J Hum Genet 78(2), 303-314

Lázaro C, Ravella A, Gaona A, Volpini V, Estivill X (1994): Neurofibromatosis type 1 due to germ-line mosaicism in a clinically normal father N Engl J Med 331(21), 14031407

Lemmers RJ, van der Wielen MJ, Bakker E, Padberg GW, Frants RR, van der Maarel SM (2004): Somatic mosaicism in FSHD often goes undetected Ann Neurol $\underline{55}(6), 845-850$

Levin DL, Muster AJ, Newfeld EA, Paul MH (1973): Concordant aortic arch anomalies in monozygotic twins $J$ Pediatr 83(3), 459-461

Li Q, Wrange O, Eriksson P (1997): The role of chromatin in transcriptional regulation Int J Biochem Cell Biol 29 (5), 731-742

Lund AM, Schwartz M, Raghunath M, Steinmann B, Skovby F (1996): Gly802Asp substitution in the pro alpha $2(\mathrm{I})$ collagen chain in a family with recurrent osteogenesis imperfecta due to paternal mosaicism Eur J Hum Genet 4(1), 39-45

Malcov M, Reches A, Ben-Yosef D, Cohen T, Amit A, Dgany O, Tamary H, Yaron Y (2010): Resolving a genetic paradox throughout preimplantation genetic diagnosis for autosomal dominant severe congenital neutropenia Prenat Diagn 30(3), 207-211 
Mannan AU, Krawen P, Sauter SM, Boehm J, Chronowska A, Paulus W, Neesen J, Engel W (2006): ZFYVE27 (SPG33), a novel spastin-binding protein is mutated in hereditary spastic paraplegia Am J Hum Genet $\underline{79}$ (2), 351-357

Marfella CG, Imbalzano AN (2007): The chd family of chromatin remodelers Mutat Res $\underline{618}(1-2), 30-40$

Metlay LA, Smythe PS, Miller ME (1987): Familial CHARGE syndrome: clinical report with autopsy findings Am J Med Genet $\underline{26}(3), 577-581$

Mitchell JA, Giangiacomo J, Hefner MA, Thelin JW, Pickens JM (1985): Dominant CHARGE association Ophthalmic Paediatr Genet $\underline{6}(1-2), 271-276$

Murray EW, Giles AR, Lillicrap D (1992): Germ-line mosaicism for a valine-tomethionine substitution at residue 553 in the glycoprotein Ib-binding domain of von Willebrand factor, causing type IIB von Willebrand disease Am J Hum Genet $\underline{50}$ (1), 199-207

Musio A, Selicorni A, Focarelli ML, Gervasini C, Milani D, Russo S, Vezzoni P, Larizza L (2006): X-linked Cornelia de Lange syndrome owing to SMC1L1 mutations Nat Genet $\underline{38}(5), 528-530$

Namikawa C, Suzumori K, Fukushima Y, Sasaki M, Hata A (1995): Recurrence of osteogenesis imperfecta because of paternal mosaicism: Gly862-->Ser substitution in a type I collagen gene (COL1A1) Hum Genet $\underline{95}$ (6), 666-670

Oley CA, Baraitser M, Grant DB (1988): A reappraisal of the CHARGE association J Med Genet $\underline{25}(3), 147-156$

Ormö M, Cubitt AB, Kallio K, Gross LA, Tsien RY, Remington SJ (1996): Crystal structure of the Aequorea victoria green fluorescent protein Science $\underline{273}(5280)$, 1392-1395 
Pagon RA, Graham JM Jr, Zoana J, Yong SL (1981): Coloboma, congenital heart disease and choanal atresia with multiple anomalies: CHARGE association $J$ Pediatr 99(2), 223-227

Pauli S, Pieper L, Häberle J, Grzmil P, Burfeind P, Steckel M, Lenz U, Michelmann HW (2009): Proven germline mosaicism in a father of two children with CHARGE symdrome Clin Genet $\underline{75}(5), 473-479$

Pauli S, von Velsen N, Burfeind P, Steckel M, Mänz J, Buchholz A, Borozdin W, Kohlhase J (2012): CHD7 mutations causing CHARGE syndrome are predominantly of paternal origin Clin Genet 1 1(3), 234-239

Pray-Grant MG, Daniel JA, Schieltz D, Yates JR $3^{\text {rd }}$, Grant PA (2005): Chd1 chromodomain links histone H3 methylation with SAGA- and SLIK-dependent acetylation Nature $\underline{433}$ (7024), 434-438

Pyott SM, Pepin MG, Schwarze U, Yang K, Smith G, Byers PH (2011): Recurrence of perinatal lethal osteogenesis imperfecta in sibships: parsing the risk between parental mosaicism for dominant mutations and autosomal recessive inheritance Genet Med 13(2), 125-130

Rodríguez-Paredes M, Ceballos-Chávez M, Esteller M, García-Domínguez M, Reyes JC (2009): The chromatin remodelling factor CHD8 interacts with elongating RNA polymerase II and controlos expression of the cyclin E2 gene Nucleic Acids Res $\underline{37}(8), 2449-2460$

Rose VM, Au KS, Pollom G, Roach ES, Prashner HR, Northrup H (1999): Germ-line mosaicism in tuberous sclerosis: how common? Am J Hum Genet 64(4), 986-992

Saiki RK, Scharf S, Faloona F, Mullis KB, Horn GT, Erlich HA, Arnheim N 1985): Enzymatic amplification of beta-globin genomic sequences and restriction site analysis for diagnosis of sickle cell anemia Science 230(4732), 1350-1354 
Sambrook, J, Fritsch EF, Maniatis T: Molecular cloning: a laboratory manual. Cold Spring Harbor/New York 1989

Sanger F, Nicklen S, Coulson AR (1977): DNA sequencing with chain-terminating inhibitors Proc Natl Acad Sci U S A $\underline{74}(12)$, 5463-5467

Scherer WF, Syverton JT, Gey GO (1953): Studies on the propagation in vitro of poliomyelitis viruses. IV. Viral multiplication in a stable strain of human malignant epithelial cells (strain HeLa) derived from an epidermoid carcinoma of the cervix $J$ Exp Med $\underline{97}(5), 695-710$

Schnetz MP, Bartels CF, Shastri K, Balasubramanian D, Zentner GE, Balaji R, Zhang X, Song L, Wang Z, Laframboise T et al. (2009): Genomic distribution of CHD7 on chromatin tracks H3K4 methylation patterns Genome Res 19 (4), 590-601

Schnetz MP, Handoko L, Akhtar-Zaidi B, Bartels CF, Pereira CF, Fisher AG, Adams DJ, Flicek P, Crawford GE, Laframboise T et al. (2010): CHD7 targets active gene enhancer elements to modulate ES cell-specific gene expression PLoS Genet $\underline{6}(7)$, e1001023

Sgambati MT, Stolle C, Choyke PL, Walther MM, Zbar B, Linehan WM, Glenn GM (2000): Mosaicism in von Hippel-Lindau disease: lessons from kindreds with germline mutations identified in offspring with mosaic parents Am J Hum Genet $\underline{66}(1), 84-91$

Shen X, Mizuguchi G, Hamiche A, Wu C (2000): A chromatin remodelling complex involved in transcription and DNA processing Nature 406(6795), 541-544

Sippel KC, Fraioli RE, Smith GD, Schalkoff ME, Sutherland J, Gallie BL, Dryja TP (1998): Frequency of somatic and germ-line mosaicism in retinoblastoma: implications for genetic counseling Am J Hum Genet 62(3), 610-619

Song JJ, Kingston RE (2008): WDR5 interacts with mixed lineage leukemia (MLL) protein via the histone H3-binding pocket J Bio Chem 283(50), 35258-35264 
Soriano P, Jaenisch R (1986): Retroviruses as probes for mammalian development: allocation of cells to the somatic and germ cell lineages Cell $\underline{46}(1), 19-29$

Srinivasan S, Armstrong JA, Deuring R, Dahlsveen IK, McNeill H, Tamkun JW (2005): The Drosophila trithorax group protein Kismet facilitates an early step in transcriptional elongation by RNA Polymerase II Development 132(7), 1623-1635

Srinivasan S, Dorighi KM, Tamkun JW (2008): Drosophila Kismet regulates histone H3 lysine 27 methylation and early elongation by RNA polymerase II PLOS Genet 4(10), e1000217

Terriente-Félix A, Molnar C, Gómez-Skarmeta JL, de Celis JF (2011): A conserved function of the chromatin ATPase Kismet in the regulation of hedgehog expression Dev Biol 350 (2), 382-392

Therrien M, Morrison DK, Wong AM, Rubin GM (2000): A genetic screen for modifiers of a kinase suppressor of Ras-dependent rough eye phenotype in Drosophila Genetics 156(3), 1231-1242

Thompson BA, Tremblay V, Lin G, Bochar DA (2008): CHD8 is an ATP-dependent chromatin remodeling factor that regulates beta-catenin target genes $\mathrm{Mol} \mathrm{Cell} \mathrm{Biol}$ 28 (12), 3894-3904

Tonkin ET, Wang TJ, Lisgo S, Bamshad MJ, Strachan T (2004): NIPBL, encoding a homolog of fungal Scc2-type sister chromatid cohesion proteins and fly Nipped-B, is mutated in Cornelia de Lange syndrome Nat Genet 36(6), 636-641

Verloes A (2005): Updated diagnostic criteria for CHARGE syndrome: a proposal Am J Med Genet A 133A(3), 306-308

Vissers LE, van Ravenswaaij CM, Admiraal R, Hurst JA, de Vries BB, Janssen IM, van der Vliet WA, Huys EH, de Jong PJ, Hamel BC, Schoenmakers EF, Brunner HG, Veltman JA, van Kessel AG (2004): Mutations in a new member of the chromodomain gene family cause CHARGE syndrome Nat Genet $\underline{36}$ (9), 955-957 
Wincent J, Holmberg E, Strömland K, Soller M, Mirzaei L, Djureinovic T, Robinson K, Anderlid B, Schoumans J (2008): CHD mutation spectrum in 28 Swedish patients diagnosed with CHARGE syndrome Clin Genet 74(1), 31-38

Wong SC, Cobben JM, Hiemstra S, Robinson PH, Heeg M (1998): KarschNeugebauer syndrome in two sibs with unaffected parents Am J Med Genet $\underline{75}(2)$, 207-210

Woodage T, Basrai MA, Baxevanis AD, Hieter P, Collins FS (1997): Characterization of the CHD familiy of proteins Proc Natl Acad Sci U S A $\underline{94}(21), 11472-11477$

Xue Y, Wong J, Moreno GT, Young MK, Côté J, Wang W (1998): NURD, a novel complex with both ATP-dependent chromatin-remodeling and histone deacetylase activities $\mathrm{Mol}$ Cell $\underline{2}(6), 851-861$

Yates JA, Menon T, Thompson BA, Bochar DA (2010): Regulation of HOXA2 gene expression by the ATP-dependent chromatin remodeling enzyme CHD8 FEBS Lett $\underline{584}(5), 689-693$

Yuan CC, Zhao X, Florens L, Swanson SK, Washburn MP, Hernandez N (2007): CHD8 associates with human Staf and contributes to efficeient U6 RNA polymerase III transcription Mol Cell Biol $\underline{27}(24)$, 8729-8238

Zahir F, Firth HV, Baross A, Delaney AD, Eydoux P, Gibson WT, Langlois S, Martin H, Willatt L, Marra MA, Friedman JM (2007): Novel deletions of 14q11.2 associated with developmental delay, cognitive impairment and similar minor anomalies in three children J Med Genet 44 (9), 556-561

Zhang Y, Reinberg D (2001): Transcription regulation by histone methylation: interplay between different covalent modifications of the core histone tails Genes Dev $\underline{15}(18), 2343-2360$

Zlotogora J (1998): Germ line mosaicism Hum Genet 102(4), 381-386 


\section{Danksagung}

Mein herzlichster Dank gilt Herrn Prof. Dr. Dr. h. c. W. Engel für die Überlassung des Themas dieser Dissertation, die Korrektur des Manuskriptes sowie die stete Motivation und die notwendige Prise Druck, die Arbeit zu Ende zu bringen.

Frau Dr. Silke Pauli gilt ein ganz besonderer Dank für die wissenschaftliche Betreuung der Arbeit in einer Form, die sich ein Doktorand nur wünschen kann. Insbesondere das große Interesse am Fortkommen der Versuche, die ständige Verfügbarkeit für Rückfragen und die vielen Anregungen in jeder Phase der Dissertation seien hier erwähnt.

Für die Unterstützung bei den in dieser Arbeit benötigten Methoden der Reproduktionsmedizin und die angenehme Zusammenarbeit sei Herrn Prof. Dr. H. W. Michelmann besonders gedankt.

Ein Dank gilt auch Herrn Dr. Pawel Grzmil für die Einweisung in molekulargenetische Techniken sowie die ständige Hilfsbereitschaft im Labor.

Frau Astrid Backhaus und Frau Maja Studencka haben sich um diese Arbeit mit ihrer tatkräftigen Unterstützung im Labor im Besonderen verdient gemacht, auch hierfür ein großer Dank! 